\title{
The formation of glass: a quantitative perspective
}

\author{
Zhong-Hong Jiang ${ }^{1,2}$ and Qin-Yuan Zhang ${ }^{1 *}$
}

In constant use since ancient times, glass remains a highly valued material that is ubiquitous in daily life. Today, glass has become an indispensable and essential component in such fields as photonics, optical communications, photovoltaic cells, household appliances, vehicles, and building materials. However, one of major stumbling blocks for its optimal use is the low glass-forming ability (GFA) of many glass-forming compositions, which is far from being adequately solved. Understanding the nature of the GFAs of materials is the key to the development of new glasses with improved properties and manufacturability for various engineering applications. The rapid development of new glasses over the past several decades has led to increasingly complex material compositions. However, the phase diagrams of these materials have yet to be properly addressed even though such diagrams are extremely useful in rationally designing glass-forming compositions and predicting their behavior in pursuit of new functional glasses with particular desired properties. In this context, the present review strives to provide new insights into the formation of glasses and glass-forming regions through quantitative calculations and predictions based on a comprehensive survey and analysis of the existing experimental observations and theoretical considerations, a considerable portion of which stems from work performed in our own laboratory.

\section{INTRODUCTION}

Glasses, non-crystalline solids, and amorphous materials are presently playing increasingly important roles in modern technology [1-6]. In addition to conventional glass, which is an indispensable material in the current economy in architecture, transport, lighting, and environmental control, a wide variety of glasses and amorphous materials are being used in increasingly sophisticated applications in optics, electronics, optoelectronics, energy science and biotechnologies [7-27]. Glasses are often simply identified as non-crystalline materials. This definition is clearly overly broad, as it encompasses materials that exhibit entirely different properties even though they are non-crystalline. Furthermore, quenching a liquid is not the only method of obtaining non-crystalline solids. The terms "amorphous" and "non-crystalline" are often considered to be synony- mous $[28,29]$. It would therefore seem more appropriate to reserve the term "glasses" only for those non-crystalline solids that present the phenomenon of a "glass transition"; namely, when a glass is heated or cooled, the thermal expansion coefficient and specific heat capacity undergo an abrupt change in a temperature range from two thirds to one third of the melting point or liquidus temperature.

Goldschmidt [30] has proposed empirical criteria for glass formation in the case when the ratio of the radii of the cations and anions in the glass-forming oxides lies in the range of $0.2-0.4$, typical for anions located at the vertices of tetrahedral [31-33]. Based on the concept of disordered locations of atoms, which must remain unchanged after the cooling of the melt and the formation of glass, Smekal [34] has suggested that the presence of "composed" chemical bonds is necessary for glass formation. Zachariasen [35] has proposed a random network theory of glass structure and glass formation based on the crystal chemistry view of Goldschmidt. He has classified the cations in a glass as follows: (a) network formers, such as Si, B, P, Ge, As, and Be, which normally have coordination numbers of 3 or 4 ; (b) network modifiers, such as $\mathrm{Na}, \mathrm{K}, \mathrm{Ca}$, and $\mathrm{Ba}$, which generally have coordination numbers of $\geqslant 6$; and (c) intermediates, which may either reinforce the network (coordination number of 4) or further loosen the network (coordination numbers of 6-8) but cannot form a glass per se.

Several authors have proposed criteria for glass formation based on the nature of the inter-atomic bonds rather than the structure of the material. The intention was to identify criteria that would cover a broad range of materials, including glass-forming elements, such as selenium, as well as oxides [32,36]. Thus, Winter [37] concluded that the ability of a material to form a glass might be related to the number of outer-shell p electrons per atom. The most favorable number should be 4 , but glasses could form from substances containing 2-4 p electrons per atom. However, the reason behind this proposition was unclear, and no explanation was offered for the considerable variation in glass-forming ability (GFA) amongst the substances that satisfy this criterion. In a series of papers, Stanworth

${ }^{1}$ State Key Laboratory of Luminescent Materials and Devices, and Institute of Optical Communication Materials, South China University of Technology, Guangzhou 510641, China

${ }^{2}$ Shanghai Institute of Optics and Fine Mechanics, Chinese Academy of Sciences, Shanghai 201800, China

*Corresponding author (email: qyzhang@scut.edu.cn) 
[38-41] drew attention to the significance of the degree of covalence of inter-atomic bonds, as measured by the electronegativity differences between constituent atoms. Using Pauling's electronegativity values for silicon and oxygen and Pauling's curve, which relates the degree of covalence to the electronegativity difference, the silicon-oxygen bond is found to be $50 \%$ covalent. The cation electronegativity for the well-known glass-forming oxides (or network formers) lies between 1.8 and 2.1. The range is 1.5 to 1.8 for intermediate oxides that can behave as network-formers under suitable circumstances, and 0.7 to 1.2 for modifiers, such as alkali and alkaline earth oxides. Stanworth [12] noted that the electronegativity of Te is the same as that of $\mathrm{P}(2.1)$, suggesting that $\mathrm{TeO}_{2}$ might be a glass former, similar to $\mathrm{P}_{2} \mathrm{O}_{5}$, an observation that led him to investigate glass formation in tellurite systems. In a subsequent paper that reviewed more recent information on glass-forming oxides, Stanworth $[12,41,42]$ recognized that bond type alone is not a sufficient criterion. Thus, he stated that the most general conclusion is that the compounds $\mathrm{A}_{x} \mathrm{~B}_{y}$ can form glass from their melts when they have sufficiently open and sufficiently covalent network structures. This statement echoes much of the thinking behind the Zachariasen rules $[35,42]$. These simple bond-type criteria have little general fundamental significance, although they may be of some value within a particular group of compounds. Many considerably different types of inorganic substances are known to form glasses, including simple fused salts, in which the relevant bonds are largely ionic, and a large number of metallic systems. Myuller [43-46] connected the disposition of certain substances towards glass formation to the predominance of directional bonds with a reduced radius of action, which were initially powerful covalent bonds [47]. The valences of elements play an important role in determining trigonal and tetrahedral configurations of chemical bonding. Covalent bonds in the atomic network at moderate temperatures cause a reduction in the vibrational amplitude of the atoms compared with the vibrational amplitude of the ions in the ionic lattice. In Myuller's opinion, the cause of the high viscosity and the increased activation energy of the atomic re-grouping, as observed in substances disposed toward glass formation, lay in this difference. Sun [48] recognized that the processes of melting and crystallization often involve the breaking of inter-atomic bonds. Stronger bonds result in more sluggish processes of structural rearrangement and hence a greater likelihood of glass formation upon cooling. He noted that the calculated values of single-bond strengths were particularly high in the glass-forming oxides, such as $\mathrm{SiO}_{2}$ and $\mathrm{B}_{2} \mathrm{O}_{3}$; however, he was clearly aware of the limitations of such a simple correlation because he also paid attention to the importance of structural factors. In an isodesmic structure, some bonds are extremely strong, whereas others are weak; thus, it is not clear which bond strength is relevant [15]. Rawson $[49,50]$ noted that the use of a bond-strength criterion must include the thermal energy available at the melting point for bond breaking. Thus, glass formation would be more likely when the ratio of a single bond strength to the melting point is high, which may explain why a boric oxide melt is nearly impossible to crystallize. The $\mathrm{B}-\mathrm{O}$ bonds are extremely strong, whereas the melting point of the material is relatively low $\left(450^{\circ} \mathrm{C}\right){ }^{[} 15,49$ ]. Rawson [49-51] extended this argument to binary and multi-component systems, noting that regions of glass formation or particularly low devitrification rates are observed when the liquidus temperature is low. Commercial glass compositions are typically quite complex for a number of reasons. One reason is that adding further oxide components often lowers the liquidus temperature and thus causes the glass to be less prone to devitrification [36].

Not surprisingly, the simple relationship between glass stability and low liquidus temperature appears to break down in some oxide systems. Structural factors also play an important role. The kinetic and thermodynamic energy terms associated with these factors must change throughout the system. Some melts may also contain appreciable unknown percentages of components such as $\mathrm{CO}_{2}$ and combined water, which affect the liquidus temperature and introduce a complicating factor that has rarely been considered in studies of glass formation $[32,34,36]$. This emphasis on the liquidus temperature is clearly based on the qualitative ideas behind the classical theory of nucleation and crystal growth (a point clearly emphasized by Turnbull and Cohen [52]). Despite the exceptions, the liquidus-temperature criterion has a broad range of applicability and appears to work equally well for a number of quite different types of materials, including both metallic and oxide glasses. However, this approach has limitations as a simple predictive tool because there is no simple method of predicting the melting points of elements and compounds or the variation in the liquidus temperature with composition in binary and multi-component systems.

A melt may form a glass because within a limited temperature range below the liquidus temperature, the rate of crystal growth and/or nucleation is sufficiently low on a time scale determined by the rate of cooling. Cooling the melt to a temperature below the transformation range must be possible without crystallization, which merely refocuses the question of further understanding glass formation onto a consideration of the factors that determine the nucleation and crystal growth rates for a particular substance $[31,32,53]$. In particular, Uhlmann and his colleagues [5456] conducted many experimental and theoretical studies of crystallization and nucleation kinetics in supercooled 
oxide melts. Their work has been highly valuable in many areas of glass science but offers a limited capability to suggest new glass-forming compositions or provide a general understanding of why some compositions form glasses more readily than others $[15,31,32,36]$. The equations of classical nucleation and crystal growth theory describe the temperature dependences of the nucleation and crystal growth rates and contain many thermodynamic and kinetic parameters that cannot be easily measured or do not relate in a simple manner to what may be known about the composition and structure of the material under consideration [36,57]. Given this situation, it is not surprising that many individuals have sought simple criteria, preferably with some theoretical basis, that have some predictive power with respect to potential glass-forming compositions. Glass formation is always a process of competition between the liquid phase and the resulting crystalline phases. If the liquid phase is stabilized upon cooling and the competing crystalline phases can precipitate out only with difficulty, then the glass formation of the melt would be facilitated. Thus, in this regard, the GFA of a liquid essentially relies upon two components: the liquid-phase stability and the stability of the competing crystalline phases [58,59].

Glass is in a thermodynamically metastable state, has a high enthalpy and tends to release energy and become crystalline. However, in terms of crystallization kinetics, the crystallization process becomes impossible because of the high melt viscosity; thus, glass exists in the form of a "supercooled liquid" [7,15,31]. Glass formation presents several interesting questions. In general, for a melt to form into glass without crystallization, thermodynamic non-equilibrium must be maintained until the material has frozen into glass. Two major methods of preventing a glass from reaching thermodynamic equilibrium from initial molten-glass are as follows: preventing molecular motion, and ensuring that the glass does not have sufficient time to achieve thermodynamic equilibrium. The first method is accomplished by increasing the viscosity of the glass at the melting point until it is sufficient to prevent the movement of molecules into a crystal structure. The second method is accomplished by increasing the cooling rate to avoid shifting into the thermodynamically stable state. Therefore, in the context of thermodynamics, if any melt reaches a steady state, then the only possible steady state should be crystallization. However, from the perspective of kinetics, any melt can form a glass as long as the cooling rate is sufficiently high. Therefore, the most critical parameters that determine whether a melt can form a glass are the viscosity and the cooling rate. The viscosity is determined by the nature of the materials, and the cooling rate is determined by the applied fabrication methods.

\section{THE FORMATION OF GLASS: CLASSICAL APPROACHES}

\section{Typical methods of glass formation}

To obtain a glass or an amorphous solid, it is necessary either to retain the disordered state of a liquid or gas at ambient temperature, or to destroy (amorphise) the structure of a crystal $[1,15,31,32,60]$. It is also possible to produce a disordered structure directly via suitable chemical reactions, which may or may not be assisted by external fields (electrical or chemical potentials). Thus, glasses can be formed using a variety of techniques, including, but not limited to, various conventional melting-quenching processes. At present, glass is a sophisticated product that requires stateof-the-art technologies, which include various rapid cooling methods, e.g., melt-spinning, rolling methods, splat quenching, evaporation methods, and so on. Some of these methods are of purely academic value or are still in early stages of laboratory development, whereas others have already gained industrial importance. For convenience, glass formed using typical methods of glass formation maybe divided into four categories: glasses formed via cooling from a liquid; glasses formed via the deposition or reaction of a vapor; glasses formed from a solid, and glasses formed through the reaction of a solid surface with a liquid or gas phase [61].

Table 1 presents a summary of various glasses formed via cooling from a liquid. In principle, for any type of melt, the glass transition can be achieved if the cooling rate is sufficiently high $[57,60,62]$. However, for manufacturing large glass samples, the cooling rate must be controlled within a certain range; when rapid cooling methods such as the double-roller or rolling methods, are used, only thin sheets or ribbons of glass can be obtained. At present, most industrial-scale manufacturing of glasses is based on the melting-quenching method. Fig. 1 illustrates various types of techniques used to prepare glasses $[18,63]$. For the manufacture of a new glass that contains multiple alkali metal or rare earth oxides, the low melt viscosity requires an increased cooling rate. Volatile compounds must be melted and cooled in a sealed container. Glasses containing substances easy to sublimate, such as arsenic, and sulphur-containing chalcogenides with high vapor pressures, are fabricated in vacuum-sealed glass tubes. The conventional method for producing chalcogenide glasses is through the use of sealed-ampoule melting. In this technique, the glass precursor materials are sealed under vacuum into a silica ampoule, melted, and then quenched to form a glass within the ampoule, as shown in Fig. 2a [64]. The viscosity of the melt is sufficiently low to allow for full mixing without the need for a rocking furnace, which is necessary for melting 
Table 1 A summary of glasses formed via cooling from a liquid [62]

\begin{tabular}{|c|c|}
\hline \multicolumn{2}{|r|}{ Glasses } \\
\hline Elements & S, Se,Te, P \\
\hline Oxides & $\begin{array}{l}\mathrm{B}_{2} \mathrm{O}_{3}, \mathrm{SiO}_{2}, \mathrm{GeO}_{2}, \mathrm{P}_{2} \mathrm{O}_{5}, \mathrm{As}_{2} \mathrm{O}_{3}, \mathrm{Sb}_{2} \mathrm{O}_{3}, \mathrm{In}_{2} \mathrm{O}_{3}, \mathrm{Tl}_{2} \mathrm{O}_{3}, \mathrm{SnO}_{2}, \mathrm{PbO}_{2}, \mathrm{SeO}_{2}, \text { Conditional } \mathrm{TeO}_{2}, \mathrm{SiO}_{2}, \mathrm{MoO}_{3}, \mathrm{WO}_{3}, \mathrm{Bi}_{2} \mathrm{O}_{3} \text {, } \\
\mathrm{Al}_{2} \mathrm{O}_{3}, \mathrm{Ba}_{2} \mathrm{O}_{3}, \mathrm{~V}_{2} \mathrm{O}_{5}, \mathrm{Nb}_{2} \mathrm{O}_{3}\end{array}$ \\
\hline Sulfides & $\begin{array}{l}\mathrm{As}_{2} \mathrm{~S}_{3}, \mathrm{Sb}_{2} \mathrm{~S}_{3} \\
\text { Various compounds of } \mathrm{B}, \mathrm{Ga}, \mathrm{In}, \mathrm{Te}, \mathrm{Ge}, \mathrm{Sn}, \mathrm{N}, \mathrm{P}, \mathrm{Bi} \\
\mathrm{CS}_{2} \\
\mathrm{~B}_{2} \mathrm{~S}_{3}-\mathrm{Li}_{2} \mathrm{~S}, \mathrm{P}_{2} \mathrm{~S}_{5}-\mathrm{Li}_{2} \mathrm{~S}\end{array}$ \\
\hline Selenides & Various compounds of Tl, $\mathrm{Sn}, \mathrm{Pb}, \mathrm{As}, \mathrm{Sb}, \mathrm{Bi}, \mathrm{Si}, \mathrm{P}$ \\
\hline Tellurides & Various compounds of $\mathrm{Tl}, \mathrm{Sn}, \mathrm{Pb}, \mathrm{As}, \mathrm{Sb}, \mathrm{Bi}, \mathrm{Ge}$ \\
\hline Halides & $\begin{array}{l}\mathrm{ZnCl}_{2} \text {, multi-compound chlorides based on } \mathrm{ZnCl}_{2}, \mathrm{CdCl}_{2}, \mathrm{BiCl}_{3} \text {, and } \mathrm{ThCl}_{4} \\
\mathrm{BeF}_{2}, \mathrm{AlF}_{3}, \mathrm{ZrF}_{4}, \mathrm{HfF}_{4}, \mathrm{ScF}_{3}, \mathrm{TiF}_{4} \text {, as glass-formers and many other ions as intermediatesand modifiers } \\
\mathrm{AgI}-\mathrm{AgF}-\mathrm{AlF}_{3}, \mathrm{Sb}_{2} \mathrm{~S}_{3}-\mathrm{Ag}_{2} \mathrm{~S}, \mathrm{Sb}_{2} \mathrm{~S}_{3}-\mathrm{AgI}, \mathrm{Sb}_{2} \mathrm{~S}_{3}-\mathrm{Ag}_{2} \mathrm{~S}-\mathrm{AgI} \\
\mathrm{Cu}(\mathrm{Cl}, \mathrm{Br}, \mathrm{I})\end{array}$ \\
\hline Acetates & $\mathrm{Pb}-\mathrm{K}$ acetate, $\mathrm{Ca}-\mathrm{K}$ acetate \\
\hline Nitrates & $\mathrm{KNO}_{3}-\mathrm{Ca}\left(\mathrm{NO}_{3}\right)_{2}$ and many other binary mixtures containing alkali and alkaline earths nitrates \\
\hline Sulfates & $\mathrm{KHSO}_{4}$ and other binary and ternary mixtures \\
\hline Carbonates & $\mathrm{K}_{2} \mathrm{CO}_{3}-\mathrm{MgCO}_{3}$ \\
\hline Aqueous solutions & Acids, bases, chlorides, nitrates, and others \\
\hline Metallic alloys by splat cooling & $\begin{array}{l}\mathrm{Au}_{4} \mathrm{Si}, \mathrm{Pd}_{4} \mathrm{Si} \\
\mathrm{Te}_{x}-\mathrm{Cu}_{2.5}-\mathrm{Au}_{5}\end{array}$ \\
\hline
\end{tabular}

in an ampoule. The melt is quenched to glass by inserting the ampoule into a water-cooled jacket. On a commercial scale, more elaborate sealed chambers are used, as illustrated in Fig. 2b [65]. These chambers combine the processes of purification and melting and allow for the production of melts of several kilograms.

$\mathrm{BeF}_{2}$ is the only fluoride that can form a glass on its own. $\mathrm{BeF}_{2}$ glass exhibits a $\left[\mathrm{BeF}_{4}\right]$ tetrahedral three-dimensional network structure. $\mathrm{BeF}_{2}$ has a strong GFA because of its large viscosity at the melting point and large slope parameter. $\mathrm{ZnCl}_{2}$ is the only chloride that can form a glass. The viscosity of $\mathrm{ZnCl}_{2}$ is approximately $50 \mathrm{~Pa}$ at the melting point lower than the corresponding values for $\mathrm{BeF}_{2}$. $\mathrm{CdCl}_{2}$ has a low viscosity and a smaller slope parameter compared with $\mathrm{BeF}_{2}$ and $\mathrm{ZnCl}_{2}$, but it cannot form glass on its own; some other fluorides and chlorides can undergo a glass transition in certain multi-component systems such as $\mathrm{ZrF}_{4}-\mathrm{BaF}_{2}-$ $\mathrm{LaF}_{3}$ and $\mathrm{CdCl}_{2}-\mathrm{BaCl}_{2}-\mathrm{NaCl}$. The glass-transition ranges of these systems are based on their melting-point compositions [61].

Compared with oxides and halides, metals have high heat conductivity, so high cooling rates can be obtained using the rolling quenching method $[66,67]$, which allows for the production of metallic glasses with low liquid viscosities; thus, large critical cooling rates become possible. Fig. 3 presents a schematic illustration of the melt-spinning process [66]. In the melt-spinning method, a small quantity of alloy is melted inside a crucible or via levita- tion methods and is then ejected under pressurization through a fine nozzle onto a rapidly rotating $\mathrm{Cu}$ wheel. Each of the parameters applied in each of these steps can be carefully controlled to obtain ribbons of the desired size, shape, and thickness. The solidification rates achieved in this process are typically approximately $10^{5}-10^{6} \mathrm{~K} / \mathrm{s}$ [66]. Multi-component metal glasses are more likely to vitrify than single-component ones. The critical cooling rate of $\mathrm{Pd}_{77} \mathrm{Cu}_{6} \mathrm{Si}_{17}$ glass is considerably less than that of singlecomponent $\mathrm{Ni}$ glass $(1010 \mathrm{~K} / \mathrm{s})$. However, $\mathrm{Pd}$, Ca, and $\mathrm{Si}$ cannot be formed into glasses using the rolling method of rapid cooling [66]. The double-roller method is another melt-quenching method in which oxides that are non-volatile up to $2500^{\circ} \mathrm{C}$ are melted within a duration of a few minutes and then poured into a twin-roller quenching system to form a glass slice, as illustrated in Fig. 4 [68].

\section{Theoretical approaches to glass formation}

The formation of glasses is an extremely interesting phenomenon. In terms of thermodynamic phase equilibrium, no substance should persist in the glassy state because glass is a metastable state. However, in terms of kinetics, any material can form a glassy state as long as the cooling rate and the melting viscosity are sufficiently high to prevent crystallization. A comprehensive understanding of the nature of glass formation and the factors that predominantly dominate the GFAs and glass-forming regions of glass-forming materials is of fundamental importance for advancing the 

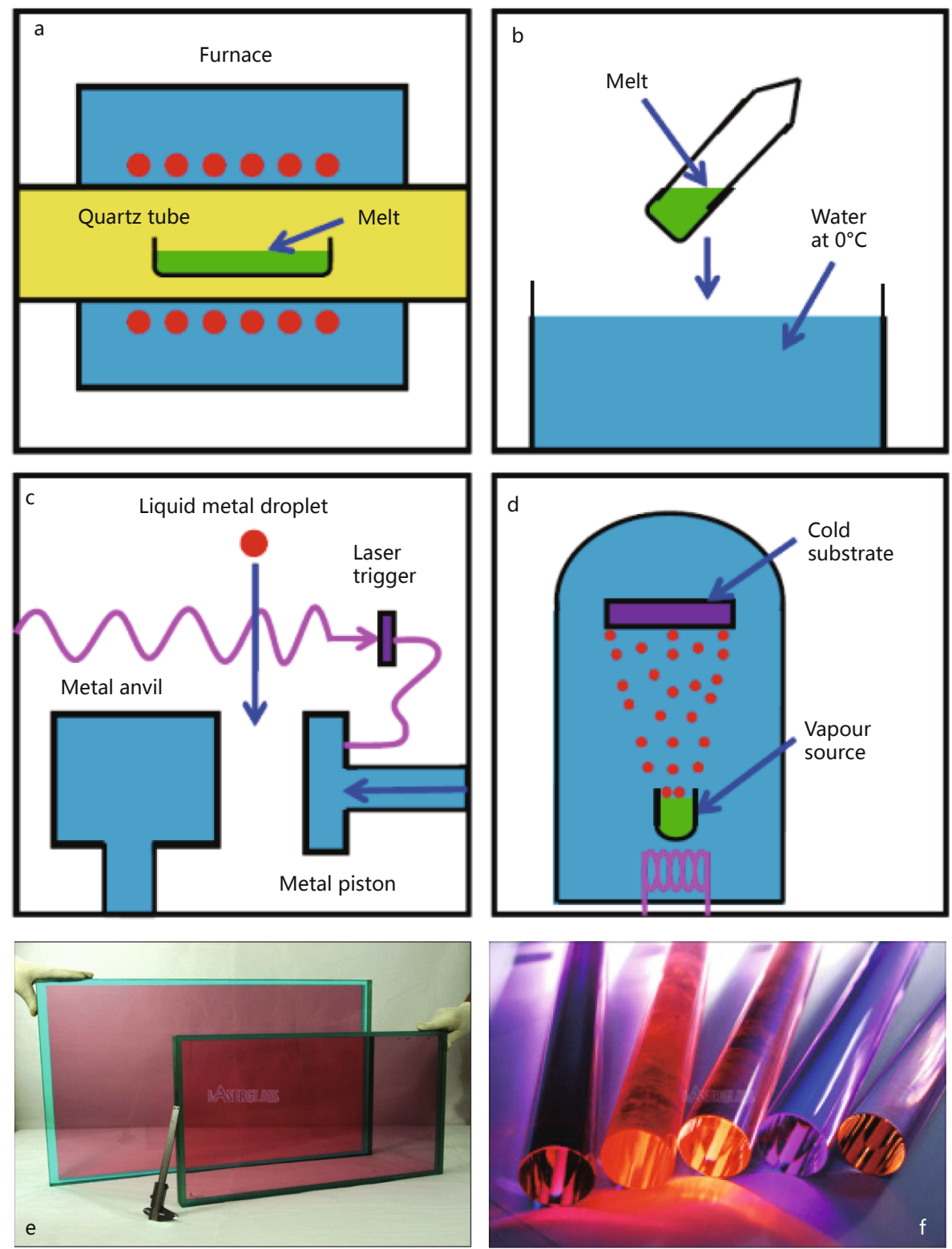

Figure 1 Various types of techniques used to prepare glasses. (a) Slow cooling in the melting-quenching method, (b) moderate quenching, (c) rapid splat quenching, (d) condensation from the gas phase, and (e, f) laser glasses prepared using the conventional melting-quenching method.

technological applications of glasses. The existing theories, concepts, criteria, semi-empirical rules, and models of glass formation can be divided into three groups: thermodynamic, structural-chemical, and kinetic.

\section{Thermodynamic considerations}

Glass is a supercooled liquid in a thermodynamically metastable state [7,31,32,69-73]. According to earlier studies, glass can be characterized using a series of plots of thermodynamic properties (energy, volume, enthalpy, or entropy) as a function of temperature $[15,32,74]$. In general, the behavior of the thermodynamic parameters of supercooled melts from the melting temperature $T_{\mathrm{m}}$ to the glass transition temperature $T_{\mathrm{g}}$ can only be predicted by extrapolating high-temperature data to the low-temperature region because of the strong tendency of such melts to crystallize [75]. As precise experimental calorimeters have become available over the past century, it has become feasible and inevitable for a wide variety of supercooled liquids and the glasses they form to be examined in detail and with increasing accuracy [76]. The most commonly studied change in thermodynamic properties resulting from the glass transi- 

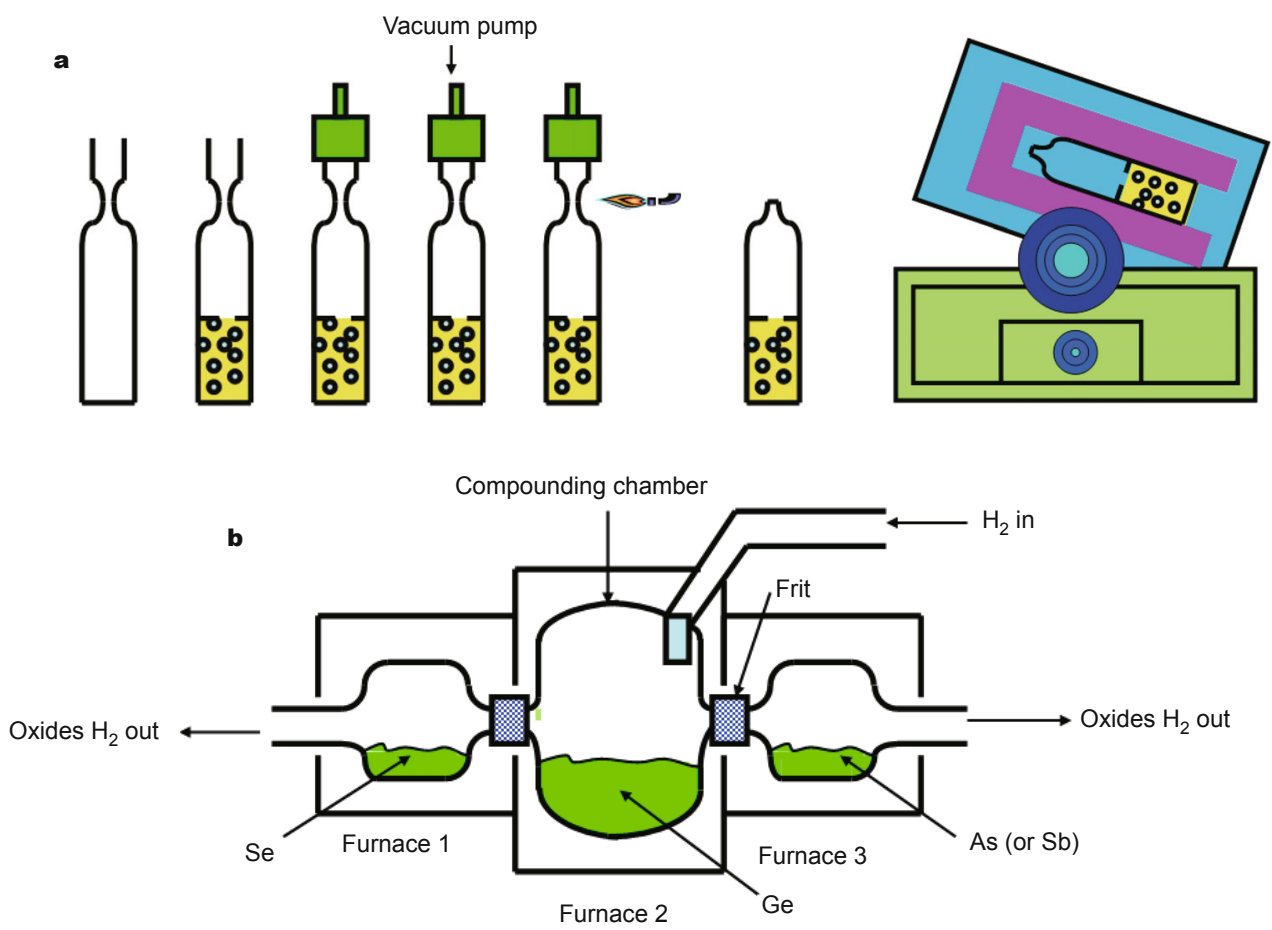

Figure 2 Process of sealed-ampoule melting, in which purified elements are sealed under vacuum and melted while the molten compound is mixed (a) (Reproduced with permission from Ref. [64], Copyright 2010, Research Signpost), and chalcogenide melting chamber pioneered for the purification and melting of selenide-based glasses (b) (Reproduced with permission from Ref. [65], Copyright 1975, Elsevier).

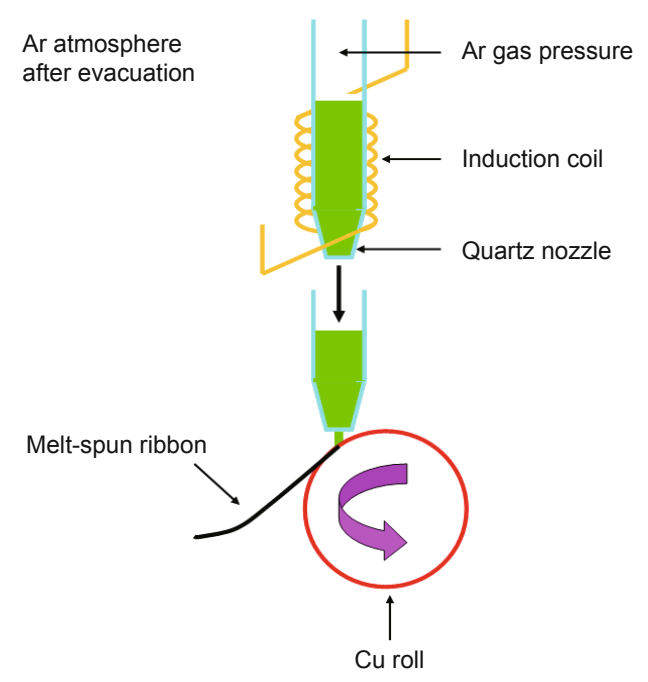

Figure 3 Schematic illustration of the melt-spinning process (Reproduced with permission from Ref. [66], Copyright 2011, CRC Press).

tion is that of the heat capacity $\left(C_{p}\right)$. The $C_{p}$ of a glass arises primarily from vibration contributions, whereas there are three major types of contributions for a liquid including: rotation, translation, and vibration. Fig. 5 presents features obtained when inspecting the change in $C_{p}$ with temperature for a melt and the corresponding glass [77]. At
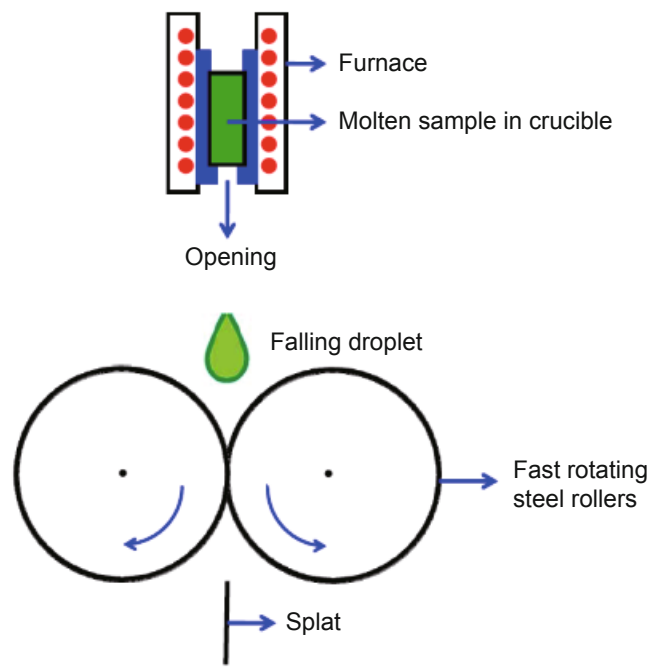

Figure 4 Schematic diagram of a liquid-quenching apparatus (Reproduced with permission from Ref. [68], Copyright 1967, Society of Glass Technology).

$T_{g}, C_{p}$-decreases considerably from the liquid to the glass state. The mechanical properties change at $T_{\mathrm{g}}$, from those of a hard and typically brittle solid to liquid-like properties. Upon cooling through the glass transition, the structure of the glass does not change, but the cooperative, large-amplitude molecular motion stops, causing a change in $C_{p}$; for 


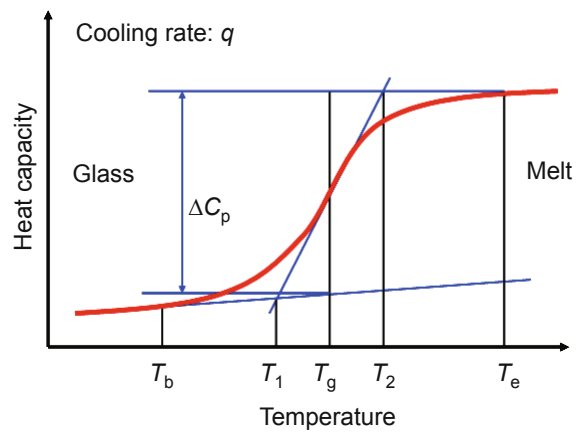

Figure 5 The variation heat capacity $C_{p}$ with temperature for a melt and the corresponding glass. $T_{\mathrm{b}}$ denotes the beginning of melting and $T_{\mathrm{e}}$ denotes the end of melting. The glass-transition range is from $T_{1}$ to $T_{2}$ (Reproduced with permission from Ref. [77], Copyright 2007, Wiley Periodicals, Inc.)

flexible molecules, this change is typically a decrease. The glass state below $T_{\mathrm{g}}$ is often referred to as the thermodynamic state of a vitrified substance; however, it is still not an equilibrium state [78]. The change in heat capacity at the glass transition, $\Delta C_{p}$, measures the difference between the liquid and solid $C_{p}$ values and can be used to estimate the difference in the Gibbs free energy, $\Delta G$, and other thermodynamic parameters. Fig. 6 illustrates the glass-transformation behavior with respect to either volume or enthalpy versus temperature at a constant pressure [79]. Glass (a) is formed at a slower cooling rate than glass (b). $T_{\mathrm{g}}$ decreases as the cooling rate decreases because the structural units have more time to reorganize, and therefore, $T_{\mathrm{g}}$ is lower. At higher temperatures, the structural units are able to rapidly reorganize themselves into a quasi-equilibrium liquid, whereas glass-forming liquids are those that are able to bypass the melting point $T_{\mathrm{m}}$; such liquids may have a high viscosity, which makes it difficult for atoms of the liquid to diffuse or rearrange into a crystalline structure. If the

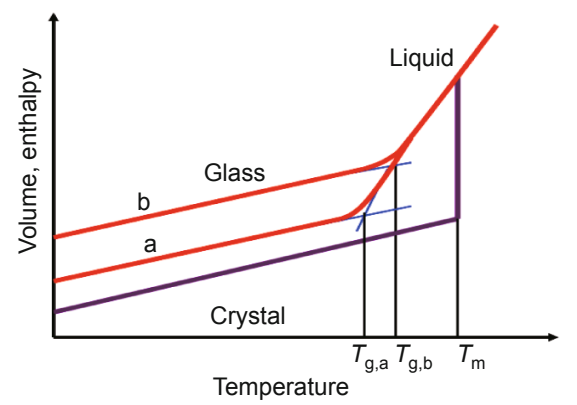

Figure 6 Temperature dependence of a liquid's volume or enthalpy at constant pressure. The glass transition temperature, $T_{\mathrm{g}}$, depends on the cooling rate of the liquid: higher cooling rates produce higher transition temperatures $T_{\mathrm{g}, \mathrm{b}}$ and $T_{\mathrm{g}, \mathrm{a}}$, and vice versa (Reproduced with permission from Ref. [79], Copyright 2001, Nature Publishing Group). cooling rate is sufficiently high, the liquid does not have sufficient time to crystallize, and thus, crystallization can be avoided. The volume continues to decrease as the temperature decreases, but the slope of the cooling curve in the glassy state, namely, the thermal expansion coefficient, is significantly smaller than that in either the liquid or supercooled liquid state [80].

Interestingly, as noted above, the variation of thermodynamic properties, such as enthalpy, volume, or specific heat across the glass transition, with temperature is dependent on the cooling (or heating) rate of the liquid [81-83]. Thus, the transition from liquid to glass or from glass to liquid is primarily a kinetic phenomenon. In the glass-transition range, there are decisive changes in microstructure that require increasing amounts of time as the lower temperature limit is approached. For this reason, all glass properties in this range depend on temperature and time, and therefore, different heating and cooling rates, or any variations in time and temperature (thermal history), will induce variations in the values of these properties $[1,15,32]$. This dependence is the primary reason that $T_{\mathrm{g}}$ varies with thermal history.

\section{Chemical-bond-structure viewpoint}

The discussion presented in INTRODUCTION section demonstrates the process of glass formation is an anti-crystallization kinetics process and requires a sufficiently high viscosity at the crystallization temperature to prevent the occurrence of crystal nucleation and growth. The cooling conditions constitute an external factor. Under constant temperature conditions, the melt viscosity is determined by the structural chemistry. The following factors determine the viscosity: (i) Chemical bonds. Metallic and ionic bonds exhibit high liquidity and low viscosity. Ionic and covalent bonds may form a network structure, thereby leading to a high viscosity. The viscosity of an alloy composed of metals and metalloids with covalent bonds are considerably greater than that of an alloy based on metallic bonds. (ii) The linkage of the structure. The viscosities of materials decrease with the dimensionality of their structures in the following order: 3-dimensional structures, 2-dimensional structures, 1-dimensional structures, and isolated points, as illustrated in Tables 2 and 3. (iii) The eutectic point. The viscosity of a substance with several intertwined structures at the eutectic point is larger than that of each separate structure.

In terms of chemical structure, glassy substances consist of complex chains or layered molecular groups; thus, their viscosity in the molten state is high. These chains or layers are interlaced with each other, and the formation of a crystal with good symmetry is difficult; therefore, the substance becomes a supercooled liquid when the temperature is be- 
Table 2 The relationship between viscosity and the linkage of the structure. The viscosities of materials decrease with their structural dimensionality, in the following order: 3-dimensional structures, 2-dimensional structures, 1-dimensional structures, and isolated points

\begin{tabular}{|c|c|c|c|c|c|c|}
\hline \multirow{3}{*}{$\begin{array}{l}\text { Glass systems } \\
\mathrm{Na}_{2} \mathrm{O}-\mathrm{B}_{2} \mathrm{O}_{3}\end{array}$} & \multicolumn{6}{|c|}{ Viscosity at melting point (Pa s) } \\
\hline & \multicolumn{2}{|c|}{ 3-dimensional } & \multicolumn{2}{|c|}{ 2-dimensional: layer structures or chain structures } & \multicolumn{2}{|c|}{ 1-dimensional and isolated ionic groups } \\
\hline & $\mathrm{B}_{2} \mathrm{O}_{3}$ & $10^{6}$ & $\mathrm{Na}_{2} \mathrm{O} \cdot 2 \mathrm{~B}_{2} \mathrm{O}_{3}$ & $10^{1.6}$ & $\mathrm{Na}_{2} \mathrm{O} \cdot \mathrm{B}_{2} \mathrm{O}_{3}$ & $10^{0.4}$ \\
\hline $\mathrm{Li}_{2} \mathrm{O}-\mathrm{B}_{2} \mathrm{O}_{3}$ & $\mathrm{~B}_{2} \mathrm{O}_{3}$ & $10^{6}$ & $\mathrm{Li}_{2} \mathrm{O} \cdot 2 \mathrm{~B}_{2} \mathrm{O}_{3}$ & $10^{0.5}$ & $\mathrm{Li}_{2} \mathrm{O} \cdot \mathrm{B}_{2} \mathrm{O}_{3}$ & $10^{-0.8}$ \\
\hline $\mathrm{Li}_{2} \mathrm{O}-\mathrm{SiO}_{2}$ & $\mathrm{SiO}_{2}$ & $10^{7}$ & $\mathrm{Li}_{2} \mathrm{O} \cdot 2 \mathrm{SiO}_{2}$ & $10^{1.8}$ & $\mathrm{Li}_{2} \mathrm{O} \cdot \mathrm{SiO}_{2}$ & $10^{0}$ \\
\hline $\mathrm{CaO}-\mathrm{SiO}_{2}$ & $\mathrm{SiO}_{2}$ & $10^{7}$ & - & - & $\mathrm{CaO} \cdot \mathrm{SiO}_{2}$ & $10^{2.5}$ \\
\hline
\end{tabular}

Table 3 Structures and GFAs of selected oxides

\begin{tabular}{|c|c|c|c|}
\hline Oxides & Valence $(Z)$ & Structure & GFA \\
\hline SO & 4 & Molecular structure & \\
\hline $\mathrm{P}_{2} \mathrm{O}_{5}$ & 4 & 2-dimensional lay structure & Network-formers \\
\hline $\mathrm{B}_{2} \mathrm{O}_{3}$ & 3 or 4 & 2-dimensional lay structure & Network-formers \\
\hline $\mathrm{SiO}_{2}$ & 4 & 3-dimensional frame structure & Network-formers \\
\hline $\mathrm{GeO}_{2}$ & 4 & 3-dimensional frame structure & Network-formers \\
\hline $\mathrm{Al}_{2} \mathrm{O}_{3}$ & 4 or 6 & Sapphire structure & Intermediates \\
\hline $\mathrm{MgO}$ & 4 or 6 & $\mathrm{NaCl}$ structure & Intermediates \\
\hline $\mathrm{Na}_{2} \mathrm{O}$ & 6 or 8 & $\mathrm{CaF}_{2}$ structure & Network-modifiers \\
\hline
\end{tabular}

low the "freezing point". For the structure to form chains or layers, the chemical bonds can only be either ionic and covalent or covalent and metallic. When an ionic-bond compound melts, it takes the form of positive and negative ions, and its viscosity is low. During the cooling process, such a compound can easily become arranged into a crystalline because of the electrical properties of the positive and negative ions. Metallic-bond compounds are similarly characterized by low viscosity, high kinematic velocity and facile crystallization. Covalent-bond compounds naturally exist in the molecular form; molecules either are not linked or are linked by weak van der Waals forces and can easily form crystals. Therefore, compounds with pure ionic, metallic and covalent bonds cannot satisfy the requirement of high viscosity. More detailed description on the relationship between glass formation and structure has been discussed in earlier studies $[7,20]$.

\section{Kinetic approach to glass formation}

Kinetic consideration for glass formation basically focuses on the depression of atomic diffusion, and high viscosity or structural relaxation time through whole supercooled liquid region is an advantage [84]. Glass formation has been widely explored, and some parameters such as reduced glass transition $\left(T_{\mathrm{g}} / T_{1}\right)$, degree of supercooling $\left(\Delta T_{\mathrm{x}}=T_{\mathrm{x}}-\right.$ $T_{\mathrm{g}}$ ), and similar variables are used to characterize GFA $[15,31,85]$. Unlike previous approaches, which were based on the stabilization of the liquid phase and ignored the effect of the composition on the stability of the crystalline phases, Ref. [58] proposed that the GFA of non-crystalline materials is predominantly related to two factors, $1 /\left(T_{\mathrm{g}}+T_{1}\right)$ and $T_{\mathrm{x}}$ (where $T_{\mathrm{x}}$ is the onset crystallization temperature, $T_{\mathrm{g}}$ is the glass transition temperature, and $T_{1}$ is the liquidus temperature), and could be predicated by a unified parameter gamma defined as $T_{\mathrm{x}} /\left(T_{\mathrm{g}}+T_{1}\right)$. The three- $\mathrm{T}$ (TTT) diagram presented by Ref. [58] contains the information required to predict the formability and stability of a given glass, as shown in Fig. 7. To create an amorphous solid material, the liquid must be cooled sufficiently rapidly from above the liquidus temperature through the glass transition temperature that the TTT curve is not intersected. The minimum cooling rate required for glass formation (i.e., the critical cooling rate) is the cooling rate required to

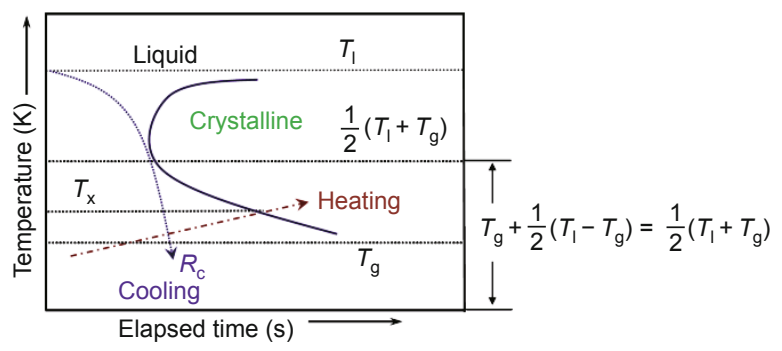

Figure 7 Schematic time-temperature-transformation (TTT) diagram. Crystallization occurs between $T_{1}$ and $T_{\mathrm{g}}$ and can be avoided with sufficiently rapid cooling of the liquid $\left(R_{\mathrm{c}}\right)$; when an amorphous solid is isochronally heated at a constant heating rate, the sample begins to crystallize at an onset temperature denoted by $T_{\mathrm{x}}$ (Reproduced with permission from Ref. [58], Copyright 2003, American Physical Society). 
bypass the knee of the TTT curve. The average position of the TTT curve along the temperature scale is represented by a line at $\left(T_{\mathrm{g}}+T_{1}\right) / 2$.

In terms of dynamics, theoretically, if the cooling rate is sufficiently high, then nearly all substances can form glasses; however, under normal circumstances, only a small number of materials can form glasses. The difficulty of glass formation during the cooling process is related to the melt viscosity at the solidification temperature. Facile glass-forming materials traditionally have large viscosities at their melting points, whereas materials with low viscosities at their melting temperatures readily form crystals. In terms of thermodynamics, the large internal energies of glassy materials tend to decrease near the crystalline transition. However, in terms of dynamics, crystallization must overcome a certain potential barrier, which includes the interfacial energy associated with establishing new nucleation interfaces and the activation energy for particle diffusion that is required for growth. When the potential barrier is large and the melt is cooled rapidly, the melt viscosity increases and the particles do not have sufficient time to form an orderly array; thus, nucleation and growth are difficult to achieve, facilitating the formation of glass.

Uhlmann [86-93] regards the crystal-volume ratio $V_{c} / V$ as a critical quantity for defining a crystal or non-crystal. He believes that glass has a measurable crystal volume of less than $10^{-6}$ per unit. The formation of glass-forming dynamics proposed by Uhlmann is related to the nose peak of the three- $\mathrm{T}$ diagram at a specific crystallization content $V_{\mathrm{c}} / V$.

The critical cooling rate, $R_{\mathrm{c}}$, that is required for glass formation for a material with certain known parameters can be estimated using the dynamic theory [20]. For a certain material with a crystallization rate of $V_{c} / V$ and a peak location near 0.77 , the corresponding equation is given by [20]:

$$
\begin{aligned}
R_{\mathrm{c}}= & 0.4628 T_{\mathrm{s}}^{2} \exp \left(\frac{5.1912+0.3495 \ln \eta_{\mathrm{s}}-0.01435\left(\ln \eta_{\mathrm{s}}\right)^{2}}{0.01104 \ln \eta_{\mathrm{s}}-0.4232}\right) \\
& \times\left(\frac{V_{\mathrm{c}}}{V}\right)^{-1 / 4} \cdot
\end{aligned}
$$

Therefore, the thermodynamic crystal parameters can be neglected in the Uhlmann formula provided that the upper-limit temperature $T_{s}$ of glass crystallization and $\eta_{s}$ deduced from the glass viscosity above $T_{\mathrm{s}}$ are known. Thus, the glass-forming dynamics proposed by Uhlmann, which are applicable to the corresponding fusion compound, can be modified into a more suitable form for application to common multi-component complex glasses. The glasscrystallization rate $V_{c} / V$ required for glass formation is predominantly determined by the viscosity and cooling rate, as shown in Equation (2). In general, $V_{c} / V$ is inversely proportional both to $R_{\mathrm{c}}$ and $\eta_{\mathrm{s}}$, and the influence of $T_{\mathrm{s}}$ is not large.

$$
\left(\frac{V_{\mathrm{c}}}{V}\right)^{1 / 4}=\frac{0.4628 T_{\mathrm{s}}^{2} \exp \left(\frac{5.1912+0.3495 \ln \eta_{\mathrm{s}}-0.01435\left(\ln \eta_{\mathrm{s}}\right)^{2}}{0.01104 \ln \eta_{\mathrm{s}}-0.4232}\right)}{R_{\mathrm{c}}} .
$$

\section{THE FORMATION OF GLASS: A VISCOSITY/ COOLING-RATE APPROACH}

\section{Common characteristics of classical approaches to glass formation}

Zachariasen [35] proposed a random network theory for glass formation based on the crystal chemistry view of Goldschmidt [30]. In this theory, he proposed the requirements that a glass former must satisfy: (i) the coordination number of the cation should not be overly large and is typically 4 or 3; (ii) an oxygen atom is linked to no more than two cations; (iii) the polyhedra share only corners with each other, not edges or faces; and (iv) at least three corners of each oxygen polyhedron are shared $[32,35,36]$. The oxides that satisfy these requirements are $\mathrm{A}_{2} \mathrm{O}_{3}, \mathrm{AO}_{2}$ and $\mathrm{A}_{2} \mathrm{O}_{5}$; oxides of the forms $\mathrm{A}_{2} \mathrm{O}, \mathrm{AO}, \mathrm{AO}_{3}$ and $\mathrm{A}_{2} \mathrm{O}_{7}$ cannot form glass. Zachariasen further noted that oxides that can form glass include $\mathrm{B}_{2} \mathrm{O}_{3}, \mathrm{As}_{2} \mathrm{O}_{3}, \mathrm{P}_{2} \mathrm{O}_{3}, \mathrm{Sb}_{2} \mathrm{O}_{3}, \mathrm{SiO}_{2}, \mathrm{GeO}_{2}$, $\mathrm{P}_{2} \mathrm{O}_{5}, \mathrm{As}_{2} \mathrm{O}_{5}, \mathrm{~V}_{2} \mathrm{O}_{5}, \mathrm{Nb}_{2} \mathrm{O}_{5}$ and $\mathrm{Ta}_{2} \mathrm{O}_{5}$. According to previous discussions of the requirements for glass formation proposed by Zachariasen, all glass formers are ionic/covalent-bond compounds that exhibit high melt viscosities and thus readily form glass, either upon quenching in a melt furnace or naturally. To form his theory, Dietzel [94-96] began with crystal chemistry and considered atoms within the glass as small, solid spheres. Anions and cations attract each other and are joined by ionic bonds. Dietzel [94-96] noted that the ability of various oxides to form glasses can be determined based on the electric field strength $\left(Z \cdot e / r^{2}\right)$ or attraction $\left(Z_{1} \cdot Z_{2} \cdot e^{2} / a^{2}\right)$, where $Z$ is the valence of the element, $e$ is the elementary charge, $r$ is the ionic radius and $a$ is the sum of the cation and anion radii. He also noted that glasses can only be formed at high field strengths. According to his calculations, $\mathrm{B}_{2} \mathrm{O}_{3}, \mathrm{P}_{2} \mathrm{O}_{5}, \mathrm{SiO}_{2}$ and $\mathrm{GeO}_{2}$, whose field strengths are 104, 49, 29 and 23, respectively, can form glass. These oxides have high viscosities, but compounds of low $\mathrm{Z} / \mathrm{r}^{2}$, such as $\mathrm{Al}_{2} \mathrm{O}_{3}$, have low viscosities at their melting points. Table 4 illustrates that Zachariasen's classification of ions as network formers, network modifiers, or intermediates correlates well with Dietzel's field-strength values: $Z$ / $a^{2} \approx 0.1-0.4$ for network modifiers, $Z / a^{2} \approx 0.5-1.0$ for intermediates, and $Z / a^{2} \approx 1.3-2.0$ for network-formers. Dietzel's field-strength concept makes it possible to propose rules governing the behavior of a cooling melt that could not be 
$\underline{\text { Table } 4 \text { Field-strength classification of cations according to Dietzel }[32,100]}$

\begin{tabular}{|c|c|c|c|c|c|c|c|}
\hline Element & Valence $Z$ & $\begin{array}{l}\text { Ionic radius } \\
(\mathrm{nm})\end{array}$ & $\begin{array}{l}\text { Coordination } \\
\text { number }\end{array}$ & $\begin{array}{c}\text { Ionic } \\
\text { distance }\end{array}$ & Electronegativity $^{\mathrm{a}}$ & $\begin{array}{c}\text { Field } \\
\text { strength } Z / a^{2}\end{array}$ & Function in glass structure \\
\hline $\mathrm{Cs}^{\mathrm{a}}$ & 1 & 0.165 & 12 & & 0.7 & 0.10 & \multirow{14}{*}{$\begin{array}{l}\text { Network modifiers } \\
\quad Z / a^{2} \approx 0.1-0.4\end{array}$} \\
\hline $\mathrm{Rb}^{\mathrm{a}}$ & 1 & 0.149 & 10 & & 0.8 & 0.12 & \\
\hline K & 1 & 0.133 & 8 & 0.277 & 0.8 & 0.13 & \\
\hline $\mathrm{Na}$ & 1 & 0.098 & 6 & 0.230 & 0.9 & 0.19 & \\
\hline $\mathrm{Li}$ & 1 & 0.078 & 6 & 0.210 & 1 & 0.23 & \\
\hline $\mathrm{Ba}$ & 2 & 0.143 & 8 & 0.286 & 0.9 & 0.24 & \\
\hline $\mathrm{Pb}$ & 2 & 0.132 & 8 & 0.274 & & 0.27 & \\
\hline $\mathrm{Sr}$ & 2 & 0.127 & 8 & 0.269 & 1.0 & 0.28 & \\
\hline $\mathrm{Ca}$ & 2 & 0.106 & 8 & 0.248 & 1.0 & 0.33 & \\
\hline $\mathrm{Mn}$ & 2 & 0.091 & 6 & 0.223 & & 0.40 & \\
\hline $\mathrm{Fe}$ & 2 & 0.083 & 6 & 0.215 & & 0.43 & \\
\hline $\mathrm{Mn}$ & 2 & 0.083 & 4 & 0.203 & & 0.49 & \\
\hline \multirow[t]{2}{*}{$\mathrm{Mg}$} & 2 & 0.078 & 6 & 0.210 & 1.2 & 0.45 & \\
\hline & & & 4 & 0.196 & & 0.53 & \\
\hline $\mathrm{Zr}$ & 4 & 0.087 & 8 & 0.228 & & 0.77 & \multirow{13}{*}{$\begin{array}{l}\text { Intermediates } \\
Z / a^{2} \approx 0.5-1.0\end{array}$} \\
\hline $\mathrm{Be}$ & 2 & 0.034 & 4 & 0.153 & 1.5 & 0.86 & \\
\hline \multirow[t]{2}{*}{$\mathrm{Fe}$} & 3 & 0.067 & 6 & 0.199 & & 0.76 & \\
\hline & & & 4 & 0.188 & & 0.85 & \\
\hline \multirow[t]{2}{*}{$\mathrm{Al}$} & 3 & 0.057 & 6 & 0.189 & 1.5 & 0.84 & \\
\hline & & & 4 & 0.177 & & 0.96 & \\
\hline $\mathrm{Ti}$ & 4 & 0.064 & 6 & 0.196 & 1.6 & 1.04 & \\
\hline \multirow[t]{2}{*}{$\mathrm{Ga}^{\mathrm{a}}$} & 2 & 0.062 & 4 & & 1.6 & 0.9 & \\
\hline & & & 6 & & & 0.8 & \\
\hline $\mathrm{Pb}^{\mathrm{a}}$ & & 0.084 & 4 & & 1.8 & 0.86 & \\
\hline $\mathrm{As}^{\mathrm{a}}$ & 3 & 0.069 & 4 & & 2.0 & 0.83 & \\
\hline $\mathrm{Sb}^{\mathrm{a}}$ & 3 & 0.090 & 4 & & 1.9 & 0.61 & \\
\hline $\mathrm{Bi}^{\mathrm{a}}$ & 3 & 0.108 & 6 & & & 0.52 & \\
\hline \multirow[t]{2}{*}{ B } & 3 & 0.020 & 4 & 0.150 & 2.0 & 1.34 & \multirow{9}{*}{$\begin{array}{l}\text { Network formers } \\
Z / a^{2} \approx 1.3-2.0\end{array}$} \\
\hline & & & 3 & & & 1.63 & \\
\hline $\mathrm{Ge}$ & 4 & 0.044 & 4 & 0.166 & 1.8 & 1.45 & \\
\hline $\mathrm{Si}$ & 4 & 0.039 & 4 & 0.160 & 1.8 & 1.57 & \\
\hline $\mathrm{P}$ & 5 & 0.034 & 4 & 0.155 & 2.1 & 2.1 & \\
\hline $\mathrm{V}^{\mathrm{a}}$ & 5 & 0.059 & 4 & & 1.6 & 1.54 & \\
\hline $\mathrm{Sn}^{\mathrm{a}}$ & 4 & 0.074 & 6 & & 1.8 & 1.94 & \\
\hline $\mathrm{Se}^{\mathrm{a}}$ & 4 & 0.198 & 2 & & 2.4 & & \\
\hline $\mathrm{Te}^{\mathrm{a}}$ & 4 & 0.221 & 2 & & 2.1 & & \\
\hline
\end{tabular}

a) Data from Ref. [100]. 
explained based on the Zachariasen-Warren hypotheses alone.

Fig. 8 presents a schematic diagram of glass formation based on the viscosity and the single-band energy, field strength, electronegativity, or space occupancy. It should be mentioned here that, as aforementioned in INTRODUCTION section, one of the most critical parameters that determine whether a melt can form a glass is viscosity of the materials at the melting point. We summarized the physical constants of several glasses (as illustrated in Tables 4 and 5 ) and found that glass formation is an anti-crystallization kinetics process and requires a sufficiently high viscosity at the crystallization temperature to prevent the occurrence of crystal nucleation and growth. Under constant temperature conditions, the melt viscosity is determined by the structural chemistry.

Sun $[48,97]$ proposed a single-bond-strength criterion for glass formation. Based on Sun's theory, Rawson [49-51] considered the ratio of the single-bond-strength to the melting point as the criterion for the identification of glass formers. Glass formers are compounds that have relatively high viscosities when they are melted. Although these authors did not discuss the kinetic conditions of glass formation, they referred to oxides that can form glass at natural cooling rates. Similarly, Winter $[37,98]$ and Stanworth [38-42,99], among others, judged GFA based on the p electrons, $\sigma$ bonds and electronegativities of the elements of interest. They concluded that glass formers primarily consist of oxide, halogen and chalcogenide compounds with high viscosities at their melting points. Therefore, glass formers or compounds that form glass, are characterized by high

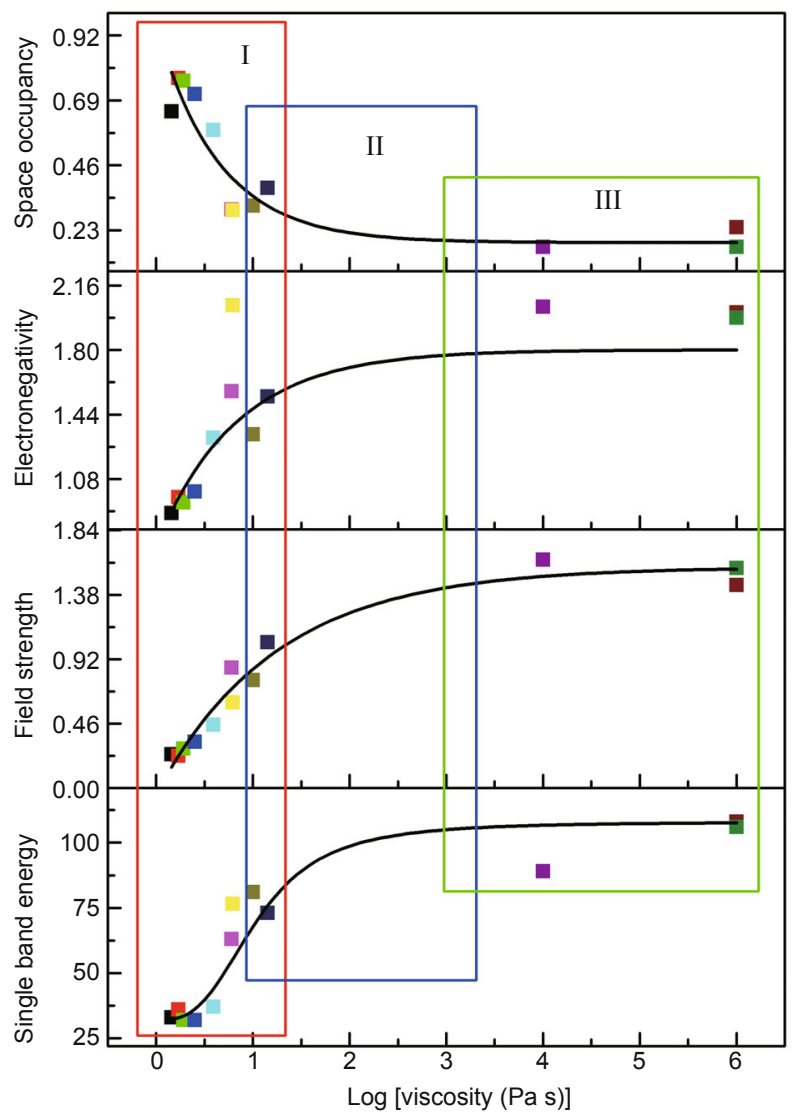

Figure 8 Schematic diagram of glass formation based on the viscosity and the single-band energy, field strength, electronegativity, or space occupancy. I: Glass can not be readily formed. II: Glass can be formed only under rapid cooling. III: Glass can be stably formed with slow cooling.

Table 5 The physical constants of some oxides

\begin{tabular}{|c|c|c|c|c|c|}
\hline Oxides & $\begin{array}{l}\text { Log viscosity } \\
\text { at melting point }(\mathrm{Pa} \mathrm{s})[101]\end{array}$ & $\begin{array}{l}\text { Single band energy } \\
\left(\mathrm{kcal} \mathrm{mol}^{-1}\right)[102]\end{array}$ & $\begin{array}{l}\text { Field strength } \\
\qquad Z / a^{2}[32]\end{array}$ & Electronegativity & Space occupancy \\
\hline $\mathrm{BaO}$ & 0.16 & 33 & 0.24 & 0.89 & $0.65^{\mathrm{a}}$ \\
\hline $\mathrm{Li}_{2} \mathrm{O}$ & 0.23 & 36 & 0.23 & 0.98 & $0.77^{\mathrm{a}}$ \\
\hline $\mathrm{SrO}$ & 0.28 & 32 & 0.28 & 0.95 & $0.76^{\mathrm{a}}$ \\
\hline $\mathrm{CaO}$ & 0.4 & 32 & 0.33 & 1.01 & $0.71^{\mathrm{a}}$ \\
\hline $\mathrm{MgO}$ & 0.59 & 37 & 0.45 & 1.31 & $0.59^{\mathrm{a}}$ \\
\hline $\mathrm{BeO}$ & 0.78 & 63 & 0.86 & 1.57 & $0.30^{\mathrm{a}}$ \\
\hline $\mathrm{Sb}_{2} \mathrm{O}_{3}$ & 0.79 & $68-85$ & 0.61 & 2.05 & 0.30 \\
\hline $\mathrm{ZrO}_{2}$ & 1 & 81 & 0.77 & 1.33 & $0.32^{\mathrm{a}}$ \\
\hline $\mathrm{TiO}_{2}$ & 1.15 & 73 & 1.04 & 1.54 & 0.38 \\
\hline $\mathrm{B}_{2} \mathrm{O}_{3}$ & 4 & 89 & 1.63 & 2.04 & 0.17 \\
\hline $\mathrm{GeO}_{2}$ & 6 & 108 & 1.45 & 2.01 & 0.24 \\
\hline $\mathrm{SiO}_{2}$ & 6 & 106 & 1.57 & 1.98 & 0.17 \\
\hline
\end{tabular}

a) Data were calculated by the equation: $f=\left(\frac{2.523 \rho}{M}\right)\left(X A_{\mathrm{r}}{ }^{3}+0.216 Y\right)[42,102]$. 
viscosities at their melting points arising from not only their melt structures but also their chemical bonds, and in strong agreements with our concept proposed based on calculated results and the corresponding phase diagram.

As for Uhlmann's kinetic theory of glass formation, the parameters required by the Uhlmann equation cannot be measured or obtained because glass is not a fixed-ingredient compound and does not have a fixed melting point. The formula can only be applied to the crystallization kinetics equation of a specific compound. The selection of viscosity as the judgment parameter can be generally applied to both the glass and the corresponding crystal melt. We previously stressed that glass formation is a result of the combined actions of thermodynamics and kinetics. Uhlmann's kinetic viewpoint is undoubtedly a milestone for the understanding of glass formation by virtue of its recognition that kinetics is also an essential element for glass formation.

Table 6 lists the viscosities of several materials at their melting points, their critical cooling rates, and the corresponding techniques of glass formation. All previously recognized and authoritative descriptions of glass formation are summarized in Fig. 9, which provides a relatively comprehensive description and addresses the limit problem of glass formation. It is found that there is an inverse function relationship between the critical cooling rates and the viscosities of the melts at their melting points; the corresponding equation is given by:

$$
\ln R_{\mathrm{c}}=A_{1} \ln \eta+\frac{A_{2}}{A_{3} \ln \eta+A_{4}}+A_{5},
$$

where $A_{i}(i=1,2,3,4$ and 5$)$ is constant, and thus the corresponding expression can be rewritten as follows:

$$
\ln R_{\mathrm{c}}=2.95 \ln \eta+\frac{80.81}{0.02 \ln \eta+0.44}-169.74 \text {. }
$$

Dependence of glass formation on viscosity and cooling rate The GFA is proportional to the viscosity at the melting point, high viscosity resulting in easier glass formation. Furthermore, according to Equation (2), the GFA is also directly proportional to the cooling rate. The melt viscosity depends on the chemical-bond properties and melts structure. First, with respect to the chemical-bond properties, the viscosity of a compound with ionic or metallic bonds is extremely low, approximately $0.1-0.001 \mathrm{~Pa} s$; the mobilities of such compounds are extremely strong, so they crystallize very readily. With respect to the melt structure, such compounds have high coordination numbers and shared edges or faces. Ionic and covalent bonds can link to each other because the cationic field strength in the structure is high. For example, when two $\mathrm{Si}^{4+}$ ions are interconnect- ed by an $\mathrm{O}^{2-}$ ion the resulting $\mathrm{Si}-\mathrm{O}-\mathrm{Si}$ bond is rather long because of the strong repulsive forces between $\mathrm{Si}^{4+}$ ions. In terms of energy, it is more appropriate to connect $\left[\mathrm{SiO}_{4}\right]$ tetrahedral through corner sharing rather than the sharing of edges or faces. Therefore, all glass network formers as defined by the Zachariasen rules are ionically or covalently bonded, have high field strengths and low coordination numbers (typically 3-4) and are connected at their corners $[34,104]$. In terms of viscosity, they are characterized by high viscosity, generally above $10^{3} \mathrm{~Pa}$. The viscosity value may be as high as $10^{6}-10^{7} \mathrm{~Pa}$ s for fourfold coordination and reaches $10^{4}-10^{5} \mathrm{~Pa}$ s for threefold coordination. According to Zachariasen, these so-called glass network formers can naturally form glasses. Based on the prevailing conditions, the definition of a glass former should include the kinetic conditions under which the melt is cooled to room temperature, either in a melt furnace or naturally, to become a transparent glass without crystallization. With such an expansion of the definition such materials as $\mathrm{BeF}_{2}$, $\mathrm{ZnCl}_{2}$ and $\mathrm{As}_{2} \mathrm{~S}_{3}$ can also be classified as glass formers. Although their chemical-bond properties are considerably different, their melt viscosities are considerably higher than those of similar halogen and chalcogen compounds. The melt viscosity can also be considered in terms of the relationship between the melt structure and the viscosity rather than through a direct discussion of the chemical bonds. In the case of silicate melts, the viscosity decreases as follows: 3-dimensional structures, layer structures, chain structures, groups of structures and island structures (more generally, 3-dimensional structures, 2-dimensional structures, 1-dimensional structures and isolated ionic groups). In the past, the variation in viscosity was considered to be attributed only to the links of $\left[\mathrm{SiO}_{4}\right]$, but in fact, the effect of the alkali ions should not be ignored because their increased presence causes the mobility to increase and the viscosity to decrease. This viewpoint can be extended to the ionic groups of other glass formers. Meanwhile, the viscosity of a three-dimensional linkage is higher than that of a two-dimensional linkage, for examples, the viscosities of $\mathrm{SiO}_{4}$ and $\mathrm{GeO}_{4}$ are higher than that of $\mathrm{BO}_{3}$. The viscosities of $\mathrm{ZrF}_{4}$ and $\mathrm{As}_{2} \mathrm{~S}_{3}$, whose chemical bonds are predominantly ionic or covalent, are lower than that of $\mathrm{SiO}_{2}$.

In the 1960s, Mackenzie [17,52] proposed that compounds with sixfold coordination can also form glass and modified Zachariasen's doctrine of glass formation. In fact, glass formation must be jointly determined by the melt structure and cooling rate. The glass-forming condition of Zachariasen applies to cooling both in a melt furnace and naturally, but that of Mackenzie also extends to rapid cooling using cold metal pressure or other means. Meanwhile, the previous use of the ratio of $\mathrm{O}$ and $\mathrm{Si}$ up to the glass-forming limit and the concept of so-called reverse 
Table 6 The viscosities of several different materials at their melting points, the critical cooling rates, and the corresponding techniques of glass formation

\begin{tabular}{|c|c|c|c|c|c|c|c|}
\hline \multicolumn{2}{|c|}{ Materials } & \multirow{2}{*}{$\begin{array}{c}T_{\mathrm{m}}(\mathrm{K}) \\
1983\end{array}$} & \multirow{2}{*}{$\begin{array}{c}\text { Log viscosity } \\
\text { at melting point (Pa s) }\end{array}$} & \multirow{2}{*}{$\begin{array}{l}\text { Refs. } \\
{[31]}\end{array}$} & \multirow{2}{*}{$\frac{\log R_{\mathrm{c}}(\mathrm{K} / \mathrm{s})}{-6}$} & \multirow{2}{*}{$\begin{array}{c}\text { Method } \\
\text { Natural cooling }\end{array}$} & \multirow{2}{*}{$\frac{\text { Samples }}{1}$} \\
\hline \multirow{23}{*}{ Oxides } & $\mathrm{SiO}_{2}$ & & & & & & \\
\hline & $\mathrm{GeO}_{2}$ & 1388 & 6 & {$[31]$} & -3 & & 2 \\
\hline & $\mathrm{Sb}_{2} \mathrm{O}_{3}$ & & 0.79 & {$[101]$} & & & 3 \\
\hline & $\mathrm{As}_{2} \mathrm{O}_{3}$ & 582 & 5 & {$[31]$} & $-4--5$ & & 4 \\
\hline & $\mathrm{B}_{2} \mathrm{O}_{3}$ & 723 & 4 & {$[31]$} & -4 & & 5 \\
\hline & $\mathrm{Al}_{2} \mathrm{O}_{3}$ & 2323 & -0.22 & {$[61]$} & & & 6 \\
\hline & $\mathrm{SiO}_{2}$ & 1907 & 7.36 & {$[62]$} & -7 & & $1^{\mathrm{a}}$ \\
\hline & $\mathrm{GeO}_{2}$ & 1389 & 5.5 & {$[62]$} & -6 & & $2^{\mathrm{a}}$ \\
\hline & $\mathrm{P}_{2} \mathrm{O}_{5}$ & 853 & 6.7 & {$[62]$} & -7 & & $3^{\mathrm{a}}$ \\
\hline & $\mathrm{Na}_{2} \mathrm{O} \cdot 2 \mathrm{SiO}_{2}$ & 1151 & 3.8 & {$[62]$} & -4 & & $4^{\mathrm{a}}$ \\
\hline & $\mathrm{BaO} \cdot 2 \mathrm{~B}_{2} \mathrm{O}_{3}$ & 1183 & 1.7 & {$[62]$} & -3 & & $5^{\mathrm{a}}$ \\
\hline & $\mathrm{PbO} \cdot 2 \mathrm{~B}_{2} \mathrm{O}_{3}$ & 1047 & 1.0 & {$[62]$} & -4 & & $6^{\mathrm{a}}$ \\
\hline & $\mathrm{Na}_{2} \mathrm{O} \cdot 2 \mathrm{SiO}_{2}$ & & & & -2.2 & & 7 \\
\hline & $\mathrm{Li}_{2} \mathrm{O} \cdot \mathrm{SiO}_{2}$ & 1573 & 0.5 & & 2 & & 8 \\
\hline & $\mathrm{Li}_{2} \mathrm{O} \cdot 2 \mathrm{SiO}_{2}$ & 1306 & 2 & & -0.3 & & 9 \\
\hline & $\mathrm{Li}_{2} \mathrm{O} \cdot 3 \mathrm{SiO}_{2}$ & 1306 & 2.2 & & -0.5 & & 10 \\
\hline & $\mathrm{Li}_{2} \mathrm{O} \cdot \mathrm{B}_{2} \mathrm{O}_{3}$ & 1116 & 0.8 & & 1 & & 11 \\
\hline & $\mathrm{Li}_{2} \mathrm{O} \cdot 2 \mathrm{~B}_{2} \mathrm{O}_{3}$ & 1190 & 0.4 & & -1 & & 12 \\
\hline & $\mathrm{Li}_{2} \mathrm{O} \cdot 3 \mathrm{~B}_{2} \mathrm{O}_{3}$ & 1155 & 0.7 & & -2 & & 13 \\
\hline & $\mathrm{Li}_{2} \mathrm{O} \cdot \mathrm{B}_{2} \mathrm{O}_{3}$ & 1108 & 1 & & -2.1 & & 14 \\
\hline & $\mathrm{Na}_{2} \mathrm{O} \cdot 2 \mathrm{~B}_{2} \mathrm{O}_{3}$ & 1015 & 1.6 & & -1.2 & & 15 \\
\hline & $\mathrm{Na}_{2} \mathrm{O} \cdot 3 \mathrm{~B}_{2} \mathrm{O}_{3}$ & 1087 & 1.5 & & -1 & & 16 \\
\hline & $\mathrm{BeO}$ & & 0.78 & [101] & & & 17 \\
\hline \multirow{6}{*}{$\begin{array}{l}\text { Fluorides } \\
\text { ionic compounds }\end{array}$} & $\mathrm{BeF}_{2}$ & 813 & 5 & {$[31]$} & & Natural cooling & 18 \\
\hline & $\mathrm{ZnCl}_{2}$ & 591 & 0.7 & {$[61]$} & & Rapid cooling methods & 19 \\
\hline & $\mathrm{CdCl}_{2}$ & 841 & -2.7 & {$[61]$} & & & 20 \\
\hline & $\mathrm{LiCl}$ & 886 & -2.7 & {$[31]$} & & Rapid cooling methods & 21 \\
\hline & $\mathrm{CdBr}_{2}$ & 840 & -2.52 & {$[31]$} & & & 22 \\
\hline & $\mathrm{NaCl}$ & 1014 & 1.1 & {$[31]$} & & & 23 \\
\hline \multirow{7}{*}{ Chalcogenides } & S & & $3-4$ & {$[103]$} & & $\begin{array}{l}\text { Shooting to a cooled copper } \\
\text { substrate }\end{array}$ & 24 \\
\hline & $\mathrm{Te}$ & 996 & -3 & {$[103]$} & 10 & & 25 \\
\hline & $\mathrm{Se}$ & 480 & $3-4$ & [103] & & & 26 \\
\hline & $\mathrm{As}_{2} \mathrm{~S}_{3}$ & 212 & 5.7 & [103] & & & 27 \\
\hline & $\mathrm{As}_{2} \mathrm{Se}_{3}$ & 187 & 3 & {$[103]$} & & & 28 \\
\hline & $\mathrm{As}_{2} \mathrm{Te}_{3}$ & 130 & 3 & [103] & & & 29 \\
\hline & $\mathrm{Ge}-\mathrm{Te}$ & & & {$[36]$} & 5 & Splat-cooling method & 30 \\
\hline \multirow{14}{*}{ Metals } & Typical metal & & & & 9 & & \\
\hline & $\mathrm{Na}$ & 371 & -3 & {$[31]$} & 9 & & 31 \\
\hline & $\mathrm{Ag}$ & & -3 & {$[61]$} & $8-10$ & Rolling method & 32 \\
\hline & $\mathrm{Pb}$ & 873 & -3 & {$[61]$} & 8 & & 33 \\
\hline & $\mathrm{Zr}$ & & & {$[36]$} & $7-8$ & & 34 \\
\hline & $\mathrm{Zn}$ & 693 & -2.52 & {$[31]$} & & & 35 \\
\hline & $\mathrm{Fe}$ & 1808 & -2.15 & {$[31]$} & & & 36 \\
\hline & $\mathrm{Ni}$ & 1733 & -2 & {$[61]$} & 10 & & 37 \\
\hline & $\mathrm{Pd}_{77} \mathrm{Cu}_{6} \mathrm{Si}_{17}$ & 1023 & -1 & {$[61]$} & 2.57 & & 38 \\
\hline & $\mathrm{Pd}_{77} \mathrm{Cu}_{6} \mathrm{Si}_{17}$ & 1023 & -1 & {$[61]$} & $2-3$ & & 39 \\
\hline & $\mathrm{Pd}_{82} \mathrm{Si}_{18}$ & & 0 & {$[61]$} & 3.7 & & 40 \\
\hline & $\mathrm{Au}_{77.8} \mathrm{Ge}_{13.8} \mathrm{Si}_{8.4}$ & & -1 & {$[57]$} & $6-7$ & & 41 \\
\hline & $\mathrm{Pd}_{40} \mathrm{Ni}_{40} \mathrm{P}_{20}$ & 885 & -3 & {$[27]$} & $4-12$ & $\begin{array}{l}\text { Fast cooling methods, } \\
\text { evaporation methods }\end{array}$ & 42 \\
\hline & $\mathrm{Ni}_{30} \mathrm{Zr}_{70}$ & 562 & & {$[26]$} & $3-7$ & Rolling method Splat & 43 \\
\hline
\end{tabular}

a) Data from reference [62]. 


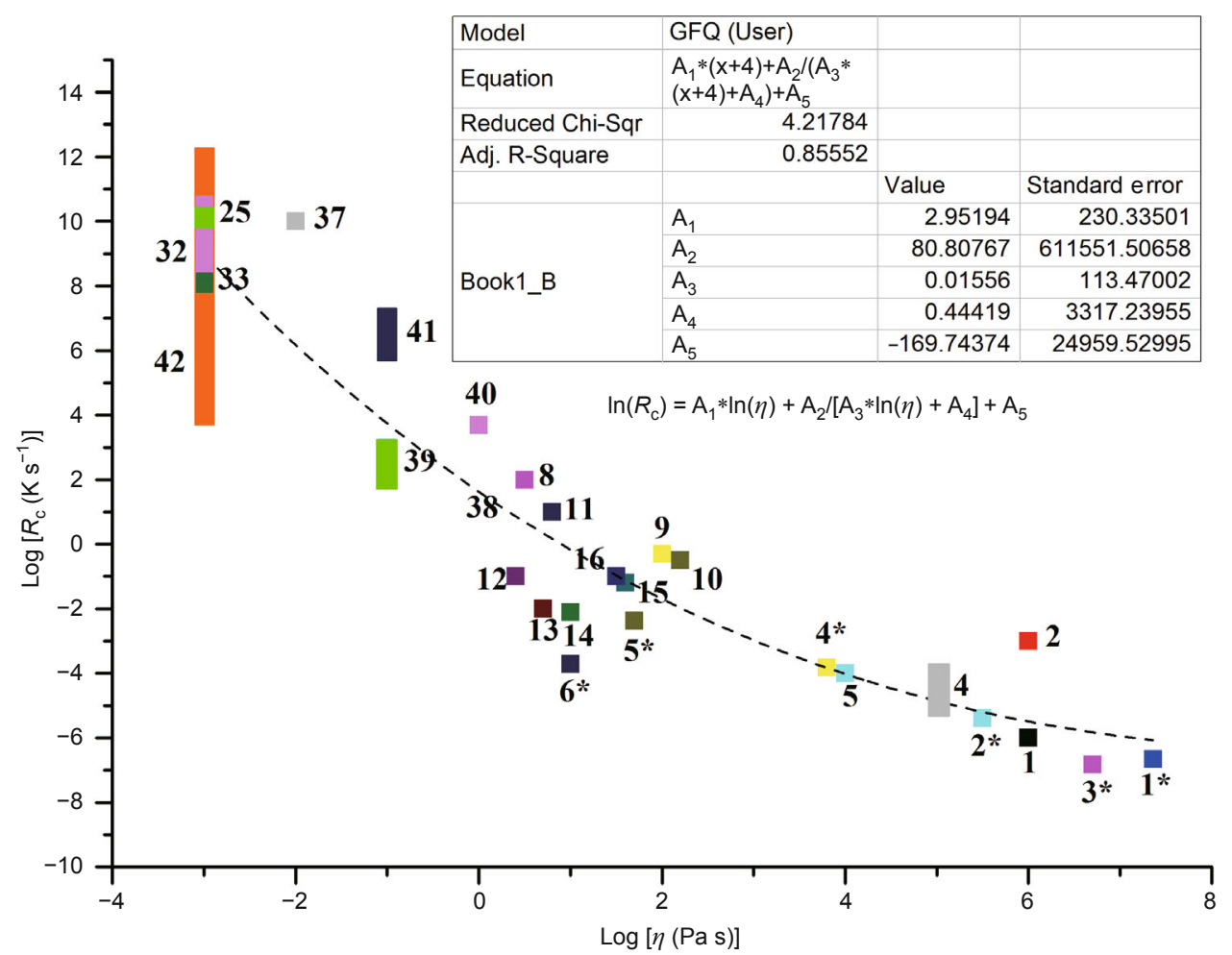

Figure 9 Schematic diagram of GFA with respect to the viscosity and cooling rate: square, experimental data from Table 6; dashed line, calculated by authors.

glass are not consistent with Zachariasen's doctrine of glass formation. This inconsistency results from the consideration of glass formation only in terms of the relationship between glass composition and structure. However, it ignores the fact that glass formation is also a dynamic process.

We propose a schematic diagram of glass formation based on the viscosity of the glass at the melting point and the cooling rate, as shown in Fig. 10 and Equations (3) and (4). The vertical axis represents the viscosity $(\log \eta)$, and the horizontal axis corresponds to the cooling rate $\left(\log R_{\mathrm{c}}\right)$ in the range of $10^{-8}-10^{12} \mathrm{~K} / \mathrm{s}$. In Fig. 10, the melt viscosity (slightly higher than the crystallization temperature) is presented, as is a statement of whether the material can form glass at the corresponding cooling rate. Glass formers can form glass at the natural cooling rate, but network modifiers (outside bodies) cannot form glass under natural cooling conditions. In terms of the dynamics of glass formation, determining whether a melt can form glass is less important than determining whether a melt can form glass at a given cooling rate. In general, metals and ionic compounds exhibit values of approximately $\log \eta=-3$ to -1 , whereas metallic, salt, and fluoride glasses exhibit values of approximately $\log \eta=-1$ to 2 , and oxide glass formers and more stable glasses exhibit values of $\log \eta>3.5$.

\section{A viscosity/cooling-rate approach}

In region (I) of Fig. 10, the glass formers defined by the Zachariasen rules have three-dimensional linkages, corner-sharing connections, and low coordination numbers of approximately 3 4. They are characterized by extremely high viscosities at the melting point and directive polar covalent bonds after natural cooling. In region (II), with the transformation from a three-dimensional structure to a two-dimensional strip structure, the ionic part of the polar covalent bonds increases, and the viscosity decreases (fabricated via natural cooling). In region (III), with the transformation from a two-dimensional structure to a one-dimensional chain structure, the ionic part of the bonds further increases, and the viscosity clearly decreases to within in the range of $\log \eta \pm 1$ (fabricated via natural cooling with air blasting). In region (IV), the covalent-bond component of the isolated island structure is still higher than that of the general inorganic salt mixture (fabricated via rapid cooling methods). In region (V), salt compounds based on ionic bonds and eutectic compounds can be prepared (fabricated via rapid cooling methods, e.g., rolling methods, splat quenching, or evaporation methods). In region (VI), the ionic and metallic bonds exhibit extremely low melt viscosities, and a glassy state can be prepared via rapid cooling methods (e.g., evaporation methods, rolling methods, 


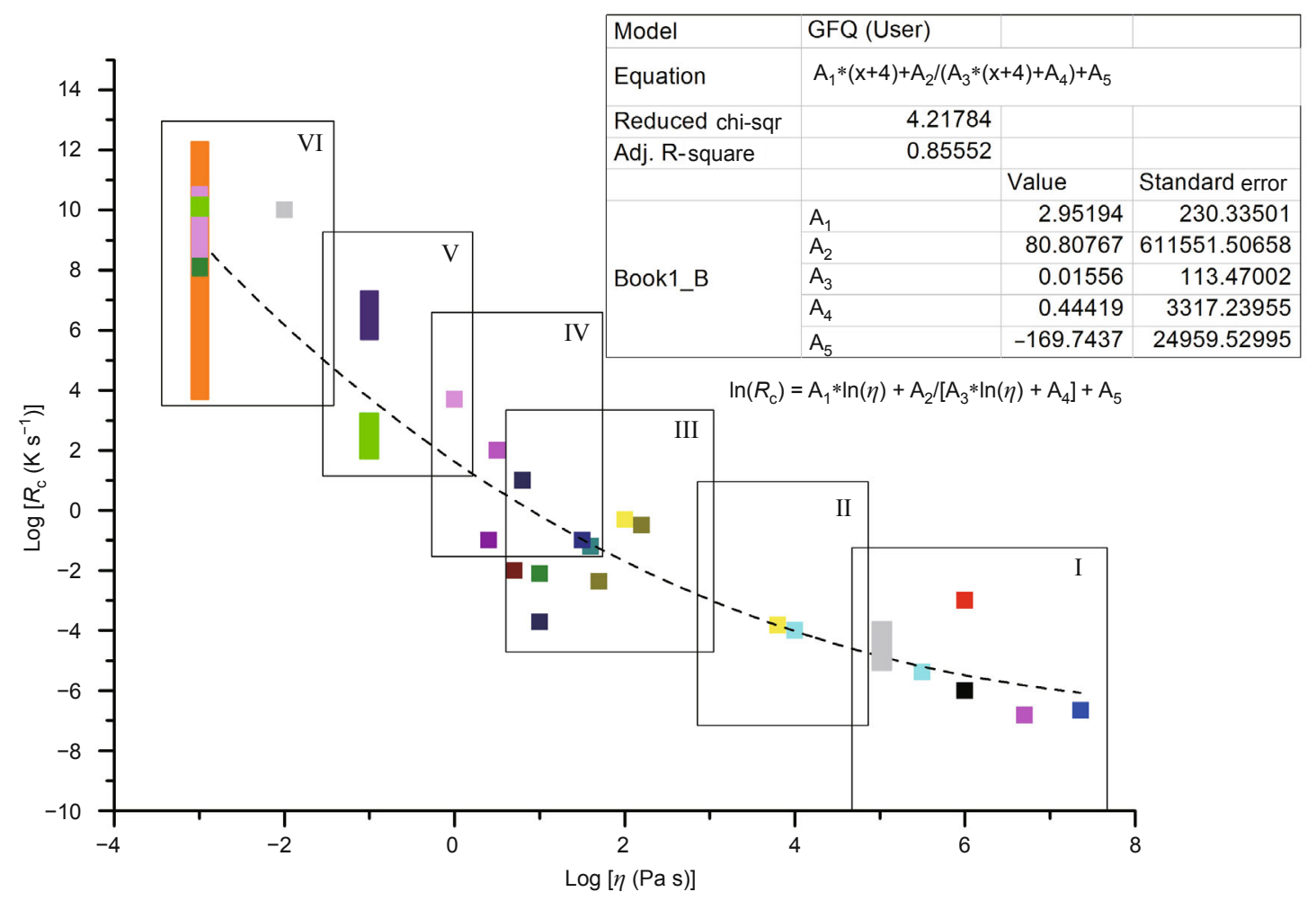

Figure 10 Schematic diagram of theories of glass formation with respective to the viscosities and cooling rates to which they apply: square, experimental data from Table 6; dashed line, calculated by authors.

or splat quenching using cooled $\mathrm{Cu}$ substrate).

\section{Some atypical examples}

Viscosity is the most important factor in glass formation as aforementioned and can be used to determine the cooling rate required for glass formation. However, there are some atypical examples for which the viscosities at the melting point are equal but the resulting glass-forming behaviors are not the same. Such results might arise for the following reasons:

(i) The melt-cooling process depends on the difference between the nucleation and crystal-nucleus-growth temperatures, $\Delta T$. Glass formation becomes more difficult as $\Delta T$ decreases, and vice versa.

(ii) Glass formation is closely related to material composition; in general, single-component compounds crystallize readily, whereas multi-component compounds, especially those containing ions with different charges and sizes, can readily form glasses because the various components interfere with each other in the crystallization process. In the case so-called reverse glasses; these materials have a low rate of crystallization.

(iii) When a variety of structures are present, the coexisting structures will reduce the capability of the glass to crystallize and thus promote the formation of glass by interfering with each other, increasing the difficulty of achieving orderly arrangement in accordance with their respective crystal requirements. Glass can be readily obtained at the eutectic point in the phase diagram because of the mutual cross-linking of two structures as well as the low liquid temperature. However, crystallization will be facilitated if one of the structures primarily forms crystal nuclei.

(iv) The polarization factor exerts some effect. $\mathrm{PbO}$ is an oxide with an extremely broad range of glass formation, and the $\mathrm{PbO}$ content in a glass can be reach 70-75 mol\%; according to the literature [15,32,33], polarization changes the structure of the oxide and leads to the appearance of $\left[\mathrm{PbO}_{4}\right]$, as demonstrated by experimental results obtained using infrared and NMR spectroscopy. How can glass containing high level of $\mathrm{PbO}$, which has a low viscosity, form stable glass? The reason for this phenomenon is that the structure of $\mathrm{PbO}$ contains inert atom pairs, which results in the generation of $\left[\mathrm{PbO}_{4}\right]$, as has been experimentally demonstrated. Therefore, the formation of connections between the $\left[\mathrm{PbO}_{4}\right]$ and $\left[\mathrm{SiO}_{4}\right]$ or $\left[\mathrm{BO}_{4}\right]$ reduces the degree of the broken network; thus, the range of glass formation expands, and the stability of the glass increases. However, when $\left[\mathrm{PbO}_{4}\right]$ is incorporated into the glass network, the network binding affinity is reduced and the viscosity decreases. $\mathrm{PbO}$ displays different features from other glass 
formers with higher viscosities. Some lead enters the network in the form of $\left[\mathrm{PbO}_{4}\right]$, and more lead in the form of $\mathrm{Pb}^{2+}$ acts as a network modifier in the glass structure. Other elements with inert electron pairs, such as bismuth and thallium, are also characterized by low viscosity and a broad region of glass formation.

(v) The intermediate also exerts some effect. Based on the bond-energy criterion, Sun $[48,97]$ has proposed a category of intermediates in addition to the network formers and network modifiers. An intermediate does not feature in the glass structure, and the definition of an intermediate is provided in detail in our previous papers [20]. Examples include ions that can be transferred from the external network under certain conditions, such as $\mathrm{Al}^{3+}$ and $\mathrm{Zn}^{2+}$. When external network ions with sufficiently low field strength appear, they can be converted into $\left[\mathrm{AlO}_{4}\right]$ and $\left[\mathrm{ZnO}_{4}\right]$ by satisfying the corresponding requirements of charge and coordination number, connecting the broken network and serving as network formers. $\mathrm{Al}_{2} \mathrm{O}_{3}$ and $\mathrm{ZnO}$ appear in the basic compounds $\mathrm{Al}(\mathrm{OH})_{3}$ and $\mathrm{Zn}(\mathrm{OH})_{2}$ under strongly acidic conditions, and they appear in the acidic compounds $\mathrm{Na}_{3} \mathrm{AlO}_{3}$ and $\mathrm{Na}_{2} \mathrm{ZnO}_{2}$ under strongly basic conditions. Such compounds are called intermediate compounds. A compound that acts not only as a network modifier but also a network former and enters the network is called a network intermediate. However, most network intermediates are different from those described by Sun $[48,97]$. Intermediate compounds can reconnect broken networks, increasing the viscosity and enhancing the GFA with respect to a melt with the same viscosity and a more broken network.

(vi) Although the melt viscosities of two materials may be similar, the variation of viscosity with temperature may be different between the crystallization temperature and the temperature $T_{\mathrm{g}}$, which will affect the GFA.

(vii) The thicknesses and coefficients of heat transfer of different melts can vary, leading to different cooling rates for identical melt viscosities.

\section{THE EUTECTIC POINT AND THE GLASS-FORMING REGION: QUANTITATIVE PREDICTION AND CALCULATION}

The glass-forming regions of a system are most likely to be situated in the eutectic region, where the glass-former content is high. Almost all glass systems follow this rule, from silicate to borate, boron silicate, metaphosphate, germinates and tellurites as well as non-oxide glasses, such as fluorides, halogenides, chalcogenides, and even metallic glasses. This phenomenon occurs because the viscosity of the melt increases rapidly with decreasing temperature at the eutectic point, where it is difficult to achieve the nucle- ation and growth of particles in the melt, a situation that is conducive to the ready formation of glass.

\section{The eutectic point and glass-forming region in oxide-glass systems}

For the synthesis of new glasses with unique properties, the composition of the materials should be located in the stable glass-forming range. Glass devitrification prevents the development of novel types of glasses; therefore, it is important for glass researcher to find methods of avoiding glass devitrification. The glass-forming region of a system typically is situated near the eutectic region, and therefore, it is critical to investigate the relationship between the composition and the eutectic point or phase-separation regions in the area. However, because of the lack of phase diagram data, useful data for the development of new glasses are traditionally obtained by conducting a large number of experiments.

\section{Calculation and prediction of eutectics}

When two types of compounds are mixed without producing a new compound, the Gibbs free energy of the resulting binary-mixture solution $\left(G_{\mathrm{m}}^{\mathrm{L}}\right)$ or solids $\left(G_{\mathrm{m}}^{\mathrm{S}}\right)$ consisting of components $\mathrm{A}$ and $\mathrm{B}$ is represented by [105-107]:

$$
\begin{aligned}
G_{\mathrm{m}}^{\mathrm{L}} & =R T\left(x_{\mathrm{A}} \ln x_{\mathrm{A}}+x_{\mathrm{B}} \ln x_{\mathrm{B}}\right), \\
G_{\mathrm{m}}^{\mathrm{S}} & =-\left(x_{\mathrm{A}} \cdot \Delta G_{\mathrm{f}, \mathrm{A}}+x_{\mathrm{B}} \cdot \Delta G_{\mathrm{f}, \mathrm{B}}\right),
\end{aligned}
$$

and

$$
\begin{gathered}
\Delta G_{\mathrm{f}, \mathrm{A}}=\Delta H_{\mathrm{f}, \mathrm{A}} \cdot\left(1-\frac{T}{T_{\mathrm{A}}}\right), \\
\Delta G_{\mathrm{f}, \mathrm{B}}=\Delta H_{\mathrm{f}, \mathrm{B}} \cdot\left(1-\frac{T}{T_{\mathrm{B}}}\right),
\end{gathered}
$$

where $x_{\mathrm{A}}$ and $x_{\mathrm{B}}$ are the molar fraction of components A and $\mathrm{B}$, respectively; $\Delta H_{\mathrm{f}, \mathrm{A}}$ and $\Delta H_{\mathrm{f}, \mathrm{B}}$ are the heats of fusion of compounds $\mathrm{A}$ and $\mathrm{B}$, respectively; $T_{\mathrm{A}}$ and $T_{\mathrm{B}}$ are the melting points of compounds $A$ and $B$, respectively; and $R$ is the gas constant.

A glass is not a regular solution. Therefore, for a glass, the experimentally determined activity $\alpha$ should be used instead of the concentration $x$ in the above formulas. However, the value of $x$ cannot be predicted if $\alpha$ is used in the calculation. Thus, we would rather use $x$ than $\alpha$ and consider the error between the calculated value and experimental value from the phase diagram to indicate the accuracy of the method. The calculation approaches used in this paper are different from those used by Slater [108], Cottrell [109], and in the introductions of many other metallurgical studies. In this work, a tangent method based on 
analytical geometry is used to determine the free-energy equilibrium condition of two phases instead of using the value obtained through mass calculation. The composition $x$ of the eutectic point can be calculated by solving for the minimum equilibrium temperature $T$ (of the irregular solution). Thus, Equation (5) can be simplified to a parabolic equation:

$$
G_{\mathrm{m}}^{\mathrm{L}}=2.3 x(x-1) R T-0.1181 R T .
$$

For a two-phase equilibrium, the temperatures $T$ are equal. The value of $T$ can be obtained by simultaneously solving Equations (6) and (7):

$$
T=\frac{\left(\Delta H_{\mathrm{f}, \mathrm{B}}-\Delta H_{\mathrm{f}, \mathrm{A}}\right) x+\Delta H_{\mathrm{f}, \mathrm{A}}}{2.3 R x^{2}+\left(\frac{\Delta H_{\mathrm{f}, \mathrm{B}}}{T_{\mathrm{B}}}-\frac{\Delta H_{\mathrm{f}, \mathrm{A}}}{T_{\mathrm{A}}}-2.3 R\right) x+\frac{\Delta H_{\mathrm{f}, \mathrm{A}}}{T_{\mathrm{A}}}-0.1181 R} .
$$

The minimum value of $T$ in Equation (10) is the eutectic temperature $T_{\mathrm{E}}$, and the value of $x$ at this temperature is the eutectic mixture composition. Selected calculated results are listed in Table 7.

It should be mentioned that the glass-transition studies in a binary eutectic phase diagram of methyl $o$-toluate versus methyl $p$-toluate recently by Wang et al. [84] found that the best vitrification region is located between the eutectic and the midpoint compositions of the eutectic line, as shown in Fig. 11, indicating a remarkable deviation from the eutectic composition. The extensive surveys of glass-forming simple binary eutectic systems prove to uphold the observed rule, indicating a universal character [84].

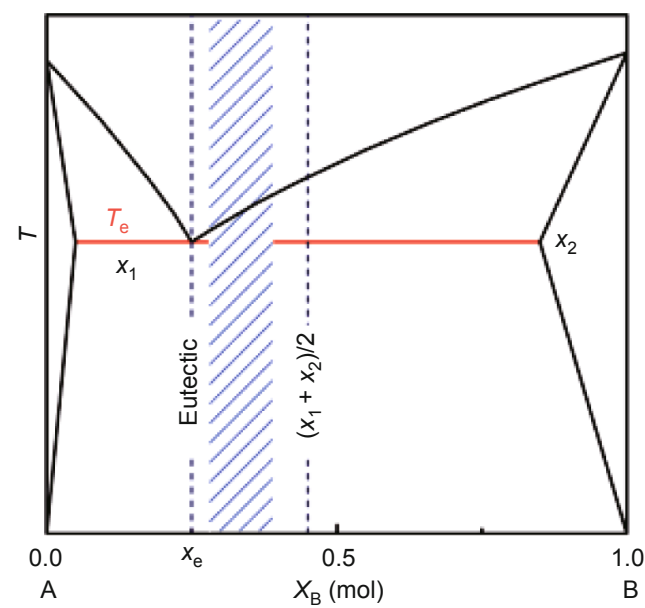

Figure 11 Schematic plot of the best glass-forming composition in simple binary eutectic system, emphasizing the composition range between the eutectic and the medium points (Reproduced with permission from Ref. [84], Copyright 2010, American Chemical Society).
Eutectics and glass-forming regions in multi-component systems

Through an analysis of a large number of phase diagrams, we conclude that if a compound is added to a binary eutectic system without a new compound being produced, then a new eutectic at a lower temperature will always be located between the original eutectic and the added compound. The method presented above can be extended based on this observation. Each eutectic-point position in the phase diagram is fixed; therefore, its chemical composition is fixed, and it can be regarded as a "quasi-compound". The new eutectic points of the glasses can thus be calculated as listed in Table 8. The new eutectic point between the eutectic composition and the third compound is lower than the previous eutectic composition. If no minimum value can be found using Equation (10), then there will be no new eutectic point between the previous eutectic composition and the third compound.

To prove the "quasi-compound" features of the eutectic compositions identified through such characteristic calculations, the new eutectic points of several systems were both measured and calculated. Indeed, such a situation is not common but can be observed in many phase diagrams. From the connections between two eutectic points in the $\mathrm{Na}_{2} \mathrm{O}-\mathrm{B}_{2} \mathrm{O}_{3}-\mathrm{SiO}_{2}$ ternary phase diagram, as summarized in Table 8 , the composition at the minimum temperature can be calculated and is found to be highly similar to that deduced from the phase diagram, as shown in Figs 12 and 13.

Using Equations (5-8), the eutectic points of borate, boron silicate, silicate, and metaphosphate in the glass-forming region were calculated and found to be quite comparable to the data of the corresponding phase diagrams. This method proves to be fairly reliable, as the deviation in composition between the experimental calculations and the corresponding phase diagrams is generally less than 7 mol.\%.

\section{The eutectic point and glass-forming region in halides}

Current conventional glasses are largely based on complex silicates, borates and phosphates, which ensure good chemical durability and stability against devitrification. Exotic glasses that are free of classical glass formers are less common and often require special processing [114-116]. However, an increasing number of studies of non-oxide glasses have been performed with the development of infrared (IR) technology [15,22,117-122].

Non-oxide glasses typically can be divided into halide glasses and chalcogenide glasses. Halide glasses are essentially fluorides based on zirconium or indium, acting as glass formers associated with barium fluoride, with $\mathrm{Ba}^{2+}$ ions acting as glass modifiers [22]. Optical fibers and planar waveguides that contain paramagnetic lanthanide ions can 


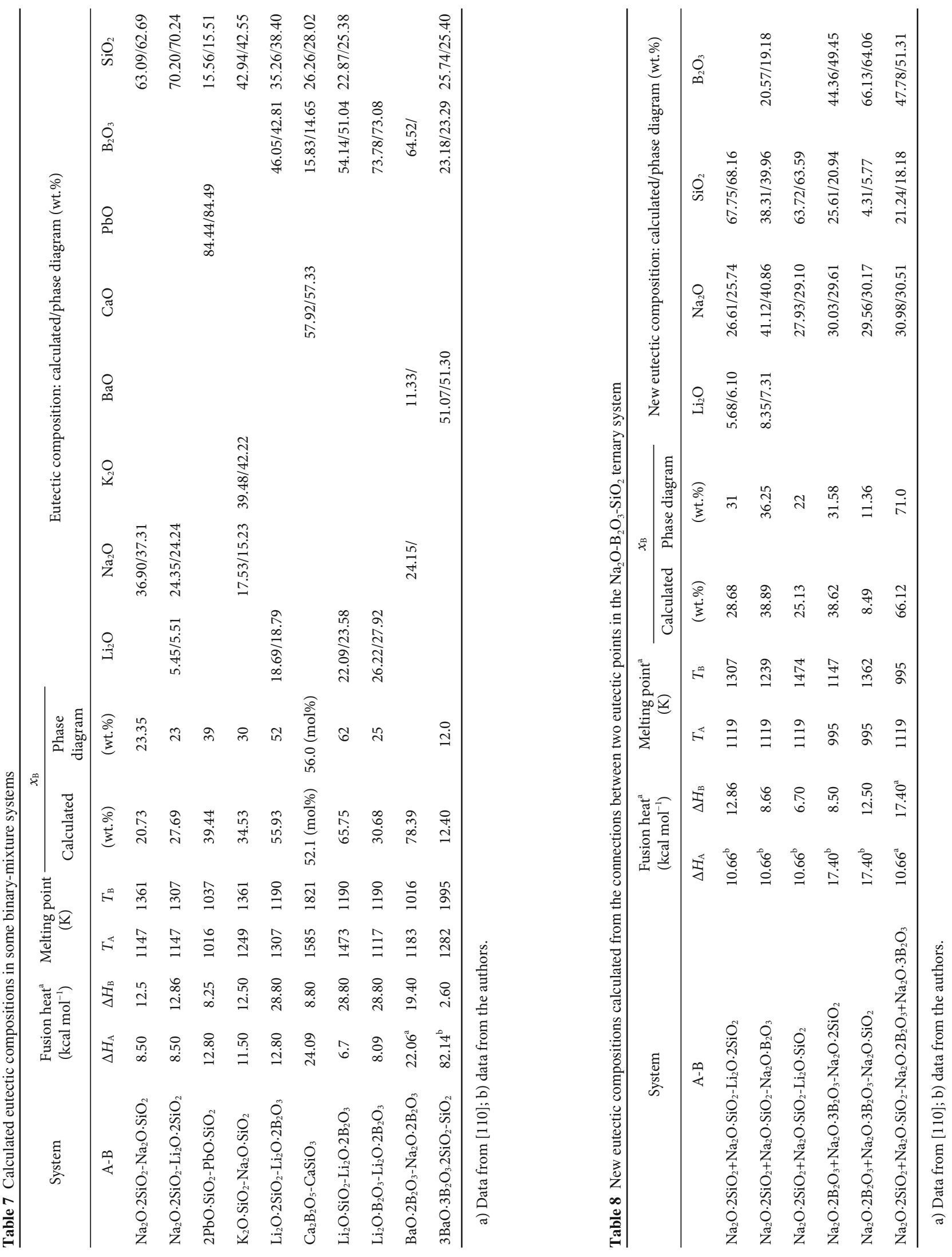



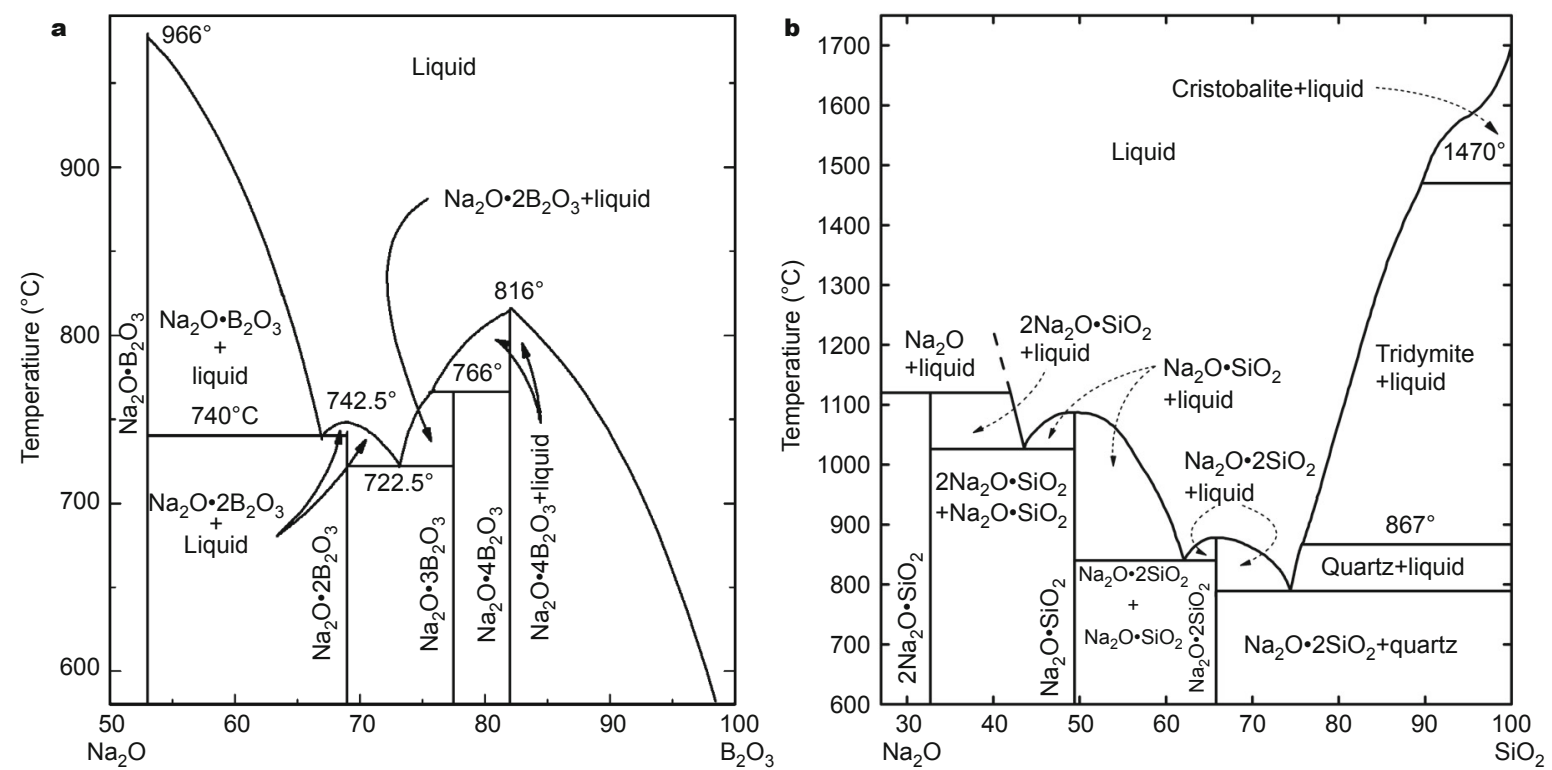

Figure 12 Phase diagrams of (a) the $\mathrm{Na}_{2} \mathrm{O} \cdot \mathrm{B}_{2} \mathrm{O}_{3}$ glass system by Morey and Merwin (Reproduced from Ref. [111], Copyright 1936, American Chemical Society), and (b) the $\mathrm{Na}_{2} \mathrm{O} \cdot \mathrm{SiO}_{2}$ glass system by Kracek (Reproduced from Ref. [112], Copyright 1930, American Chemical Society).

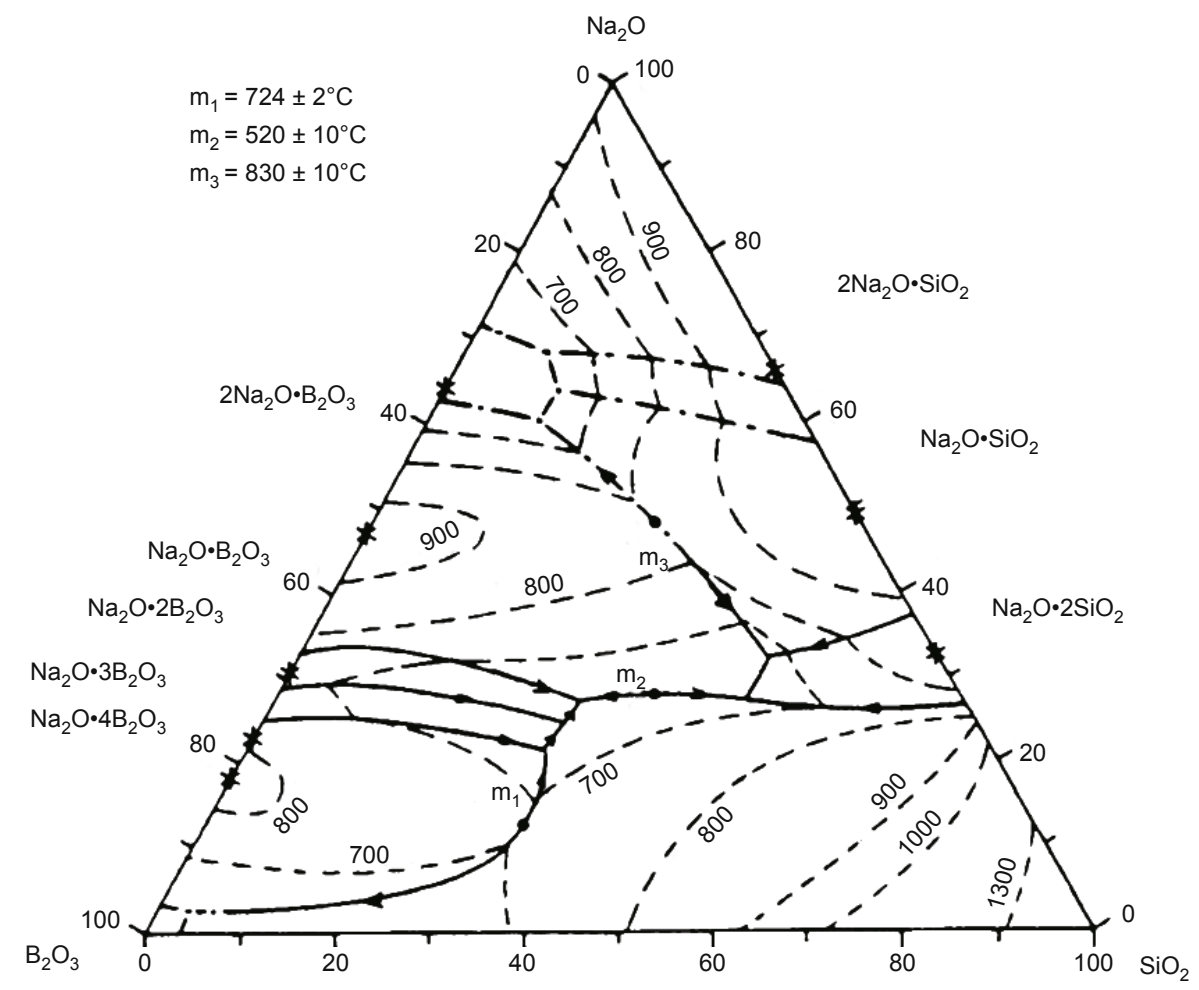

Figure 13 Phase diagram of $\mathrm{Na}_{2} \mathrm{O}-\mathrm{B}_{2} \mathrm{O}_{3}-\mathrm{SiO}_{2}$ ternary glass system, demonstrating the liquidus surface and position of some isotherms (Reproduced with permission from Ref. [113], Copyright 1993, The American Ceramic Society).

be fabricated using fluoride glasses. Thus, efficient fluoride fiber lasers and fiber amplifiers have been demonstrated at wavelengths that are not available when oxide glasses are used. Optical transmission is an essential physical char- acteristic of halide glasses in the sense that this property clearly differentiates halide glasses from traditional oxide glasses. Fluoride glasses typically begin transmitting at approximately $250 \mathrm{~nm}$ in the UV range, which corresponds to 
an energy gap of approximately $5 \mathrm{eV}$. For comparison, pure silica exhibits a better UV transparency with an energy gap of $8 \mathrm{eV}$.

The determination of the glass-forming ranges of halogen glasses (such as fluoride glasses) must be based on many experimental data from the most current papers, followed by the characterization of the prepared glass. Such research is costly, and only data unique to the investigated particular compositions are obtained. Here, we attempt to predict the formation regions of glasses by analyzing their characteristics. In fluoride glasses, the glass formers have high coordination numbers, except for $\mathrm{BeF}_{4}$, which has a coordination number of 4 . This type of glass is rather difficult to form unless other network modifiers are added, which may lower the coordination number to balance the charge and easily transform the network into a glassy state.

\section{Glass-forming behavior of halides}

Halide glass formers, similar to the oxides, have mixed chemical bonds and vertex-angle connections, and they can be divided into the following groups: (i) For those with a coordination number of four $\left(K_{z}=4\right)$, vertex-angle connections and a neutral electric valence, e.g., $\mathrm{BeF}_{2}$, $\mathrm{ZnCl}_{2}$ and $\mathrm{ZnBr}_{2}$, a stable glass can be formed; moreover, the formation region will be enlarged when some low-valence compound is introduced as a second component. (ii) Those with a coordination number of four $\left(K_{z}=4\right)$ and vertex-angle connections but a non-neutral electric valence, e.g., $\mathrm{AlP}_{3}$, can also exhibit a coordination number of six $\left(K_{z}\right.$ $=6$ ), but they cannot form a stable glass alone unless special high-rate quenching is employed. Only when a second component is introduced to neutralize the residual electric valence, can the structural units link through their vertices to form a network structure. (iii) Those with a coordination number of six $\left(K_{z}=6\right)$, vertex-angle connections and anon-neutral electric valence, e.g., $\mathrm{ZnF}_{2}, \mathrm{ZrF}_{4}, \mathrm{ThF}_{4}, \mathrm{HfF}_{4}$ and $\mathrm{ThCl}_{4}$, exhibit glass-forming behavior similar to that of group (ii) [123-129].

\section{Eutectics and the glass-forming ability of halides}

As in oxide systems, the eutectic points play an important role in glass formation in halide systems and are generally located at the positions where the ratios of the network former to the network modifier are 3:1, 2:1, and 1:1 [122,128]. Therefore, the glass-forming regions are typically located near the regions where the glass-former content is approximately $60 \mathrm{~mol} \%$. Because of the influence of the locations of the eutectic points, the glass-forming regions will extend toward the directions in which compositions with 45 or 70 mol\% network formers lie. Thus, the most promising glass-forming region in a ternary system can be predicted by identifying the eutectic points of the related binary systems.

Calculations can be performed based on the phase diagrams of various types of binary systems using the available thermodynamic data, such as melting points and heats of fusion of the related components. As a result, there is no significant variation in the location of the eutectics. Hence, it would be reasonable to estimate the approximately locations of eutectics based on the related thermodynamic data of halides. The eutectics and GFAs of halides were calculated using the aforementioned thermodynamic Equations (5-8), and the results are summarized in Tables 9 and 10, and an example in Fig. 14. The calculated results for the halide and fluoride systems are quite consistent with the experimental data. However, Equations (5-8) are only ap-

Table 9 Eutectics of novel types of glasses

\begin{tabular}{|c|c|c|c|c|c|c|c|c|}
\hline \multirow{2}{*}{\multicolumn{2}{|c|}{ System }} & \multirow{2}{*}{\multicolumn{2}{|c|}{ Fusion heat ${ }^{\mathrm{a}}\left(\mathrm{kcal} \mathrm{mol}^{-1}\right)$}} & \multirow{2}{*}{\multicolumn{2}{|c|}{ Melting point ${ }^{\mathrm{a}}(\mathrm{K})$}} & \multicolumn{2}{|c|}{$x_{\mathrm{B}}$} & \multirow{3}{*}{ Glass formation range } \\
\hline & & & & & & \multirow{2}{*}{$\begin{array}{l}\text { Calculated } \\
(\mathrm{mol} \%)\end{array}$} & \multirow{2}{*}{$\begin{array}{l}\text { Phase diagram } \\
\quad(\mathrm{mol} \%)\end{array}$} & \\
\hline & $A-B$ & $\Delta H_{\mathrm{A}}$ & $\Delta H_{\mathrm{B}}$ & $T_{\mathrm{A}}$ & $T_{\mathrm{B}}$ & & & \\
\hline \multirow{2}{*}{$\begin{array}{l}\text { Salino-genide } \\
\text { glasses }\end{array}$} & $\mathrm{Ca}\left(\mathrm{NO}_{3}\right)_{2}-\mathrm{NaNO}_{3}$ & 5.60 & 3.49 & 834 & 579 & 63.53 & 53 & $55-62^{a}$ \\
\hline & $\mathrm{Ca}\left(\mathrm{NO}_{3}\right)_{2}-\mathrm{KNO}_{3}$ & 5.60 & 2.30 & 834 & 607 & 51.16 & 50 & $40-70^{\mathrm{a}}$ \\
\hline \multirow{4}{*}{ Fluoride glasses } & $\mathrm{Na}_{2} \mathrm{O} \cdot 2 \mathrm{~B}_{2} \mathrm{O}_{3}-\mathrm{NaF}$ & 19.4 & 7.80 & 1016 & 1265 & 19.86 & 19.94 & \\
\hline & $2 \mathrm{LiF} \cdot \mathrm{BeF}_{2}-\mathrm{BeF}_{2}$ & 10.60 & 1.135 & 745 & 825 & 77.47 & 73.03 & \\
\hline & $\mathrm{AlF}_{3}-\mathrm{CaF}_{2}$ & & & & & & & \\
\hline & $\mathrm{AlF}_{3}-\mathrm{BaF}_{2}$ & & & & & & & \\
\hline \multirow{4}{*}{$\begin{array}{l}\text { Metallic } \\
\text { glasses }\end{array}$} & $\mathrm{Au}-\mathrm{Si}$ & 2.955 & 12.10 & 1336 & 1683 & 17.10 & 19.00 & \\
\hline & $\mathrm{MnSi}-\mathrm{Si}$ & 14.20 & 12.10 & 1548 & 1683 & 21.68 & 24.00 & $15-25^{b}$ \\
\hline & $\mathrm{Ge}-\mathrm{Au}$ & 8.80 & 3.050 & 1213 & 1336 & 61.00 & 70.00 & \\
\hline & $\mathrm{Ag}-\mathrm{Cu}$ & 2.65 & 3.10 & 1234 & 1356 & 45.00 & 40.00 & $35-65^{\mathrm{b}}$ \\
\hline
\end{tabular}

a) Data from [130]; b) data from [131]. 
Table 10 Comparison of the calculated eutectic compositions with that of the experimental one in halide glasses

\begin{tabular}{|c|c|c|c|c|c|c|c|c|}
\hline \multirow{2}{*}{\multicolumn{2}{|c|}{ System }} & \multirow{2}{*}{\multicolumn{2}{|c|}{ Melting temperature $T_{\mathrm{m}}(\mathrm{K})$}} & \multirow{2}{*}{\multicolumn{2}{|c|}{ Fusion heat $\Delta H_{\mathrm{f}}\left(\mathrm{kJ} \mathrm{mol}{ }^{-1}\right)$}} & \multicolumn{3}{|c|}{ Eutectic composition B (mol\%) } \\
\hline & & & & & & \multicolumn{2}{|c|}{ Calculated } & \multirow{2}{*}{ Measured } \\
\hline A & $\mathrm{A}_{x} \mathrm{~B}_{y}$ & $T_{\mathrm{A}}^{\mathrm{m}}$ & $T_{\mathrm{A}_{x} \mathrm{~B}_{y}}^{\mathrm{m}}$ & $\Delta H_{\mathrm{A}}^{\mathrm{m}}$ & $\Delta H_{\mathrm{A}_{x} \mathrm{~B}_{y}}^{\mathrm{m}}$ & $x_{\mathrm{B}}$ & $x_{\mathrm{B}} \pm 3$ & \\
\hline $\mathrm{CaF}_{2}$ & $\mathrm{CaAlF}_{5}$ & 1673 & 1146 & 29,300 & 8530 & 40.7 & $37.7-43.7$ & 38 \\
\hline $\mathrm{AlF}_{3}$ & $\mathrm{BaAlF}_{5}$ & 1161 & 1193 & 98,000 & 29,582 & 33.2 & $30.2-36.2$ & 35 \\
\hline $\mathrm{CdCl}_{2}$ & $\mathrm{KCdCl}_{3}$ & 841 & 713 & 48,580 & 84,532 & 37.8 & $34.8-40.8$ & 34 \\
\hline $\mathrm{PbCl}_{2}$ & $\mathrm{~K}_{2} \mathrm{PbCl}_{4}$ & 769 & 763 & 21,900 & 5731 & 48.1 & $45.1-51.1$ & 47 \\
\hline $\mathrm{ZnCl}_{2}$ & $\mathrm{~K}_{2} \mathrm{ZnCl}_{4}$ & 583 & 719 & 27,000 & 4775 & 45.3 & $42.3-48.3$ & 46 \\
\hline
\end{tabular}

Notes: (1) data were calculated from phase diagram and reference [132]. (2) $\Delta H_{\mathrm{A}_{x} \mathrm{~B}_{y}}^{\mathrm{m}^{\prime}}=\Delta H_{\mathrm{A}_{x} \mathrm{~B}_{y}}^{\mathrm{m}} /(x+y)$.
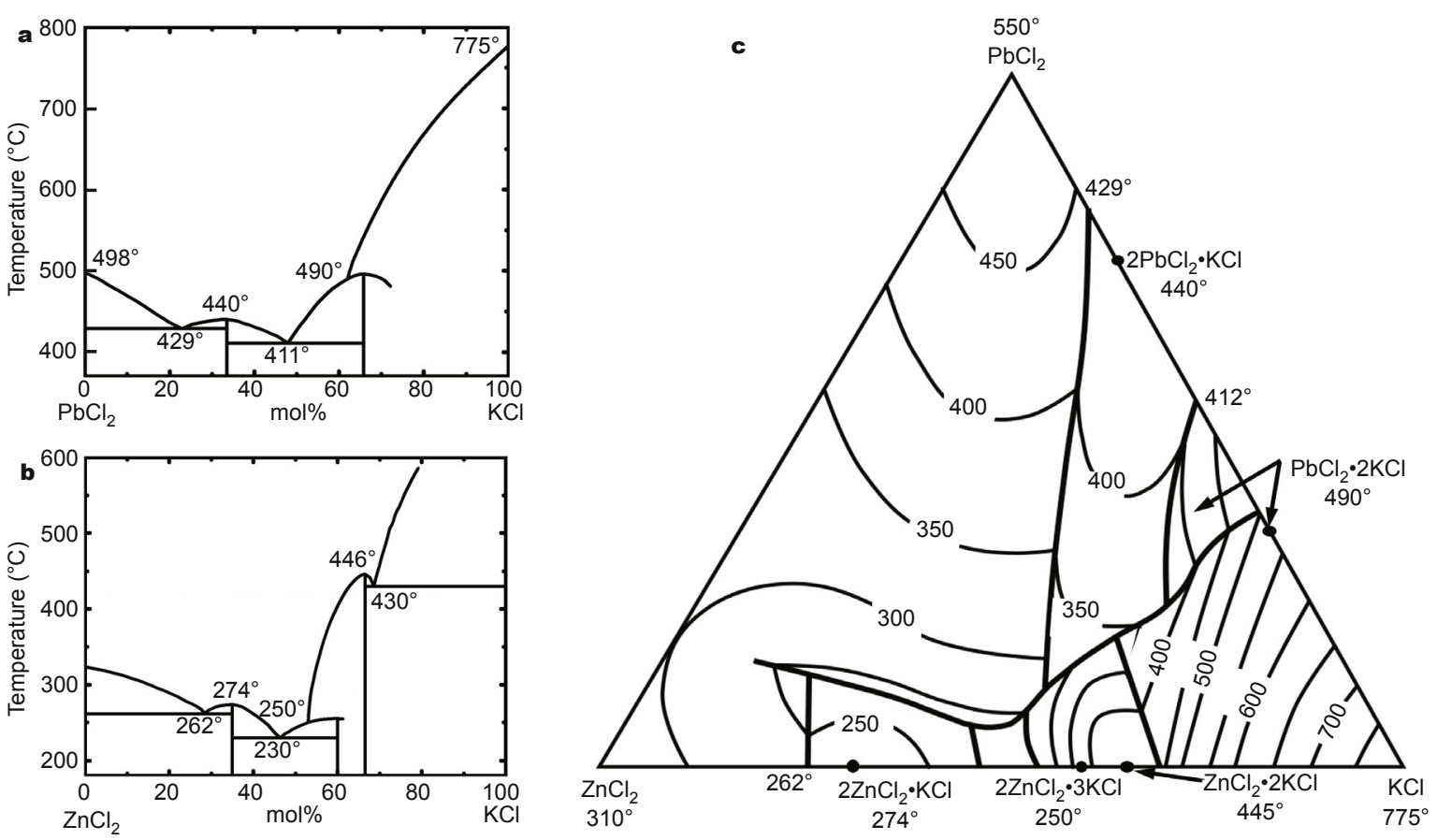

Figure 14 Phase diagrams and the glass-forming region of the $\mathrm{PbCl}_{2}-\mathrm{ZnCl}_{2}-\mathrm{KCl}$ system (Reproduced from Ref. [133], Copyright 1949, Physical Chemistry Society, USSR).

plicable to simple binary phase diagrams. As shown by the binary phase diagrams of various inorganic salts in Fig. 15, the deviation between the calculated and experimental eutectic point is not sufficiently large to distinguish, which indicates that this method can be used to calculate the positions of the eutectic points in the glass systems of halogen compounds.

A difficult problem may be encountered in the attempt to apply Equations (5-8) to halogen compounds. The majority of the glass-forming compounds that can be synthesized from halogens, such as $\mathrm{ZrF}_{4}, \mathrm{ThF}_{4}, \mathrm{HfF}_{4}, \mathrm{ThCl}_{4}$ and $\mathrm{AlF}_{3}$, sublimate directly at high temperatures. Therefore, there are no data for their melting points and heats of fusion, and thus, their eutectic points cannot be calculated directly. To solve this problem, the eutectic point of each fixed component is regarded as a "quasi-compound", and the melting point and heat of fusion are then measured and substituted into the above formulas. The eutectic points can be obtained in this manner. Because the calculated binary systems do not correspond to ideal solutions in simple binary systems, the heat of fusion of a eutectic point can be regarded as a summation of the heats of fusion of the two corresponding crystals. The heat of mixing $\Delta H_{\mathrm{m}}$ should also be considered. In the case of $\Delta H_{\mathrm{f}, \mathrm{A}} \geqslant \Delta H_{\mathrm{m}}$, this simplified calculation method based on Equations (5-8) has a limited ability to determine the position of the eutectic point. Nevertheless, this method not only allows for a considerable decrease in the number of experimental measure- 

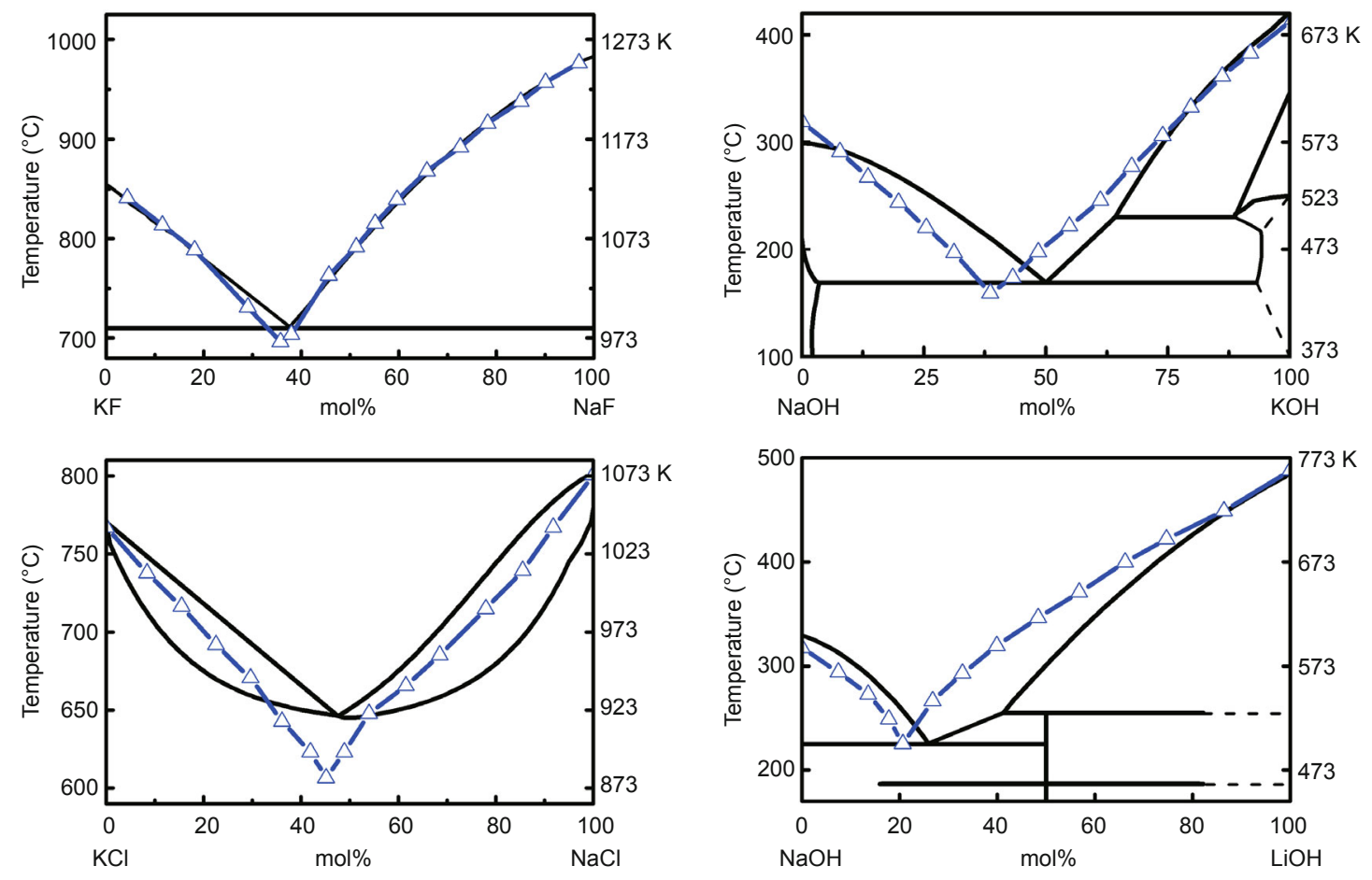

Figure 15 The calculated eutectic points in the binary phase diagrams of inorganic salts.

ments required but also provides the simplest method of calculating the glass-forming region in a particular ternary system by means of multiple computing steps. It should be mentioned that the mixing entropy should play an important role in the glass-formation of the halide systems containing no traditional glass-former. In this kind of systems the glass formation is often observed in the regions where the content of so-called glass-former and the viscosity at the melting point are very low, and the coordination number of the glass-forming cation is very large, for example in the $\mathrm{ThF}_{4}-\mathrm{NaF}-\mathrm{LiF}$ and $\mathrm{ThF}_{4}-\mathrm{BaF}_{2}-\mathrm{LiF}$ systems [129].

Fluoroaluminate glasses are candidate materials for optical fibers $[16,118]$. The transmission losses in ABCYSNZbased fibers can be reduced from 3 to $0.05 \mathrm{~dB} / \mathrm{m}$ [134]. The long-wavelength IR transmission edges of fluoroaluminate glasses $(7.5-7.8 \mu \mathrm{m})$ are close to that of ZBLAN, whereas their refractive indices (1.43-1.49) are somewhat smaller. Their Abbe numbers are approximately equal to 100 [117]. An important advantage of fluoroaluminate glasses is their high resistance to water attack. They have the highest chemical stability among fluoride glasses. Fig. 16 presents the classification of fluoroaluminate glasses proposed by Zakalyukin [135]. The rectangles in Fig. 16 enclose compositions that have been produced on a pilot scale and are potential candidates for practical application. In these formulas, cations appear in the following order: modifiers, glass-formers, and then stabilizers. In the glass compositions presented in Fig. 16, Zr can be replaced by Hf or Th, and Y can be replaced by heavy lanthanides.

Yasui et al. [136] studied glass formation in binary $\mathrm{AlF}_{3}$ systems containing $\mathrm{BaF}_{2}, \mathrm{CaF}_{2}$, and $\mathrm{SrF}_{2}$ as well as in the ternary systems $\mathrm{AlF}_{3}-\mathrm{BaF}_{2}-\mathrm{CaF}_{2}$ and $\mathrm{AlF}_{3}-\mathrm{BaF}_{2}-\mathrm{SrF}_{2}$ using liquid quenching between $\mathrm{Cu}$ rolls, as presented in Fig. 17. The existence of two glass-forming regions in the $\mathrm{BaF}_{2}-\mathrm{AlF}_{3}$ system, at 28-31 and 55-66 mol\% $\mathrm{AlF}_{3}$, appears to be attributed to the formation of the compound $\mathrm{Ba}_{5} \mathrm{Al}_{3} \mathrm{~F}_{19}$, which melts congruently at $1010^{\circ} \mathrm{C}$ and divides the glass-forming region into two. From binary to ternary systems, the stability of the glasses improves. This improvement in stability is most likely associated with the formation of low-melting-point ternary eutectics. An increase in the number of components has a similar effect: it raises the stability of the glass system, reducing the critical cooling rate. The introduction of additional glass formers has a significant effect on the glass stability (the so-called confusion effect) [38].

\section{Effects of phase separation on the glass-forming ability of halides}

At present, few studies have provided data regarding phase separation in halide glass systems. Although $\mathrm{BeF}_{2}, \mathrm{ZnCl}_{2}$ and $\mathrm{ZnBr}_{2}$ can form transparent glasses, according to Ima- 


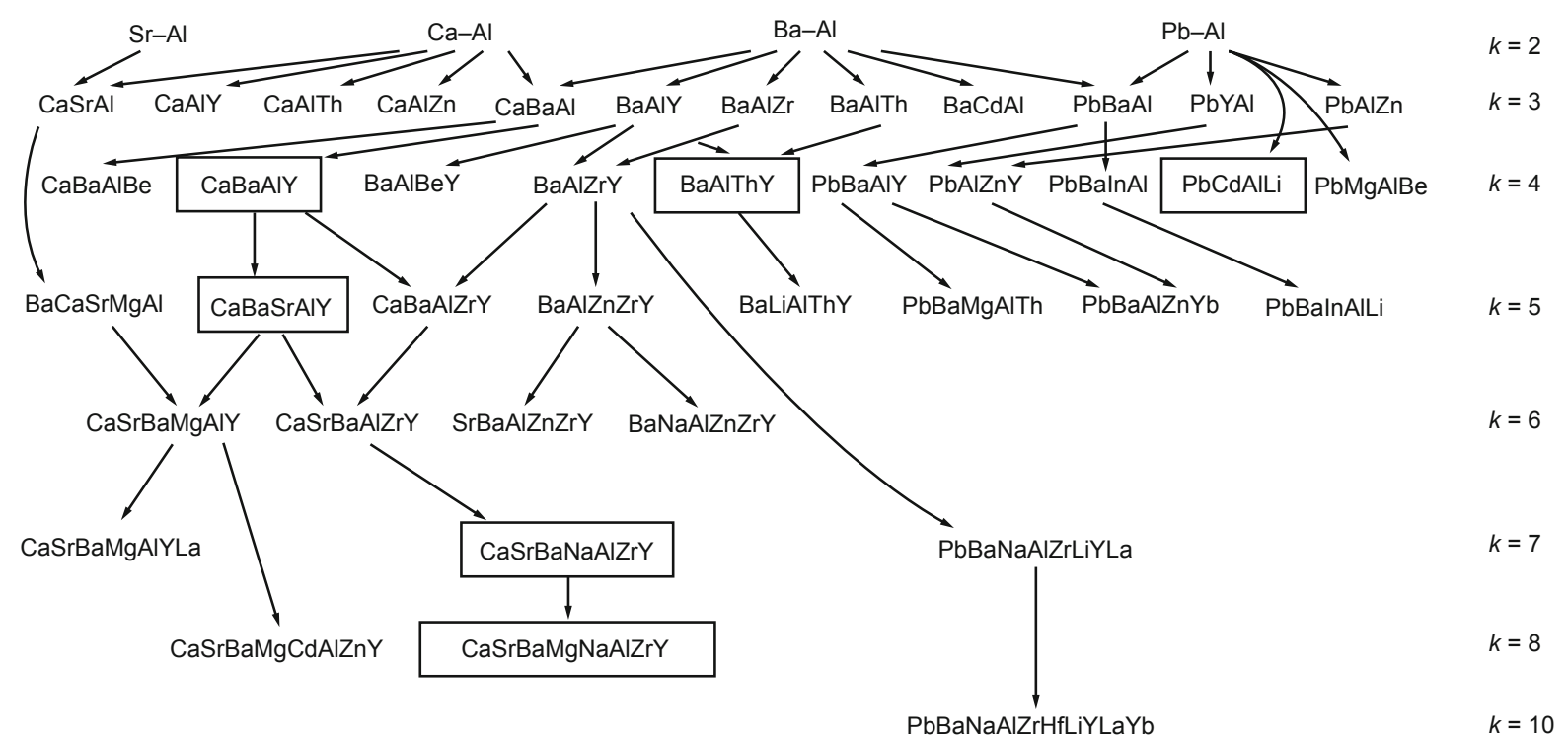

Figure 16 Tree of fluoroaluminate glass compositions; $k$ is the number of components (Reproduced from Ref. [135], Original Russian Text Copyright2003, MAIK “Nauka/Interperiodica”).
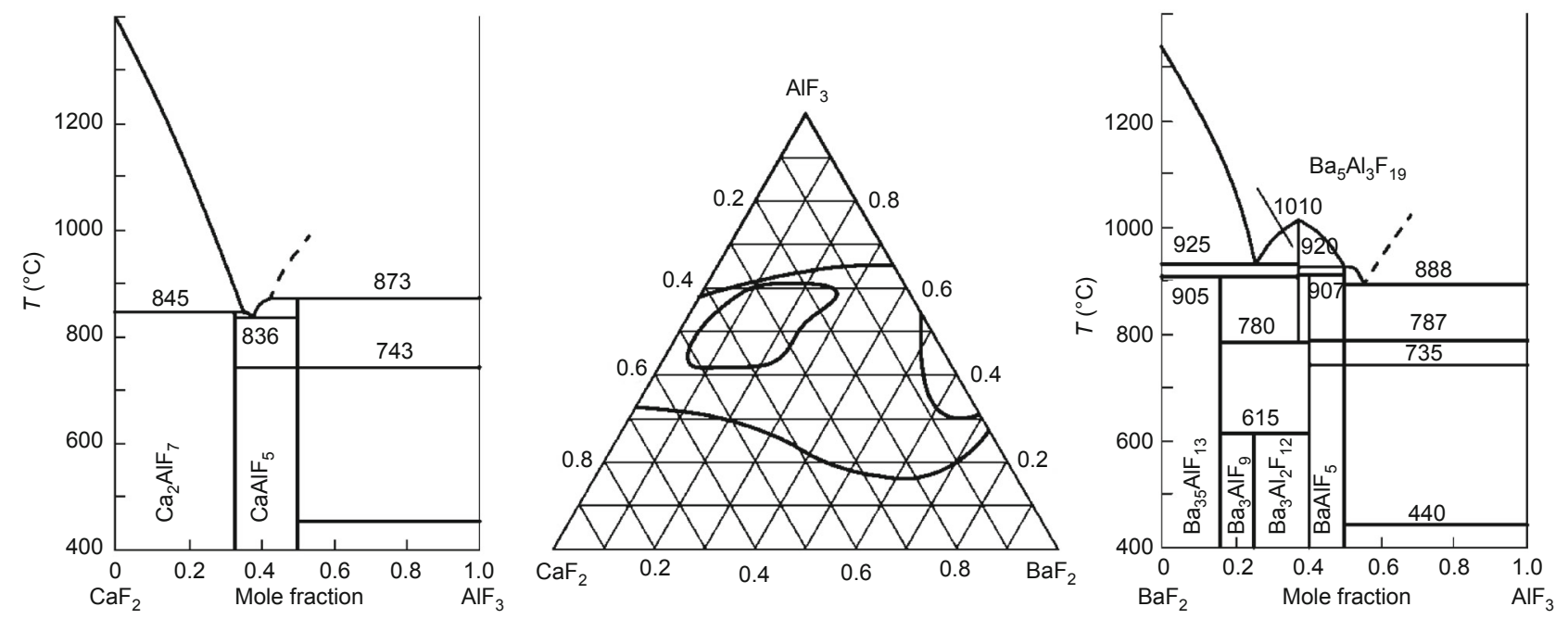

Figure $17 \mathrm{CaF}_{2}-\mathrm{AlF}_{3}$ and $\mathrm{BaF}_{2}-\mathrm{AlF}_{3}$ phase diagrams [137,138] and the glass-forming region in the $\mathrm{CaF}_{2}-\mathrm{BaF}_{2}-\mathrm{AlF}_{3}$ system; the region in the center portion encompasses glasses with $T_{\mathrm{x}}-T_{\mathrm{g}}>50 \mathrm{~K}$ (Reproduced from Ref. [135], Original Russian Text Copyright 2003, MAIK "Nauka/Interperiodica").

oka [139-142] and Vogel [32], phase separation occurs in the high-network-former regions of the binary and ternary systems of $\mathrm{BeF}_{2}$ glasses. Some studies of multi-component glass systems containing $\mathrm{ZrF}_{4}, \mathrm{ThF}_{4}, \mathrm{ZnF}_{2}$ and $\mathrm{PbF}_{2}$ have suggested that transparent glasses cannot be formed in the high-network-former regions of these systems because of phase separation and crystallization. The glass-forming behavior of halides is summarized graphically in Fig. 18.

According to the principles discussed above, experiments have been conducted on hundreds of compositions of halide systems. A large number of binary and ternary glass-forming systems have been established because their glass-forming regions can be easily determined by eye based on only a few experiments using conventional method. The glass-forming regions of several ternary systems, such as $\mathrm{ZrF}_{4}-\mathrm{BaF}_{2}-\mathrm{SrF}_{2}, \mathrm{ZrF}_{4}-\mathrm{BaF}_{2}-\mathrm{CaF}_{2}, \mathrm{ZrF}_{4}-\mathrm{BaF}_{2}-\mathrm{ZnCl}_{2}$, $\mathrm{ZrF}_{4}-\mathrm{BaF}_{2}-\mathrm{LaF}_{3}, \quad \mathrm{ZrF}_{4}-\mathrm{BaF}_{2}-\mathrm{BiCl}_{3}, \mathrm{ZnCl}-\mathrm{KCl}-\mathrm{PbF}_{2}, \mathrm{Zn}-$ $\mathrm{Cl}_{2}-\mathrm{KCl}-\mathrm{BaF}_{2}, \mathrm{ZnCl}_{2}-\mathrm{KCl}-\mathrm{PbCl}_{2}$ and $\mathrm{ZnCl}_{2}-\mathrm{LaF}_{3}-\mathrm{BaF}_{2}$, are illustrated in Fig. 19. The initial materials were fluorides, chlorides and a few bromides, all of which were chemically pure or of analytical reagent grade. Among these, $\mathrm{ZrF}_{4}$ and $\mathrm{HfF}_{4}$ are prepared and purified in our laboratory. All 

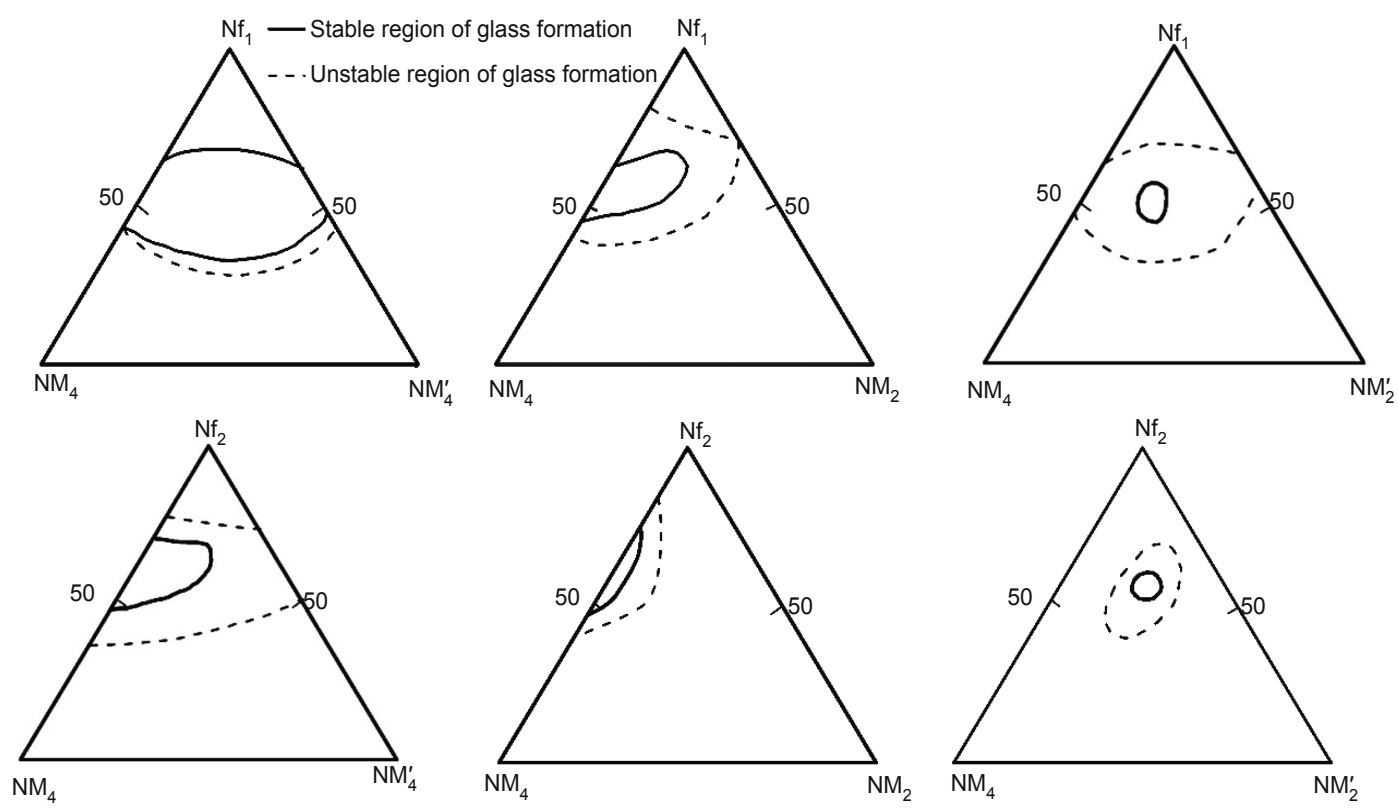

Figure 18 Typical glass-forming regions of halide glasses: $\mathrm{Nf}_{1}$ is a glass former with an electric valence of $Z=4, \mathrm{Nf}_{2}$ is a glass former with an electric valence of $Z=6$ or $4, \mathrm{NM}_{2}$ is a network modifier that contains alkaline earth metal ions, and $\mathrm{NM}_{4}$ is a network modifier with a high accumulation of ions such as $\mathrm{Zr}, \mathrm{Nb}$, Ta, La and Th.
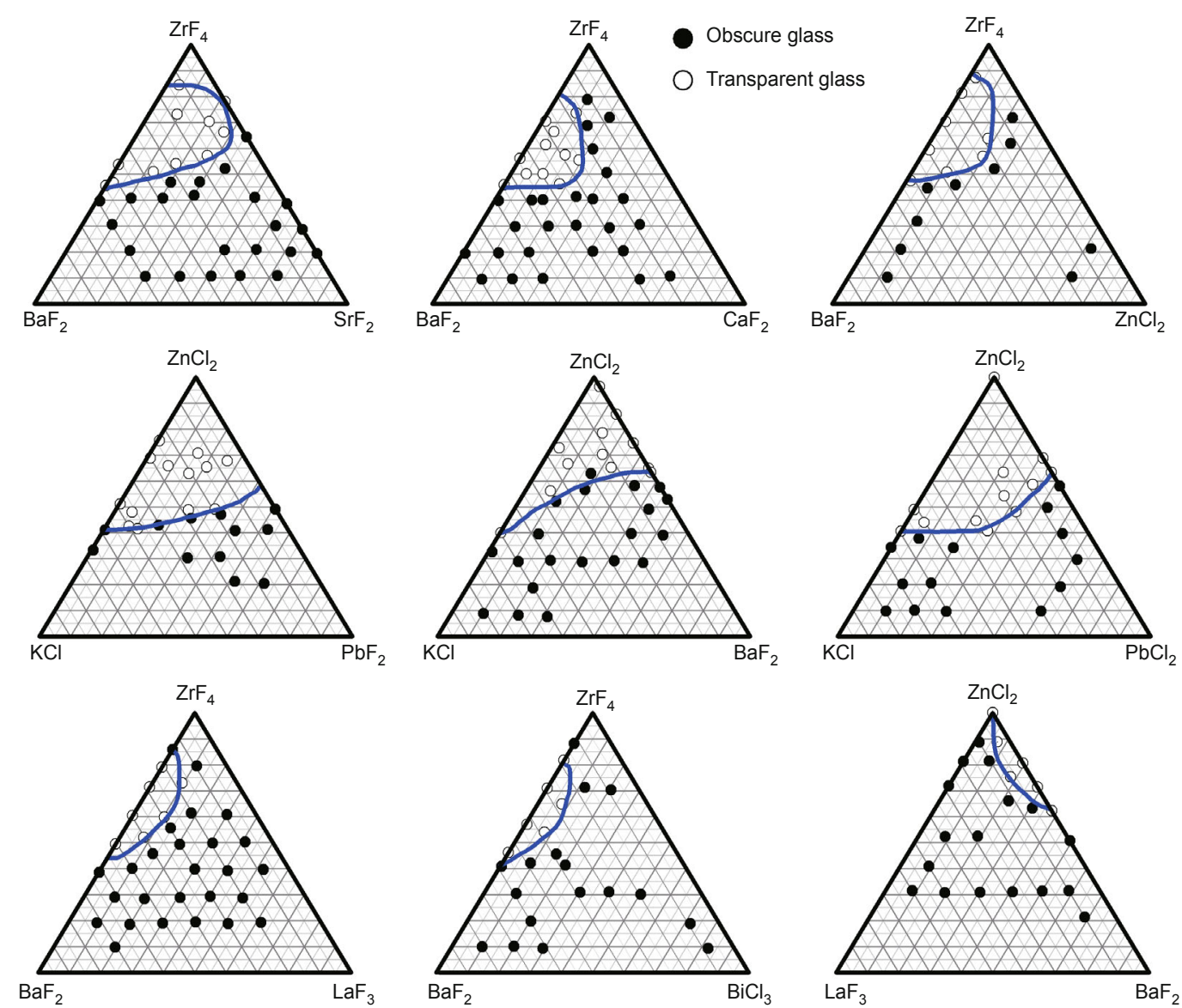

Figure 19 Typical glass-forming regions of halide glasses. 
raw materials were heated and dehydrated under an Ar atmosphere. The fluorides were confirmed, through X-ray diffraction and chemical analysis, to have a purity of more than $98 \%$.

According to the principles of glass formation, several fluoride and chloride halogen glasses in ternary systems were investigated. The heats of fusion and eutectoid temperatures were determined via DSC with a trace thermal analyzer. These values were then used to predict the formation regions of halogen glasses in the ternary systems. Using the calculation-based prediction method, the glass-forming regions could be determined rapidly and with fewer experiments.

The $\mathrm{ZrF}_{2}-\mathrm{BaF}_{2}-\mathrm{NaF}, \mathrm{ZrF}_{4}-\mathrm{BaF}_{2}-\mathrm{LiF}$ and $\mathrm{ZrF}_{4}-\mathrm{CaF}_{2}-\mathrm{BaF}_{2}$ systems were also investigated in detail. The raw material $\mathrm{ZrF}_{4}$ was introduced via fluorine zirconium. The sample was ground and placed in a platinum crucible that was heated at $800^{\circ} \mathrm{C}$ under the protection of an $\mathrm{Ar}$ atmosphere. The sample was then cast into a Cu mould for cooling, and the binary "quasi-compound" was prepared. Furthermore, the melting temperatures and heats of fusion in the eutectics of the $\mathrm{ThF}_{4}-\mathrm{NaF}-\mathrm{LiF}, \mathrm{ThF}_{4}-\mathrm{KF}-\mathrm{LiF}, \mathrm{CdCl}_{2}-\mathrm{KCl}-\mathrm{BaCl}_{2}$ and $\mathrm{ZnCl}_{2}-\mathrm{KCl}-\mathrm{PbCl}_{2}$ systems were also calculated using a multiple-addition method. After this calculation, we treated the binary eutectoid as a "quasi-compound", and obtained the new position of the eutectic point, which was simply the stable glass-forming region, through computer calculations using a multiple-addition method. The results are presented in Tables 11 and 12. The values computed using the multiple-addition-method corresponds well with the reported experimental data of the glass-forming region, which are provided in Figs 20 and 21 for comparison.

\section{The eutectic point and glass-forming region in ionic-compound glasses}

Angell $[143,144]$ and Kirilenko [145,146] determined the boundaries of the glass-forming regions in the nitrate and chloride systems as well as the glass transition temperatures as functions of the salt concentration under certain strict conditions: high cooling rates $(15-17 \mathrm{~K} / \mathrm{s})$ of the solutions and a low sample weight $(0.2 \mathrm{mg})$. Following the study, it was necessary to refine the boundaries of the glass-forming regions in these systems at low cooling rates and high sample weights. However, for nitrate, an ionic compound, the existing theories (network-structure theory and the theory of large, complex anion-group structure) are unable to explain the structures of the system. Although the structure of nitrate is fairly simple, it is generally accepted that it can form an ordered molecular arrangement during cooling. However, a relatively stable glass can form from this type of nitrate. Nitrate, as an ionic compound with low viscosity, has attracted considerable interest from scientists studying glass-forming mechanisms [147].

It is difficult for single-nitrate compounds to form glass,

Table 11 Thermal properties of new eutectics formed in the binary systems

\begin{tabular}{|c|c|c|c|c|c|}
\hline \multicolumn{2}{|c|}{ Compound } & \multicolumn{2}{|c|}{ Fusion heat $\left(\mathrm{cal} \mathrm{mol}^{-1}\right)$} & \multirow{2}{*}{ Eutectic temperature $(\mathrm{K})$} & \multirow{2}{*}{ Eutectic position $x_{\mathrm{B}}(\mathrm{mol} \%)$} \\
\hline $\mathrm{A}$ & $\mathrm{B}$ & Experimental & Calculated & & \\
\hline $\mathrm{ZnF}_{2}$ & $\mathrm{BaF}_{2}$ & 6808 & 7840 & 1013 & 67.5 \\
\hline $\mathrm{ZnF}_{2}$ & $\mathrm{NaF}$ & 8421 & 9400 & 953 & 30 \\
\hline $\mathrm{BaF}_{2}$ & $\mathrm{NaF}$ & 7434 & 7588 & 1080 & 34.33 \\
\hline $\mathrm{ZrF}_{4}$ & $\mathrm{BaF}_{2}$ & 7585 & & 800 & 50 \\
\hline $\mathrm{ZrF}_{4}$ & $\mathrm{LiF}$ & 7211 & & 773 & 50 \\
\hline $\mathrm{BaF}_{2}$ & $\mathrm{LiF}$ & 6575 & & 1038 & 56.25 \\
\hline $\mathrm{ZrF}_{4}$ & $\mathrm{CaF}_{2}$ & 7713 & & 850 & 33.4 \\
\hline $\mathrm{CaF}_{2}$ & $\mathrm{BaF}_{2}$ & 6950 & & 1323 & 50 \\
\hline $\mathrm{ZrF}_{4}$ & $\mathrm{NaF}$ & 8011 & & 772 & 50 \\
\hline $\mathrm{ThF}_{4}$ & $\mathrm{NaF}$ & & 8575 & 893 & 77 \\
\hline $\mathrm{ThF}_{4}$ & $\mathrm{LiF}$ & & 7725 & & \\
\hline $\mathrm{NaF}$ & $\mathrm{LiF}$ & & 7280 & 898 & 60 \\
\hline $\mathrm{ThF}_{4}$ & $\mathrm{KF}$ & & 7313 & 967 & 85 \\
\hline $\mathrm{LiF}$ & $\mathrm{KF}$ & & 6775 & 765 & 50 \\
\hline $\mathrm{CdCl}_{2}$ & $\mathrm{BaCl}_{2}$ & & 5778 & 723 & 45 \\
\hline $\mathrm{CdCl}_{2}$ & $\mathrm{KCl}$ & & 6910 & 653 & 34 \\
\hline $\mathrm{KCl}$ & $\mathrm{BaCl}_{2}$ & & 5340 & 917 & 43 \\
\hline $\mathrm{ZnCl}_{2}$ & $\mathrm{KCl}$ & & 3478 & 535 & 26.34 \\
\hline $\mathrm{ZnCl}_{2}$ & $\mathrm{PbCl}_{2}$ & & 3213 & 573 & 25.34 \\
\hline $\mathrm{KCl}$ & $\mathrm{PbCl}_{2}$ & & 5908 & 684 & 52.00 \\
\hline
\end{tabular}


Table 12 Thermal properties of new eutectics formed in the ternary systems

\begin{tabular}{|c|c|c|c|c|c|c|}
\hline \multicolumn{2}{|c|}{ Compound } & \multicolumn{2}{|c|}{ Fusion heat $\left(\mathrm{cal} \mathrm{mol}^{-1}\right)$} & \multicolumn{2}{|c|}{ Fusion temperature $(\mathrm{K})$} & \multirow{2}{*}{$\begin{array}{l}\text { Eutectic position } x_{\mathrm{B}} \\
(\mathrm{mol} \%)\end{array}$} \\
\hline A & B & $\Delta H_{\mathrm{A}}$ & $\Delta H_{\mathrm{B}}$ & $T_{\mathrm{A}}$ & $T_{\mathrm{B}}$ & \\
\hline $\mathrm{ZnF}_{2}+\mathrm{BaF}_{2}$ & $\mathrm{ZnF}_{2}+\mathrm{NaF}$ & 6808 & 8421 & 1013 & 953 & 51.92 \\
\hline $\mathrm{ZnF}_{2}+\mathrm{BaF}_{2}$ & $\mathrm{BaF}_{2}+\mathrm{NaF}$ & 6808 & 7434 & 1013 & 1080 & 43.90 \\
\hline $\mathrm{ZnF}_{2}+\mathrm{NaF}$ & $\mathrm{BaF}_{2}+\mathrm{NaF}$ & 8421 & 7434 & 953 & 1080 & 41.26 \\
\hline $\mathrm{ZrF}_{4}+\mathrm{BaF}_{2}$ & $\mathrm{ZrF}_{4}+\mathrm{LiF}$ & 7585 & 7211 & 800 & 773 & 54.30 \\
\hline $\mathrm{ZrF}_{4}+\mathrm{BaF}_{2}$ & $\mathrm{BaF}_{2}+\mathrm{LiF}$ & 7585 & 6575 & 800 & 1038 & 30.33 \\
\hline $\mathrm{ZrF}_{4}+\mathrm{LiF}$ & $\mathrm{BaF}_{2}+\mathrm{LiF}$ & 7211 & 6575 & 773 & 1038 & 26.78 \\
\hline $\mathrm{ZrF}_{4}+\mathrm{CaF}_{2}$ & $\mathrm{ZrF}_{4}+\mathrm{BaF}_{2}$ & 7713 & 7585 & 850 & 800 & 56.41 \\
\hline $\mathrm{ZrF}_{4}+\mathrm{CaF}_{2}$ & $\mathrm{CaF}_{2}+\mathrm{BaF}_{2}$ & 7713 & 6950 & 850 & 1323 & 18.44 \\
\hline $\mathrm{ZrF}_{4}+\mathrm{BaF}_{2}$ & $\mathrm{CaF}_{2}+\mathrm{BaF}_{2}$ & 7585 & 6950 & 800 & 1323 & 12.71 \\
\hline $\mathrm{ZrF}_{4}+\mathrm{BaF}_{2}$ & $\mathrm{ZrF}_{4}+\mathrm{NaF}$ & 7585 & 8011 & 800 & 772 & 53.04 \\
\hline $\mathrm{ZrF}_{4}+\mathrm{BaF}_{2}$ & $\mathrm{BaF}_{2}+\mathrm{NaF}$ & 7585 & 7434 & 800 & 1080 & 23.75 \\
\hline $\mathrm{ZrF}_{4}+\mathrm{NaF}$ & $\mathrm{BaF}_{2}+\mathrm{NaF}$ & 8011 & 7434 & 772 & 1080 & 20.29 \\
\hline $\mathrm{ThF}_{4}+\mathrm{NaF}$ & $\mathrm{LiF}+\mathrm{NaF}$ & 8575 & 7280 & 893 & 898 & 51.93 \\
\hline $\mathrm{ThF}_{4}+\mathrm{NaF}$ & $\mathrm{ThF}_{4}+\mathrm{LiF}$ & 8575 & 7725 & 893 & 833 & 58.78 \\
\hline $\mathrm{ThF}_{4}+\mathrm{LiF}$ & $\mathrm{NaF}+\mathrm{LiF}$ & 7725 & 7280 & 833 & 898 & 43.78 \\
\hline $\mathrm{ThF}_{4}+\mathrm{LiF}$ & $\mathrm{ThF}_{4}+\mathrm{KF}$ & 7725 & 7313 & 833 & 967 & 37.20 \\
\hline $\mathrm{ThF}_{4}+\mathrm{LiF}$ & $\mathrm{LiF}+\mathrm{KF}$ & 7725 & 6775 & 833 & 765 & 60.00 \\
\hline $\mathrm{ThF}_{4}+\mathrm{KF}$ & $\mathrm{LiF}+\mathrm{KF}$ & 7313 & 6775 & 967 & 765 & 72.35 \\
\hline $\mathrm{CdCl}_{2}+\mathrm{KCl}$ & $\mathrm{CdCl}_{2}+\mathrm{BaCl}_{2}$ & 6910 & 5778 & 653 & 723 & 42.53 \\
\hline $\mathrm{CdCl}_{2}+\mathrm{KCl}$ & $\mathrm{KCl}+\mathrm{BaCl}_{2}$ & 6910 & 5340 & 653 & 917 & 25.68 \\
\hline $\mathrm{CdCl}_{2}+\mathrm{BaCl}_{2}$ & $\mathrm{KCl}+\mathrm{BaCl}_{2}$ & 5778 & 5340 & 723 & 917 & 33.53 \\
\hline $\mathrm{ZnCl}_{2}+\mathrm{KCl}$ & $\mathrm{KCl}+\mathrm{PbCl}_{2}$ & 3478 & 5908 & 535 & 684 & 20.43 \\
\hline $\mathrm{ZnCl}_{2}+\mathrm{PbCl}_{2}$ & $\mathrm{KCl}+\mathrm{PbCl}_{2}$ & 3213 & 5908 & 573 & 684 & 26.58 \\
\hline
\end{tabular}
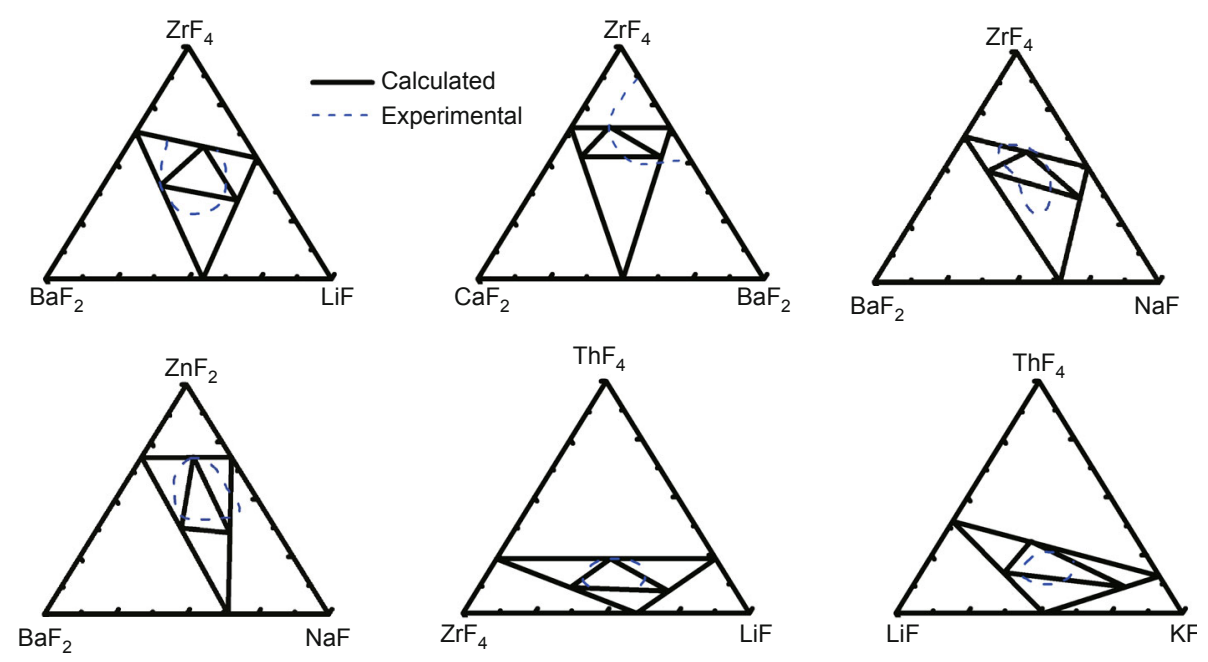

Figure 20 Glass-forming regions in the fluoride system. 


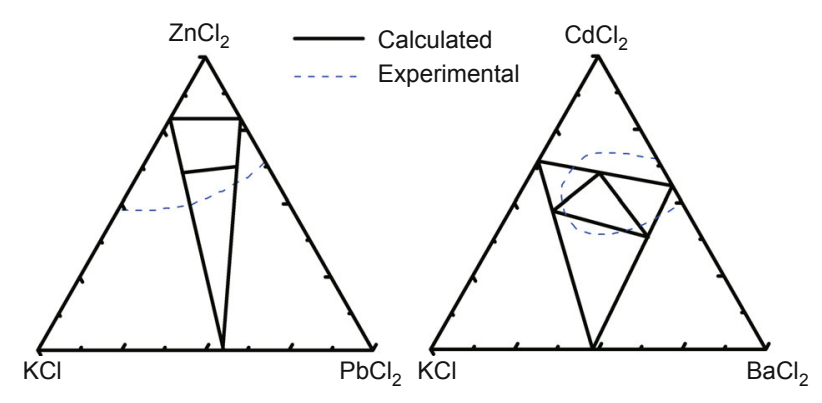

Figure 21 Glass-forming regions in the chloride system

whereas binary or multiple-nitrate melts can achieve glass formation. In a binary nitrate melt, glass formation only occurs in a system that contains both monovalent and divalent nitrates; it is difficult for a system that contains either only monovalent or only divalent nitrates to form glass. Thilo et al. [148] studied multiple binary nitrate glass systems, and their research concerning the field strengths of positive ions indicated that glass forms when the difference in the field strengths of positive ions is greater than 0.7. However, this difference in the field strengths of positive ions does not cause negative ions to be distorted during glass formation. Although the field-strength-based analysis contributes to the classification of the nitrate system based on its difficulty or facility of glass formation, determining the glass-forming regions of specific systems based on this analysis remains difficult $[49,147,148]$. Thilo et al. [148] experimentally observed nitrate glass-forming regions near the eutectic regions, and they found that the glass-forming regions became larger as the eutectic region became lower. From the dynamical perspective, a lower temperature implies a higher viscosity, and it is easier to form glass when the degree of under cooling of the eutectic glass-forming region is lesser.

Herein, we use mathematical methods based on the thermodynamics perspective to make quantitative prediction of the glass-forming regions in the nitrate system. The predicted results demonstrate that it is feasible to predict nitrate glass-forming regions based on the eutectic point and compositions with equal crystallization tendency. According to Doremus [62,149], the crystallization constant can be written as

$$
k=\Delta H_{\mathrm{m}} \cdot \Delta T / 3 \pi \lambda^{2} \eta T_{\mathrm{m}},
$$

where $T_{\mathrm{m}}$ is the melting point, $\Delta H_{\mathrm{m}}$ is the heat of fusion, $\eta$ is the viscosity, $\lambda$ is the distance of atomic migration, and $\Delta T$ is the subcooled temperature. In general, the crystallization rate of a pure-component melt typically reaches its maximum when $T$ is approximately $0.77 T_{\mathrm{m}}$ during cooling. $\Delta T$ is determined as $T_{\mathrm{m}}-0.77 T_{\mathrm{m}}$, yielding a value of $0.23 T_{\mathrm{m}}$, and the distance of atomic migration can be replaced by the diameter of the positive ions. The viscosity of the liquid phase can be considered to be approximately equal to the values obtained from previously measured and reported data; in fact, the viscosity of nitrate compounds is quite low. Therefore, the relative values of the crystallization constants for all nitrate pure-component melts can be calculated as shown in Table 13. The magnitudes of the crystallization constants follow the same order for divalent nitrates. However, it is difficult for $\mathrm{LiNO}_{3}$ and $\mathrm{NaNO}_{3}$ to form glass because of their relatively large crystallization constants, whereas $\mathrm{KNO}_{3}, \mathrm{RbNO}_{3}$ and $\mathrm{CsNO}_{3}$ can achieve glass formation more easily because of their relatively small crystallization constants. For ionic compounds, the glass-forming regions also tend to be located in the lowest liquid region. Fig. 22 present the relationships between the glass-forming regions and the phase diagram in two binary nitrate systems [152]. The glass-forming regions are closely related to the eutectic region, and there are essentially no high-melting-point intermediate compounds generated in these binary systems, as shown in Figs 22 and 23. Consequently, the glass-forming regions can be predicted and calculated based on the principle of the chemical potential of a regular solution. In the low eutectic region, the calculation formulas can be expressed as follows:

$$
\left\{\begin{array}{l}
R T \ln x_{\mathrm{A}}^{1}=-\Delta H_{\mathrm{A}}^{\mathrm{m}}\left(1-T / T_{\mathrm{A}}^{\mathrm{m}}\right), \\
R T \ln x_{\mathrm{A}_{x} \mathrm{~B}_{y}}^{1}=-\Delta H_{\mathrm{A}_{x} \mathrm{~B}_{y}}^{\mathrm{m}^{\prime}}\left(1-T / T_{\mathrm{A}_{x} \mathrm{~B}_{y}}^{\mathrm{m}}\right), \\
x_{\mathrm{A}}^{1}+x_{\mathrm{A}_{x} \mathrm{~B}_{y}}^{1}=1 .
\end{array}\right.
$$

Among divalent nitrates, $\mathrm{Mg}\left(\mathrm{NO}_{3}\right)_{2}$ decomposes relatively readily. There are no data available concerning its heat of fusion, and moreover, the thermodynamic data necessary to construct the phase diagram of $\mathrm{Mg}\left(\mathrm{NO}_{3}\right)_{2}$ are not complete. However, the heat of fusion of $\mathrm{Mg}\left(\mathrm{NO}_{3}\right)_{2}$ can be calculated using Equation (11) to be $\Delta H_{\mathrm{m}} \approx 1695 \mathrm{cal} \mathrm{mol}^{-1}$ based on the heat of fusion and the composition of the eutectic point of $\mathrm{NaNO}_{3}$ in the $\mathrm{Mg}\left(\mathrm{NO}_{3}\right)_{2}-\mathrm{NaNO}_{3}$ binary phase diagram. Although the heat of fusion of $\mathrm{Cd}\left(\mathrm{NO}_{3}\right)_{2}$ is also unknown, the thermodynamic data are required for the phase diagram of $\mathrm{Cd}\left(\mathrm{NO}_{3}\right)_{2}$ are more complete. Based on the phase diagram and general thermodynamic principles, the heat of fusion can be approximately calculated using the freezing-point depression method as follows:

$$
\Delta H_{m}=\frac{R\left(T_{\mathrm{m}}\right)^{2}}{\Delta \mathrm{T}_{\mathrm{m}}} x_{\mathrm{B}} \quad\left(x_{\mathrm{B}}<<1\right) .
$$

From the thermodynamic data of the phase diagram, the heat of fusion of $\mathrm{Cd}\left(\mathrm{NO}_{3}\right)_{2}$ can be calculated to be $\Delta H_{\mathrm{m}} \approx 5508 \mathrm{cal} \mathrm{mol}^{-1}$, and the eutectic composition in each system can be computationally obtained by substituting the known thermodynamic data into Equation (11). 
Table 13 The glass-forming regions, calculated eutectics and compositions corresponding to equal crystallization tendencies in selected binary nitrate systems

\begin{tabular}{|c|c|c|c|c|c|c|c|c|}
\hline \multirow{2}{*}{$\begin{array}{c}\text { System } \\
\text { A-B }\end{array}$} & \multicolumn{2}{|c|}{ Melting point (K) } & \multicolumn{2}{|c|}{$\begin{array}{l}\text { Fusion heat } \\
\left(\mathrm{cal} \mathrm{mol}^{-1}\right)\end{array}$} & \multirow{2}{*}{$\begin{array}{c}\text { Eutectic calculated/measured } \\
\qquad x_{\mathrm{B}}^{\mathrm{e}}(\mathrm{mol} \%)\end{array}$} & \multicolumn{2}{|c|}{$\begin{array}{l}\text { Composition with equal } \\
\text { crystallization tendency }\end{array}$} & \multirow{2}{*}{$\begin{array}{c}\begin{array}{c}\text { Glass forming } \\
\text { region }\end{array} \\
x_{\mathrm{B}}^{\mathrm{c}}(\mathrm{mol} \%)\end{array}$} \\
\hline & $T_{\mathrm{A}}^{\mathrm{m}}$ & $T_{\mathrm{B}}^{\mathrm{m}}$ & $\Delta H_{\mathrm{A}}^{\mathrm{m}}$ & $\Delta H_{\mathrm{B}}^{\mathrm{m}}$ & & $x_{\mathrm{B}}$ & $x_{\mathrm{B}} \pm 3(\mathrm{~mol} \%)$ & \\
\hline $\mathrm{Ca}\left(\mathrm{NO}_{3}\right)_{2}-\mathrm{NaNO}_{3}$ & 834 & 583 & 5120 & 3760 & $80.4 / 70.0$ & 57.6 & $54.6-60.6$ & $55-62$ \\
\hline $\mathrm{Ca}\left(\mathrm{NO}_{3}\right)_{2}-\mathrm{KNO}_{3}$ & 834 & 611 & 5120 & 2840 & $78.9 / 66.3$ & 68.1 & $65-71$ & $40-70$ \\
\hline $\mathrm{Ca}\left(\mathrm{NO}_{3}\right)_{2}-\mathrm{RbNO}_{3}$ & 834 & 578 & 5120 & 1340 & $85.8 / 75.6$ & 79.4 & $76-82$ & $32-75$ \\
\hline $\mathrm{Ca}\left(\mathrm{NO}_{3}\right)_{2}-\mathrm{CsNO}_{3}$ & 834 & 680 & 5120 & 3250 & $71.0 / 73.6$ & 62.9 & $60-66$ & $64-75$ \\
\hline $\mathrm{Sr}\left(\mathrm{NO}_{3}\right)_{2}-\mathrm{RbNO}_{3}$ & 918 & 578 & $10,500^{\mathrm{a}}$ & 1340 & $97.3 / 87.7$ & 87.4 & $84-90$ & $69-83$ \\
\hline $\mathrm{Sr}\left(\mathrm{NO}_{3}\right)_{2}-\mathrm{CsNO}_{3}$ & 918 & 680 & 10,500 & 3250 & $90.4 / 75.0$ & 75.9 & $73-79$ & $68-77$ \\
\hline $\mathrm{Mg}\left(\mathrm{NO}_{3}\right)_{2}-\mathrm{NaNO}_{3}$ & 753 & 583 & $1695^{\mathrm{b}}$ & 3760 & $48.3 / 48.3$ & 38.1 & $35-41$ & $21-57$ \\
\hline $\mathrm{Mg}\left(\mathrm{NO}_{3}\right)_{2}-\mathrm{KNO}_{3}$ & 753 & 611 & 1695 & 2840 & $49.5 / 41.4$ & 41.9 & $39-45$ & $24-61$ \\
\hline $\mathrm{Mg}\left(\mathrm{NO}_{3}\right)_{2}-\mathrm{RbNO}_{3}$ & 753 & 578 & 1695 & 1340 & $61.6 /-$ & 56.5 & $53.5-59.5$ & $40-67$ \\
\hline $\mathrm{Ba}\left(\mathrm{NO}_{3}\right)_{2}-\mathrm{CsNO}_{3}$ & 869 & 680 & $10,200^{\mathrm{a}}$ & 3250 & $83.7 / 86.0$ & 75.5 & $72.5-78.5$ & $78-79$ \\
\hline $\mathrm{Cd}\left(\mathrm{NO}_{3}\right)_{2}-\mathrm{LiNO}_{3}$ & 623 & 523 & $5508^{\mathrm{b}}$ & 6060 & $69.4 / 64.4$ & 48.9 & $46-52$ & $36-63$ \\
\hline $\mathrm{Cd}\left(\mathrm{NO}_{3}\right)_{2}-\mathrm{NaNO}_{3}$ & 623 & 583 & 5508 & 3760 & $62.8 / 54.8$ & 59.4 & $56-62$ & $28-64$ \\
\hline $\mathrm{Cd}\left(\mathrm{NO}_{3}\right)_{2}-\mathrm{KNO}_{3}$ & 623 & 611 & 5508 & 2840 & $62.8 / 59.2$ & 64.7 & $61.7-67.7$ & $21-67$ \\
\hline $\mathrm{Cd}\left(\mathrm{NO}_{3}\right)_{2}-\mathrm{RbNO}_{3}$ & 623 & 578 & 5508 & 1340 & $76.5 / 76.8$ & 78.2 & $75-81$ & $34-71$ \\
\hline $\mathrm{Cd}\left(\mathrm{NO}_{3}\right)_{2}-\mathrm{CsNO}_{3}$ & 623 & 680 & 5508 & 3250 & $52.0 /-$ & 60.0 & $57-63$ & $27-76$ \\
\hline
\end{tabular}

a) Date from reference [150]; b) date were calculated from phase diagram; c) data from reference [49]; other $\Delta H_{\mathrm{B}}$ data from reference [151].
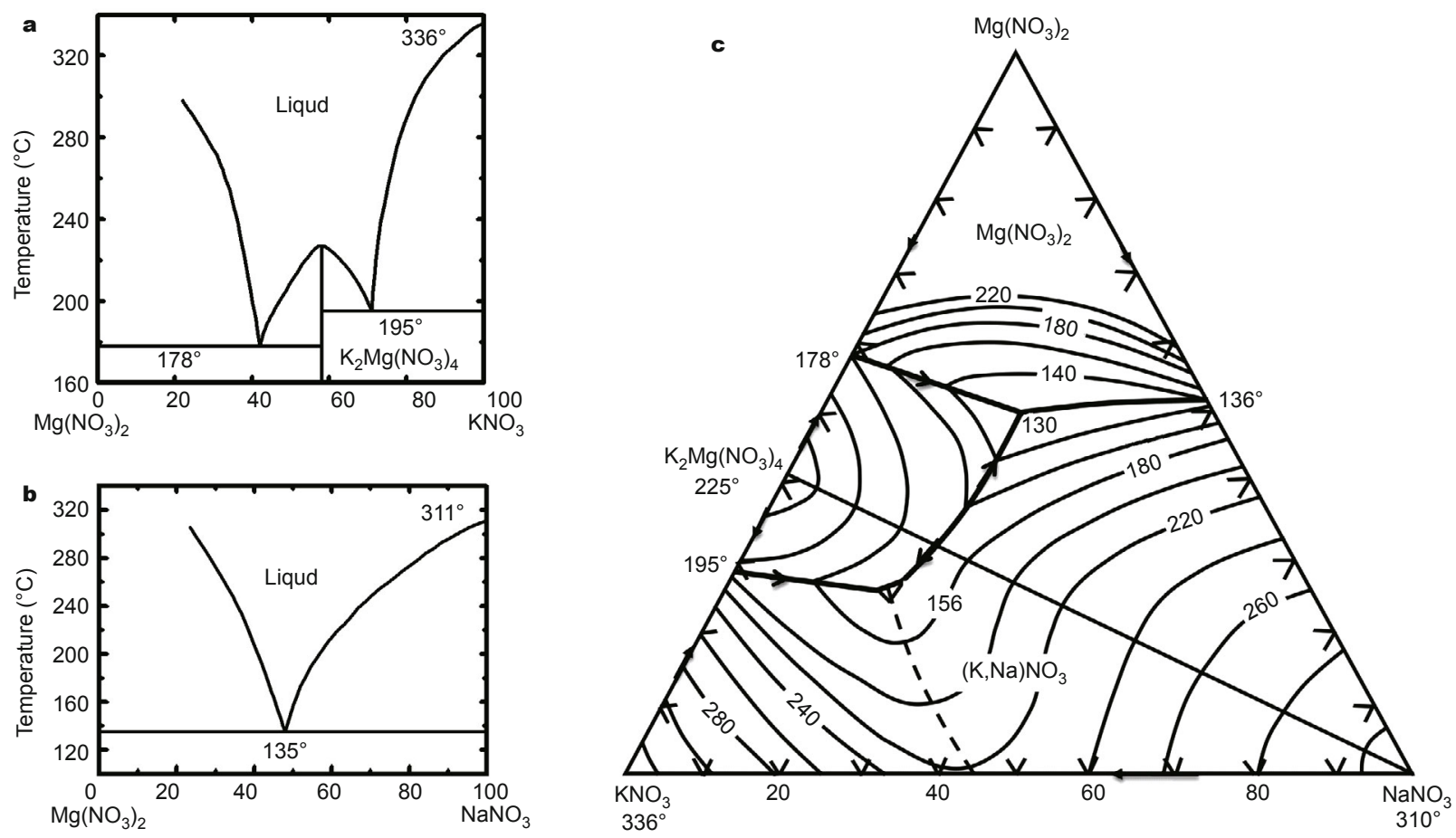

Figure 22 Phase diagrams and the glass-forming region of the $\mathrm{Mg}\left(\mathrm{NO}_{3}\right)_{2}-\mathrm{KNO}_{3}-\mathrm{NaNO}_{3}$ system (Reproduced from Ref. [152], Copyright 1942, Wiley). 


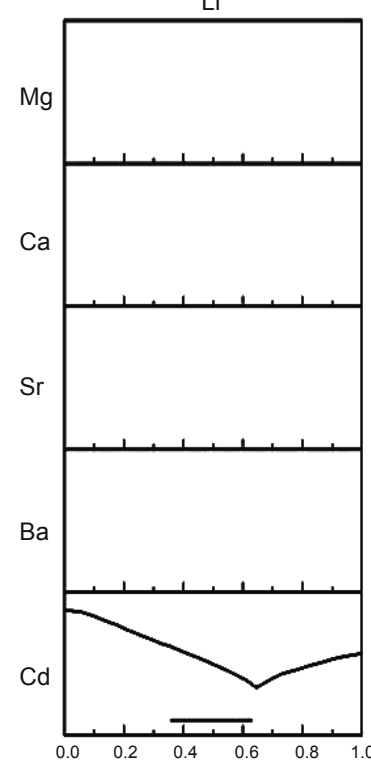

$\mathrm{Na}$

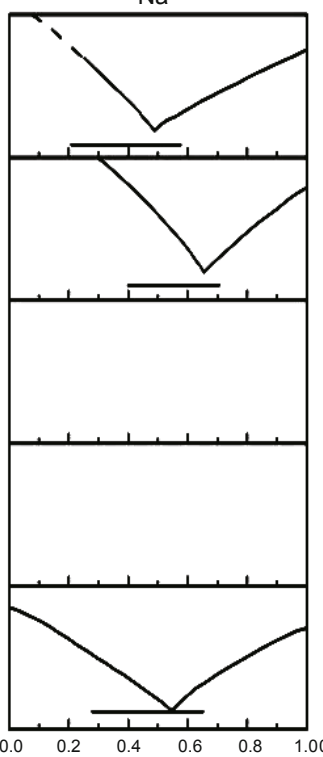

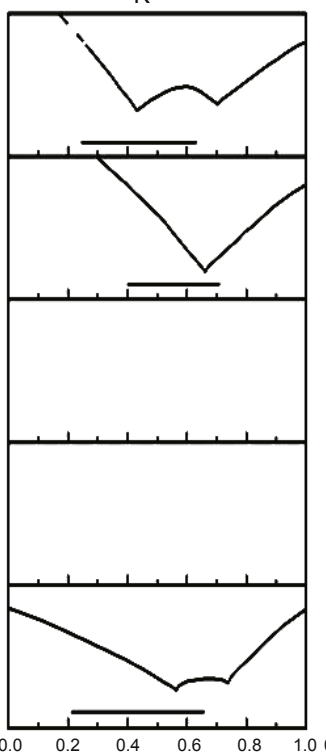

$\mathrm{Rb}$

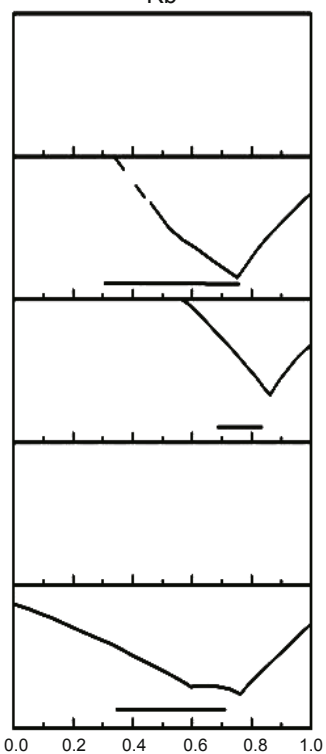

Cs

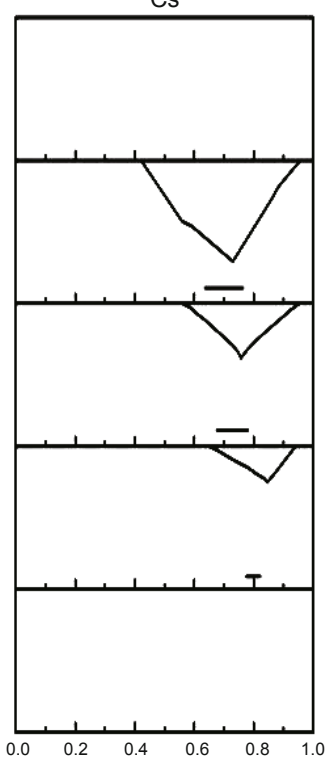

Figure 23 Regions of glass formation (indicated by horizontal bars) in various binary nitrate systems.

However, further investigation reveals that large deviations exist in some systems when thermodynamic calculations alone are used to predict the glass-forming regions. As shown in Fig. 23, some glass-forming regions deviate from the region of the eutectic point. Essentially, glass formation is a kinetic process; thus, the kinetic crystallization constant must be introduced to modify the above calculations. The inclusion of a concentration $x_{i}$ into the crystallization constant $k$ yields the following formula:

$$
k_{i}=\Delta H_{i}^{\mathrm{m}} \cdot \Delta T_{i} \cdot x_{i} / 3 \pi \lambda_{i}^{2} \eta_{i} T_{i}^{\mathrm{m}}(i=1,2,3 \cdots n) .
$$

Glass formation can readily occur at the composition in which the crystallization constant of each pure component is equal in a multiple-component system, namely, the composition corresponding to equal crystallized tendencies. The viscosity can be regarded as a constant in this calculation, and the results are presented in Table 13. The composition corresponding to equal crystallization tendencies is closer to the true glass-forming region than is the eutectic. The predictions based on equal crystallization tendency are consistent with the glass-forming regions to within $x_{\mathrm{B}}$ $\pm 3 \mathrm{~mol} \%$. These results demonstrate that it is feasible to predict nitrate glass-forming regions by determining the composition with equal crystallization tendencies.

The difficulty of glass formation in different glass systems can be preliminarily estimated by considering the relative values of the crystallization constants of each pure component. For alkali metals such as $\mathrm{LiNO}_{3}$ and $\mathrm{NaNO}_{3}$, the crystallization constants are relatively large and glass formation is difficult. By contrast, the crystallization con- stants of $\mathrm{KNO}_{3}, \mathrm{RbNO}_{3}$ and $\mathrm{CsNO}_{3}$ are relatively small, corresponding to ease of glass formation. These findings are consistent with the experimental results reported by Thilo et al. [148]; furthermore, they allow for quantitative interpretations of GFA. Unlike Thilo et al. [148], who determined the ease of glass formation based on the difference in field strength, we applied thermodynamics and kinetics to make quantitative predictions of the locations of the glass-forming region using mathematical methods. There are some deviations between the calculations and the actual glass-forming regions in the case of binary systems that contain $\mathrm{RbNO}_{3}$, which may be attributed to the use of an inaccurate value for the heat of fusion for $\mathrm{RbNO}_{3}$. It is typically difficult to measure the heat of fusion precisely. In addition, the melting point and heat of fusion of $\mathrm{RbNO}_{3}$ are inconsistent with the general observation that the melting point increases and the heat of fusion decreases as the weight of positive ions increases in an alkali nitrate. This inconsistency suggests that the structure of $\mathrm{RbNO}_{3}$ might be different from that of a general alkali nitrate, which may be another reason for the observed deviation.

\section{The eutectic point and glass-forming region in chalcogenides}

Systematic research in the field of glasses based on chalcogens, called chalcogenide glasses, began in the middle of the $20^{\text {th }}$ century. Sulfides and selenides are chalcogenide glasses that contain lanthanides. As in the case of fluorides, the search for such glasses is motivated by optical applications, which can be either passive (based on the trans- 
mission of infrared signals through lenses or fibers) or active (based on the photoluminescence of paramagnetic lanthanides) [22]. Because of their low phonon energies, chalcogenides permit the luminescence of lanthanide ions with high quantum efficiency. Thus, electronic transitions, especially those in the IR region, which do not occur in fluoride or oxide glasses, can be observed in chalcogenides.

Compared with oxide glasses, the mechanical strength and thermal stability of chalcogenide glasses are significantly lower, whereas their thermal expansion coefficients and the temperature coefficients of their refractive indices are higher. Because of the higher atomic masses and lower bonding-force constants in the chalcogenide compositions, the range of IR transparency is essentially broadened towards higher wavelengths [153-161]. Goryunova and Kolomiets [162,163] were among the pioneers in revealing the rules governing the GFAs of chalcogenide glasses, namely, the size of the glass-forming region in a two- or three-component chalcogenide alloy decreases when one of the components of the 4 th $(\mathrm{Ge}, \mathrm{Sn}), 5$ th $(\mathrm{As}, \mathrm{Sb}, \mathrm{Bi})$, or 6 th ( $\mathrm{S}, \mathrm{Se}, \mathrm{Te}$ ) main subgroups of the periodic table is replaced by an element with a greater atomic number $[164,165]$. The cause for such a decrease in GFA is the increase in the metallization degree of covalent bonds associated with the increase in the element's atomic number. The same approximately conclusion was also reached by Hilton et al. [166], who compared regions of glass-formation in ternary systems and used them as a measure of GFA. Hilton ranked elements of groups VI, V, and IV in order of decreasing glass-forming tendency as follows: $\mathrm{S}>\mathrm{Se}>\mathrm{Te}, \mathrm{As}>\mathrm{P}>\mathrm{Sb}$, $\mathrm{Si}>\mathrm{Ge}>\mathrm{Sn}$. As in oxide systems, the eutectic points also play an important role in glass formation in chalcogenide systems. The glass-forming regions of a system are most likely to be situated in the eutectic region, where the glass-former content is high. The eutectics and glass-forming regions of selected chalcogenide glasses were calculated using Equation (11) and the results are summarized in Table 14.

Minaev $[161,168]$ noted that the glass formation in binary and ternary chalcogenide systems is directly related to the structures of the corresponding phase diagrams. An analysis of more than 60 phase diagrams of binary chalcogenide systems and data regarding glass formation in these systems that was performed by Minaev led to the classification of these diagrams into four types: (1) The typical glass-forming phase diagrams of binary systems, which are diagrams with low-temperature eutectics in the range adjoining the chalcogen (Fig. 24a). Such systems include AlTe, Ge-Se, Si-Te, As-S, P-Se, and Cs-Te; (2) Glass-forming diagrams with phase segregation in the region adjoining the chalcogen and a rather low-temperature eutectic neighboring this region (Fig. 24b). Such systems include Cs-S, $\mathrm{K}-\mathrm{Se}$, Tl-S, Tl-Se, and Sb-S; (3) Glass-forming diagrams of two-chalcogen systems. The diagrams of the S-Se and S-Te systems are of this eutectic type, and the diagram of the Se-Te system is characterized by a continuous sequence of solid solutions [169,170]; (4) Non-glass-forming diagrams with a sharp rise in the liquidus temperature in the range closely adjoining the chalcogen (Fig. 24b) often followed by phase segregation (Fig. 24d).

Fig. 25 shows the glass-forming regions (bold horizontal bands) and individual glass-forming alloys (rhombi) in $\mathrm{A}^{\mathrm{IVA}}-\mathrm{B}^{\mathrm{VI}}$ systems superposed onto phase diagrams of the corresponding systems. The glass formation in a ternary system is related to the phase diagram of the system and is characterized by regions with reduced liquidus temperatures, which are typically located near the binary and ternary eutectics. To approximate the locations of glass-forming regions, Minaev $[161,168]$ has proposed that the use of curves be replaced with the so-called dilution lines (DLs) of the binary and ternary eutectics by the third and fourth components (and so on). The dilution line of binary eutectic (DLBE) in a ternary system is the line that connects the eutectic point of the binary system to the vertex of the concentration triangle, corresponding to a third-component content of $100 \%$. As seen in Fig. 26, both glass-forming regions are located along the DLBE of the common system, $\mathrm{e}_{3}$ (Te-GeTe)-As, $\mathrm{e}_{1}\left(\mathrm{Te}-\mathrm{As}_{2} \mathrm{Te}_{3}\right)-\mathrm{Ge}$, and $\mathrm{e}_{2}\left(\mathrm{As}-\mathrm{As}_{2} \mathrm{Te}_{3}\right)-\mathrm{Ge}$, as well as along the DLBEs of particular systems, for example, $\mathrm{e}_{3}(\mathrm{Te}-\mathrm{GeTe})-\mathrm{As}_{2} \mathrm{Te}_{3}$ and $\mathrm{e}_{1}\left(\mathrm{Te}-\mathrm{As}_{2} \mathrm{Te}_{3}\right)-\mathrm{GeTe}$. Minaev formulated the following qualitative criterion to characterize

Table 14 Comparison of calculated eutectic compositions with experimentally determined eutectic compositions in chalcogenide glasses

\begin{tabular}{|c|c|c|c|c|c|c|c|c|}
\hline \multirow{2}{*}{\multicolumn{2}{|c|}{ System }} & \multirow{2}{*}{\multicolumn{2}{|c|}{ Melting temperature $T_{\mathrm{m}}(\mathrm{K})$}} & \multirow{2}{*}{\multicolumn{2}{|c|}{ Fusion heat $\Delta H_{\mathrm{F}}\left(\mathrm{J} \mathrm{mol}^{-1}\right)$}} & \multicolumn{3}{|c|}{ Eutectic composition B (mol\%) } \\
\hline & & & & & & \multicolumn{2}{|c|}{ Calculated } & \multirow{2}{*}{ Measured } \\
\hline A & $\mathrm{A}_{x} \mathrm{~B}_{y}$ & $T_{\mathrm{A}}^{\mathrm{m}}$ & $T_{\mathrm{A}_{\mathrm{x}} \mathrm{B}_{\mathrm{y}}}^{\mathrm{m}}$ & $\Delta H_{\mathrm{A}}^{\mathrm{m}}$ & $\Delta H_{\mathrm{A}_{\mathrm{x}} \mathrm{B}_{\mathrm{y}}}^{\mathrm{m}}$ & $x_{\mathrm{B}}$ & $x_{\mathrm{B}} \pm 3$ & \\
\hline $\mathrm{Te}$ & $\mathrm{As}_{2} \mathrm{Te}_{3}$ & 722.57 & 654 & 17,490 & 42,672 & 18.5 & $15.5-21.5$ & 17.9 \\
\hline $\mathrm{S}$ & $\mathrm{As}_{2} \mathrm{~S}_{3}$ & 388 & 583 & 1,727 & 28,258 & 1.3 & $0-4.3$ & 2 \\
\hline As & $\mathrm{GeS}_{2}$ & 1090 & 1029 & 24,440 & 9,781 & 22.6 & $19.6-25.6$ & 24.6 \\
\hline$S$ & $\mathrm{GeS}_{2}$ & 388 & 1113 & 1,727 & 11,443 & 2.1 & $0-5.1$ & 1.5 \\
\hline $\mathrm{Te}$ & $\mathrm{S}$ & 722.57 & 388 & 17,490 & 1,727 & 95.1 & $92.1-98.1$ & 98 \\
\hline
\end{tabular}

Notes: date from references [151] and [167]. 

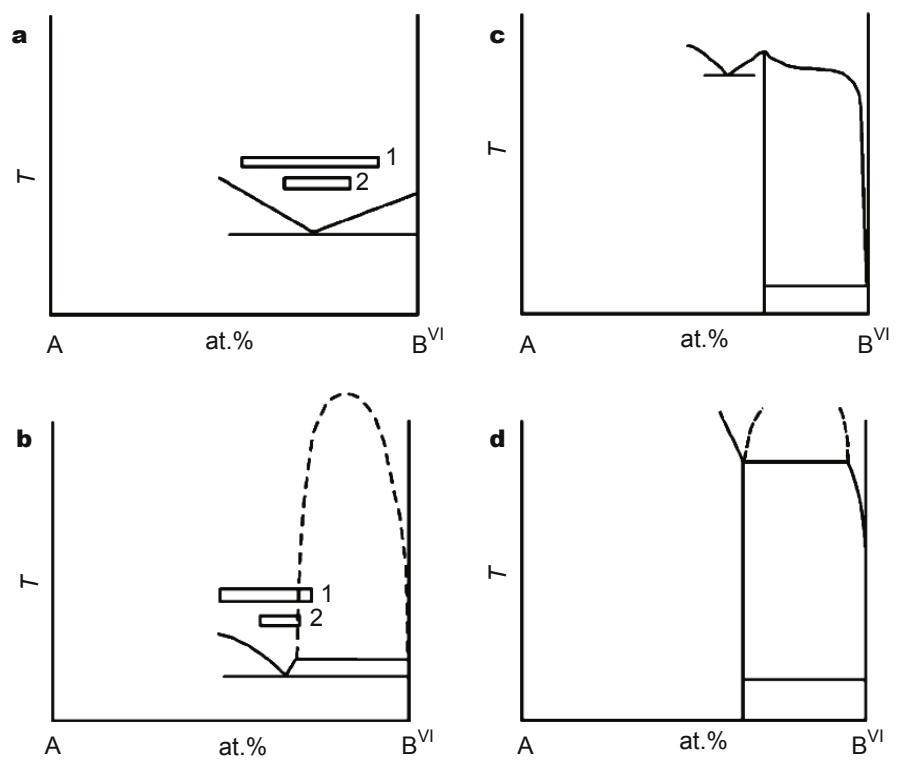

Figure 24 Types of phase diagrams of binary chalcogenide systems: (a) the glass-forming type with a chalcogen-enriched eutectic; (b) the glass-forming eutectic type with phase separation in the chalcogen-enriched region; (c) the non-glass-forming type with a sharp rise in the liquidus temperature in the chalcogen-enriched region; (d) the same as (c) but with the phase separation. In (a) and (b), (1) is the glass-forming region corresponding to the rapid quenching of the melt; (2) is the glass-formation region corresponding to the slow cooling of the melt (Reproduced with permission from Ref. [161], Copyright 2004, Elsevier Academic Press).
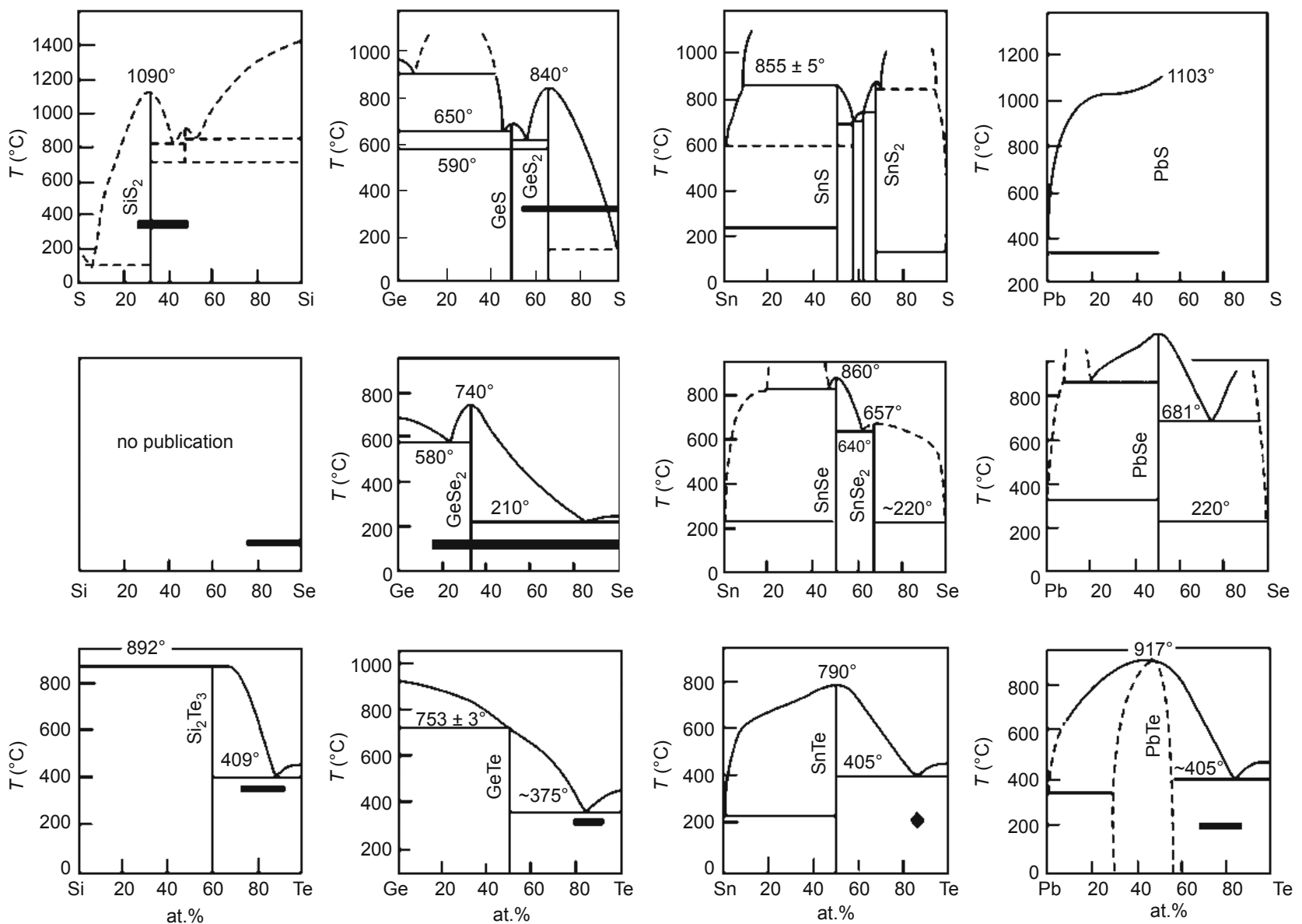

Figure 25 Phase diagrams and glass-forming regions (bold lines, rhombi) in $\mathrm{A}^{\mathrm{IVA}}-\mathrm{B}^{\mathrm{VI}}$ systems (Reproduced with permission from Ref. [161], Copyright 2004, Elsevier Academic Press). 


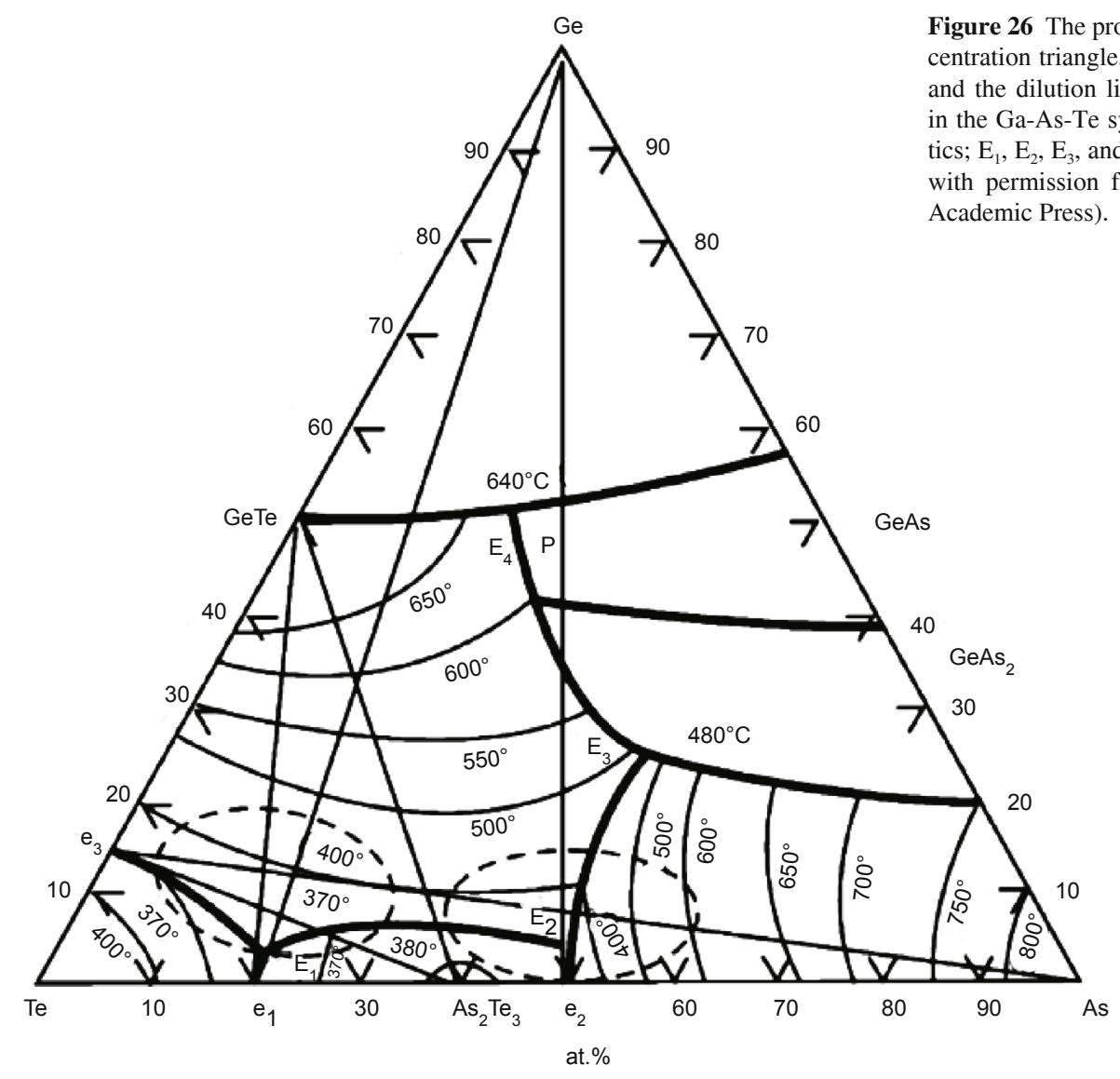

the locations of glass-forming regions: glass-forming regions of ternary chalcogenide systems are typically located near the DLs of binary eutectics by the third component. The application of this qualitative criterion of glass formation has allowed for the prediction of glass formation in several hundreds of ternary chalcogenide systems and, in particular, in several scores of ternary telluride systems.

\section{The eutectic and glass-forming region in metallic glasses}

Metallic glasses are metals and alloys without long-range order in their atomic arrangements, and these materials have received considerable attention in recent years because of certain advantages they offer, such as unique magnetic and mechanical properties, unusual electrical properties and corrosion resistance attributed to their amorphous structure. The major research efforts in this field are focused on exploring the relationship between alloy composition and glass formation. Similar to inorganic non-metallic glass, metallic glass is also a thermodynamically metastable state [171-173]. According to thermodynamics, the formation of metallic glasses and inorganic non-metallic glasses follows a common rule: the glass-forming regions are typically located near the low eutectic point in the phase diagram
[174-177]. Unlike oxide and halide glasses, which can be clearly divided into glass formers and network modifiers, not every eutectic point in the phase diagram is conducive to glass formation; the eutectic point can only play a vital role in the formation of glass potential glass-forming regions, such as the minimum liquid $T_{1}$ region.

Based on a large body of research results concerning the formation of glass from various alloys as well as several monographs and articles regarding the relationship between metal glass-forming regions and composition $[131,178,179]$, we offer the following summary of the types of metallic glasses: (a) Metal $\mathrm{T}^{2}$ (or noble metals) + metalloid $x$, where $\mathrm{T}^{2}$ is a transition metal and $x$ is silicon/phosphorus/boron or carbon; glass forms when the content of component $x$ is $15-25 \mathrm{~mol} \%$. (b) Metal $\mathrm{T}^{1}+$ metal $\mathrm{T}^{2}$ (or $\mathrm{Cu}$ ); where $\mathrm{T}^{1}$ is scandium/titanium/vanadium; glass forms when the content of component $\mathrm{T}^{2}$ is $30-40 \mathrm{~mol} \%$. (c) Metal A + metal B. A is an alkali metal or alkaline earth metal and $\mathrm{B}$ is $\mathrm{Cu} /$ zinc/aluminum and some other metal, glass forms when the content of component B is $20-40 \mathrm{~mol} \%$. (d) Metal $\mathrm{T}^{1}+$ metal A; glass forms when the content of

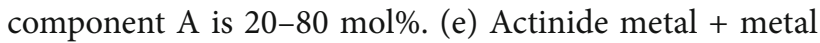
$\mathrm{T}^{1}$; glass forms when the content of component $\mathrm{T}^{1}$ is $20-40$ 
mol\%. (f) Metal $\mathrm{T}^{2}+$ rare earth metal; the glass-forming range is typically near the eutectic point on the $\mathrm{T}^{2}$ side [175].

When using thermodynamic calculations to predict the glass-forming region for an A-B binary alloy system, when $\mathrm{A}$ and $\mathrm{B}$ do not form a congruently melting compound and have the lowest possible $T_{1}$ area, we can directly use the heats of fusion of pure $A$ and pure $B$ to approximate the glass-forming region based on a simple eutectic type. However, most A-B binary alloys can form congruently melting $\mathrm{A}_{x} \mathrm{~B}_{y}$ compounds, the heats of fusion of $\mathrm{A}_{x} \mathrm{~B}_{y}$ intermetallic compounds cannot be easily determined, and few thermodynamic data are available for these compounds. Based on the phase diagrams and general thermodynamics principles, we can use the cryoscopic method to calculate the heats of fusion of intermetallic compounds; then, the eutectic points and the crystallization points can be calculated based on these data. Thus, the binary metallic glass-forming regions of congruently melting compounds can be predicted by determining the eutectic points and the compositions corresponding to equal crystallization tendencies.

Based on the principles of physical chemistry, the temperature at which solid/liquid balance is achieved is called the freezing point or melting point. Supposing that solute $\mathrm{B}$ is dissolved in liquid $\mathrm{A}$ (solvent) and that $\mathrm{A}$ and $\mathrm{B}$ do not form a solid solution, the temperature at which pure solid solvent A will precipitate out from solution (i.e., the freezing point) will be reduced compared with that of a liquid consisting of pure A. This reduction in a solution's freezing point can be expressed as follows when the content of $\mathrm{B}$, $x_{\mathrm{B}}$, is low:

$$
\Delta T_{\mathrm{m}}=\frac{R\left(T_{\mathrm{m}}\right)^{2}}{\Delta H_{\mathrm{m}}} x_{\mathrm{B}},
$$

where $T_{\mathrm{m}}$ is the freezing point (or melting point) of pure A, $\Delta H_{\mathrm{m}}$ is the molar heat of fusion of pure $\mathrm{A}$; and $R$ is the gas constant. When the heat of fusion of one component is unknown, one commonly used method to calculate the unknown heat of fusion is to use the phase diagram constructed from that component and the other components based on the cryoscopic method; the formula corresponding to this approach is expressed as shown in Equation (12).

For an A-B binary alloy system in which $\mathrm{A}$ and $\mathrm{B}$ form congruently melting $\mathrm{A}_{x} \mathrm{~B}_{y}$ compounds, when predicting the glass-forming regions via thermodynamic calculations, these calculations should be performed based on subsystems of different compositions, which can be classified based on the quantities of congruently melting compounds they contain. For such an alloy, the glass-forming region is typically closely related to the minimum- $T_{1}$ region.
For example, three intermetallic compounds exist in the Co-U system: $\mathrm{UCo}_{2} / \mathrm{UCo}$ and $\mathrm{U}_{6} \mathrm{Co}$, as shown in Fig. 27 $[171,172,174]$, of which only $\mathrm{UCo}_{2}$ is a congruently melting compound. We can classify the Co- $\mathrm{U}$ system into two subsystems, i.e., $\mathrm{U}-\mathrm{UCo}_{2}$ and $\mathrm{Co}-\mathrm{UCo}_{2}$, where the $\mathrm{U}-\mathrm{UCo}_{2}$ subsystem contains the minimum- $T_{1}$ region. Therefore, we perform our calculations based on this subsystem. According to the phase diagram, in the $\mathrm{U}-\mathrm{UCo}_{2}$ subsystem, the melting point of $\mathrm{UCo}_{2}$ will be reduced by $41 \mathrm{~K}$ upon the addition of $0.1 \mathrm{~mol} \%$ U, i.e., $T_{\mathrm{UCo}_{2}}^{\mathrm{m}}=1170+273=1443 \mathrm{~K}$. According to Equation (12), $\Delta H_{\mathrm{UCO}_{2}}^{\mathrm{m}}=1 / 41 \times 8.314 \times 14,432 \times 0.1$ $=42,224 \mathrm{~J} \mathrm{~mol}^{-1}$.

The sum of the molar fractions of all components is 1 through the entire concentration range of the phase diagram. Thus, the $\Delta H_{\mathrm{UCo}_{2}}^{\mathrm{m}}$ value calculated above cannot be used directly for thermodynamic calculations based on the phase diagram; instead, it must be multiplied by a normalization factor. For an intermetallic compounds $\mathrm{A}_{x} \mathrm{~B}_{y}$, this normalization factor is $1 /(x+y)$ :

$$
\Delta H_{\mathrm{UCo}_{2}}^{\mathrm{m}^{\prime}}=\Delta H_{\mathrm{UCo}_{2}}^{\mathrm{m}} / \mathrm{H}_{2}=14,075 \mathrm{~J} \mathrm{~mol}^{-1}
$$

Based on the above principle, we calculated the heats of fusion of intermetallic compounds in binary alloy systems that can form congruently melting compounds, and the compositions at the eutectic point were then calculated based on the obtained results. Table 15 presents a comparison between the experimental results and the calculated values. We found only slight deviations between the theoretical and experimental values. Although the glass-forming regions are closely related to the eutectic region, glass formation is essentially a kinetic process. From the dynamics perspective, we suggest that glass formation is most likely to occur when all components have the same crystallization tendency, and we define this point as the

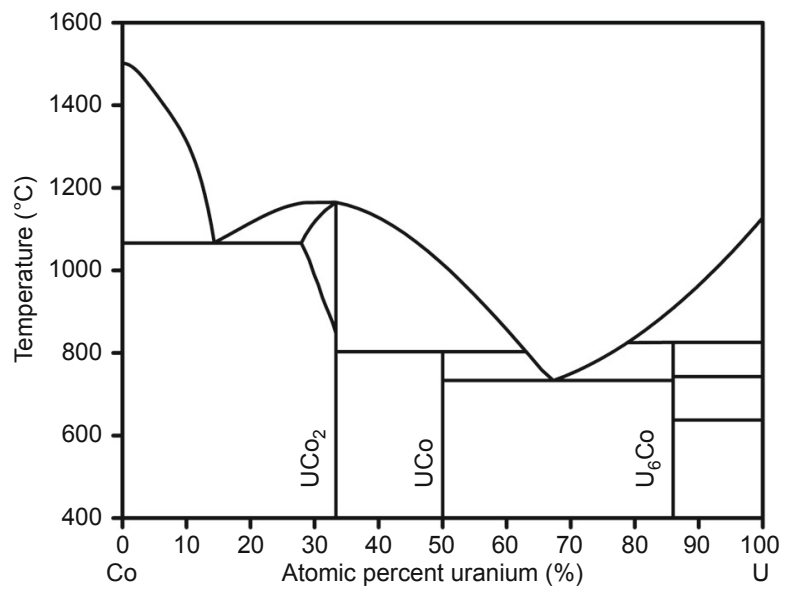

Figure 27 Phase diagram of the Co-U system (Reproduced with permission from Ref. [171], Copyright 1986, Metallurgical Industry Press). 
Table 15 Glass-forming regions, eutectic compositions and compositions corresponding to equal-crystallization tendencies in selected binary metal systems

\begin{tabular}{cccc}
\hline System A-B & Eutectic composition $(\mathrm{mol} \%)$ & Composition with equal crystallized tendency $x_{\mathrm{A}}(\mathrm{mol} \%)$ & Glass forming region $x_{\mathrm{A}}(\mathrm{mol} \%)$ \\
\hline $\mathrm{Au}-\mathrm{Si}^{\mathrm{a}}$ & 82.3 & 78.9 & $70-81.4$ \\
$\mathrm{Au}-\mathrm{Pb}^{\mathrm{b}}$ & 16.2 & 24.6 & 70.3 \\
$\mathrm{Au}-\mathrm{Ge}^{\mathrm{a}}$ & 63.7 & 80.3 & 73 \\
$\mathrm{Ag}-\mathrm{Si}^{\mathrm{a}}$ & 85.8 & 52.3 & $70-83$ \\
$\mathrm{Ag}-\mathrm{Cu}^{\mathrm{a}}$ & 54.3 & 77.0 & $35-65$ \\
$\mathrm{Al}-\mathrm{Ge}^{\mathrm{a}}$ & 82.6 & 41.6 & $20-70$ \\
$\mathrm{Co}-\mathrm{Au}^{\mathrm{a}}$ & 36.5 & 80.1 & $35-75$ \\
$\mathrm{~Pb}-\mathrm{Sb}^{\mathrm{a}}$ & 85.7 & 77.7 & 52 \\
$\mathrm{Tl}-\mathrm{Au}^{\mathrm{a}}$ & 85.6 & 36.4 \\
$\mathrm{Cr}-\mathrm{U}^{\mathrm{a}}$ & 29.5 & $40-75$ \\
\hline
\end{tabular}

a) The simple eutectic system and the system of continuous solid-solution with minimum point. b) The system with incongruent melting compound and the eutectic system with partial miscibility in the solid state.

equal-crystallization point to distinguish it from the eutectic point.

The temperature coefficient of the viscosity of a molten metal should be extremely small compared with the crystallization constant:

$$
k_{i}=\Delta H_{i}^{\mathrm{m}} \cdot \Delta T_{i} \cdot x_{i} / 3 \pi \lambda_{i}^{2} \eta_{i} T_{i}^{\mathrm{m}},
$$

where $T_{\mathrm{m}}$ is the melting point, $\Delta H_{\mathrm{m}}$ is the heat of fusion, $x_{i}$ is the concentration, $\eta$ is the viscosity, $\lambda$ is the distance of atomic migration, and $\Delta T$ is the subcooled temperature. Therefore, this coefficient can be ignored, and we can obtain the following formula for the equal-crystallization point [174]:

$$
\left\{\begin{array}{l}
\frac{x_{\mathrm{A}}}{x_{\mathrm{A}_{x} B_{y}}}=\frac{\Delta T_{\mathrm{A}_{x} B_{y}}}{\Delta T_{\mathrm{A}}} \frac{\Delta H_{\mathrm{A}_{x} B_{y}}^{\mathrm{m}^{\prime}}}{\Delta H_{\mathrm{A}}^{\mathrm{m}}} \frac{T_{\mathrm{A}}^{\mathrm{m}}}{T_{\mathrm{A}_{x} B_{y}}^{m}}, \\
x_{\mathrm{A}}+x_{\mathrm{A}_{x} B_{y}}=1 .
\end{array}\right.
$$

Based on Equation (14), we can obtain $x_{\mathrm{A}}$ and $x_{\mathrm{A}, \mathrm{B}}$, and then, the percentage of the $\mathrm{B}$ component can be calculated. Table 15 presents the predicted values of the equal-crystallization points and the actual glass-forming regions in several binary metal systems, from which it is apparent that the predicted values are mainly fall within the actual glass-forming regions. The eutectics and glass-forming regions of certain metallic glasses were calculated using Equation (11). The results are summarized in Tables 15 and 16, and Fig. 28 presents the glass-formation regions indicated on the corresponding phase diagrams.

The purpose of the prediction of metallic glass-forming regions is to identify regions within a certain composition range in which metallic glass is most likely to form in the selected systems using thermodynamics and kinetics methods. The heats of fusion of all components are needed for such a prediction. However, most intermetallic compounds are formed between metals or between a metal and

\begin{tabular}{|c|c|c|c|c|c|c|c|c|c|}
\hline \multicolumn{2}{|c|}{ System } & \multicolumn{2}{|c|}{$\begin{array}{c}\text { Melting temperature } \\
T_{\mathrm{m}}(\mathrm{K})\end{array}$} & \multicolumn{2}{|c|}{$\begin{array}{l}\text { Fusion heat } \Delta H \\
\left(\mathrm{kcal} \mathrm{mol}^{-1}\right)\end{array}$} & \multicolumn{2}{|c|}{$\begin{array}{c}\text { Eutectic composition } \\
\text { B (mol\%) }\end{array}$} & \multirow{2}{*}{$\begin{array}{l}\text { Composition of having equal } \\
\text { crystallized tendency } \\
x_{\mathrm{B}}\end{array}$} & \multirow{2}{*}{$\begin{array}{l}\text { Glass forming } \\
\text { region } \\
x_{\mathrm{B}}{ }^{\mathrm{a}}\end{array}$} \\
\hline $\mathrm{A}$ & $\mathrm{A}_{x} \mathrm{~B}_{y}$ & $T_{\mathrm{A}}^{\mathrm{m}}$ & $T_{\mathrm{A}_{\mathrm{x}} \mathrm{B}_{\mathrm{y}}}^{\mathrm{m}}$ & $\Delta H_{\mathrm{A}}^{\mathrm{m}}$ & $\Delta H_{\mathrm{A}_{\mathrm{x}} \mathrm{B}_{\mathrm{y}}}^{\mathrm{m}}$ & Calculated & Measured & & \\
\hline Co & $\mathrm{Co}_{2} \mathrm{P}$ & 1768 & 1659 & 17.14 & 12.49 & 19.0 & 19.8 & 18.9 & $18-25$ \\
\hline $\mathrm{La}$ & AuLa & 1193 & 1633 & 8.49 & 18.46 & 14.5 & 16.0 & 16.5 & $0-40$ \\
\hline $\mathrm{Pd}$ & $\mathrm{Pb}_{2} \mathrm{Si}$ & 1823 & 1603 & 17.56 & 19.76 & 17.5 & 15.0 & 16.1 & $13-25$ \\
\hline $\mathrm{Pt}$ & $\mathrm{PtSb}_{2}$ & 2043 & 1499 & 19.65 & 23.93 & 38.7 & 33.6 & 33.1 & $33-37$ \\
\hline $\mathrm{Zr}$ & $\mathrm{ZrPb}$ & 2125 & 1939 & 20.90 & 12.11 & 30.7 & 24.6 & 30.6 & $20-35$ \\
\hline $\mathrm{Fe}$ & $\mathrm{FeB}$ & 1809 & 1925 & 13.79 & 24.99 & 19.0 & 16.7 & 18.8 & $13-25$ \\
\hline $\mathrm{U}$ & $\mathrm{UCo}_{2}$ & 1403 & 1443 & 12.54 & 14.06 & 31.5 & 34.0 & 31.7 & $24-40$ \\
\hline $\mathrm{Mg}$ & $\mathrm{MgZn}_{2}$ & 923 & 861 & 8.95 & 13.68 & 30.2 & 27.9 & 27.9 & $25-32$ \\
\hline $\mathrm{Pt}$ & $\mathrm{Pt}_{2} \mathrm{Si}$ & 2043 & 1373 & 19.65 & 7.25 & 24.8 & 23.0 & 23.5 & $23-25$ \\
\hline $\mathrm{Ca}$ & $\mathrm{CaAl}_{2}$ & 1123 & 1352 & 8.36 & 8.03 & 31.3 & 35.0 & 33.5 & $12.5-47.5$ \\
\hline $\mathrm{Nb}$ & $\mathrm{NbNi}_{3}$ & 2740 & 1675 & 26.33 & 7.99 & 58.9 & 58.4 & 55.6 & $40-66$ \\
\hline
\end{tabular}

Table 16 Comparison of the calculated compositions with the experimental compositions in binary metal/intermetallic-compound systems

a) Data from references [174]. 

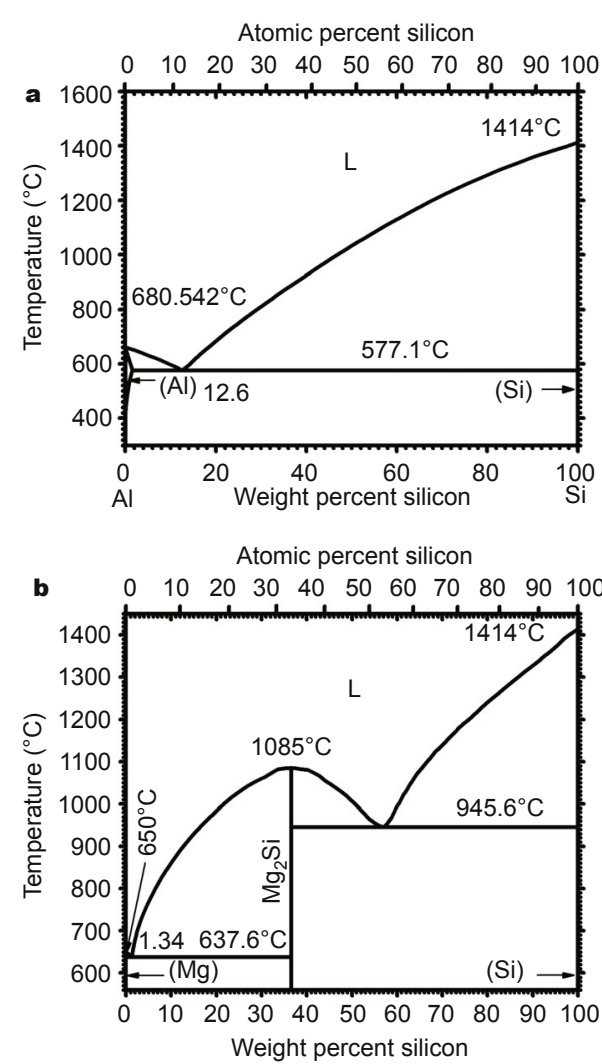

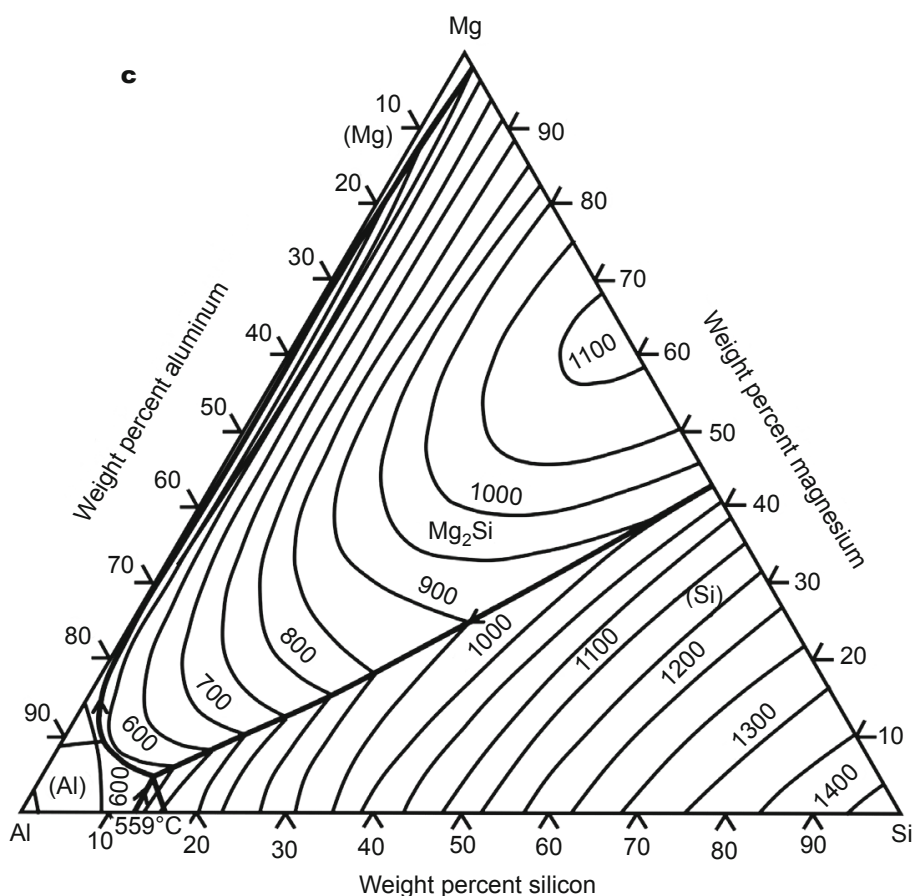

Figure 28 The phase diagrams and glass-forming regions of the Mg-Al-Si system (Reproduced with permission from Ref. [167], Copyright 1992, ASM International).

a metalloid, whose chemicalbonds are typically metallic in nature and do not follow the valence rules; their heats of fusion cannot be easily measured or obtained from thermodynamic data manuals. Here, based on the known phase diagrams, we used the cryoscopic method to calculate the heats of fusion of congruently melting intermetallic compounds. We found that the calculated $\Delta H_{\mathrm{A}_{1} \mathrm{~B}_{\mathrm{y}}}^{\mathrm{m}}$ values must be multiplied by a normalization factor of $1 /(x+y)$ before being used in the prediction calculations, as the sum of the molar concentrations of each type of atom in $\mathrm{A}_{x} \mathrm{~B}_{y}$ is not 1 . As shown in Table 16, there is some deviation between the theoretical and experimental values for the compositions of the lowest melting points, we ascribe this deviation to the error in the approximation of $\Delta H_{\mathrm{A}, \mathrm{B},}^{\mathrm{m}}$. In addition, we used the chemical potential of an ideal solution to calculate the lowest melting point; this approach is also likely to produce certain deviations from the actual process, but the effect of such deviation for further prediction is extremely small. Thus, we have developed a feasible method of obtaining the heat of fusion of this type of compound. For metallic glasses, the shear viscosity of the melt at the solidification temperature is fairly constant (approximately a few centipoise), and the melt structures of metallic glass- es are more uniform than those of network glasses, thus, the metallic GFA is more directly related to $T_{1}$. We ignored the temperature coefficient of the viscosity of the metal; in other words, we treated the viscosity as a constant. As shown in Table 15, the computed values of the crystallization points correspond well with the actual glass-forming regions within $x_{B} \pm 3 \mathrm{~mol} \%$. These findings indicate that the viscosity plays a lesser role in the process of metallic glass formation than in the formation of network glasses.

\section{GLASS-FORMING ABILITY AND GLASS- FORMING REGIONS}

The calculated results for a series of physical and chemical parameters of glass are provided to more clearly and directly demonstrate the laws governing glass formation and to reveal their internal consistency. For example, the three-T diagram is an important method of illustrating the dynamics of GFA, which is based on dynamics and crystal chemistry parameters. The diagramming of the glass-forming region based on phase equilibrium has been the most widely used diagram method to date. The glass-forming region diagram is a geometrical figure that is experimentally determined and represents the range of glass formation. 
The design of glass composition is predominantly based on a glass-forming region diagram and phase diagram $[20,102,106]$.

With the development of phase equilibrium theory, more attention has been given to the preparation of the phase diagram. At present, more than 5000 phase diagrams of silicate systems have been reported, most of which are related to glasses. The principle of selecting a glass composition according to the phase diagram (the composition range in which glass is easily formed) is to adopt a multi-component composition as close to the eutectic point or phase boundary in the phase diagram as possible. This method has played an important role in glass design to date.

However, there is some concern regarding phase diagram preparation for several systems that are currently without phase diagrams, especially for the development of new glass systems. It is extremely difficult to prepare a phase diagram. In addition to the necessity for high-temperature and high-pressure conditions and many types of precision instruments, long periods of time are also required to reach thermodynamic equilibrium. In addition, it is logistically difficult to prepare phase diagrams for certain systems such as systems with highly volatile and/or strongly corrosive components. Thus, at present, most phase diagrams are based on common and relatively simple systems. As a result, their practical application is greatly limited. To meet the needs of practical production and research design, the glass-forming abilities and composition ranges of different systems in an experiment are indicated in a constitution diagram, thereby generating a glass-forming region diagram. This method has frequently been heavily relied upon by glass researchers because it is convenient, practical, and unrestricted by time, instruments, and other such resources. Fig. 29 presents the glass forming region diagram of the common $\mathrm{Na}_{2} \mathrm{O}-\mathrm{BO}_{3}-\mathrm{SiO}_{2}$ system [102]. It shows the composition ranges of Pyrex glass and Vycor glass. The composition ranges of phase separation and boron anomalies also appear in this diagram, where the solid curve $\mathrm{A}$ represents the maximum number of abnormalities, and the dashed curve B represents the glass boundary adjacent to poly-phase glass. The boundary of the glass-forming region can be approximately described by a straight line. At present, glass-forming region diagrams are available for several glass systems. In the process of fabricating optical glass, the glass-forming region diagram is often combined with an equivalent refractive index figure, equivalent density figure, equivalent viscosity diagram or equivalent conductance figure, thus becoming an indispensable tool for production and scientific research. Fig. 30 presents the combination of the glass-forming region diagram and the equivalent refractive index figure of $\mathrm{BO}_{3}-\mathrm{La}_{2} \mathrm{O}_{3}$ glass [102] Among binary borate glasses, the $\mathrm{BO}_{3}-\mathrm{La}_{2} \mathrm{O}_{3}$ system has

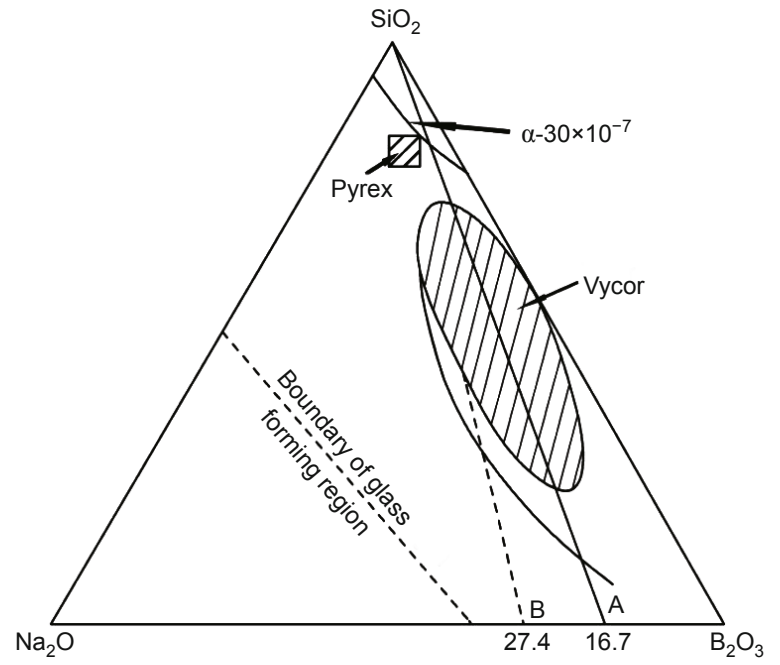

Figure 29 The glass-forming region diagram of the common $\mathrm{Na}_{2} \mathrm{O}-\mathrm{B}_{2} \mathrm{O}_{3}$ $\mathrm{SiO}_{2}$ system (Reproduced with permission from Ref. [102], Copyright 1987, The Publishing House of Ordnance Industry).

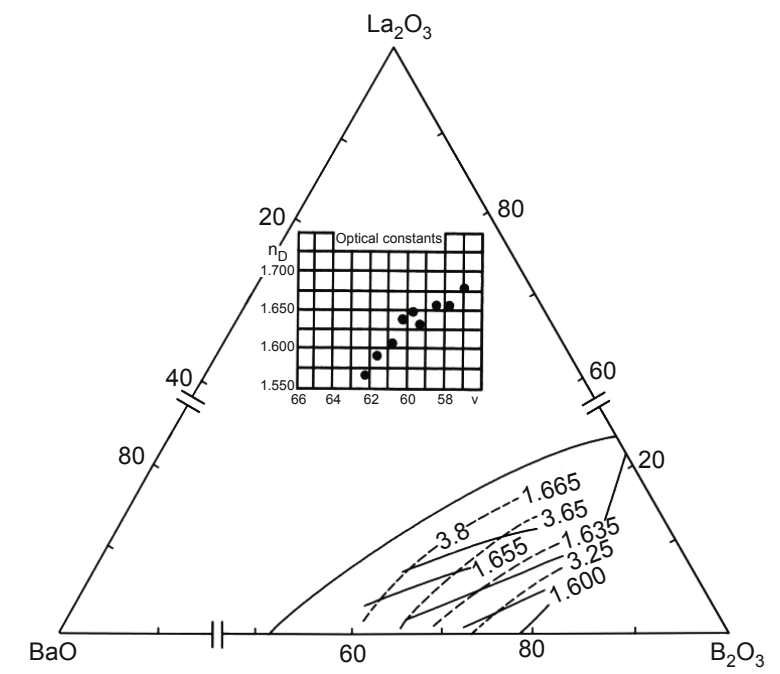

Figure 30 The combination of the glass-forming region diagram and equivalent refractive index figure of $\mathrm{BaO}-\mathrm{La}_{2} \mathrm{O}_{3}-\mathrm{B}_{2} \mathrm{O}_{3}$ glass (Reproduced with permission from Ref. [102], Copyright 1987, The Publishing House of Ordnance Industry).

the highest index of refraction, lower dispersion compared with leadglass and the best chemical stability. However, because of the strong accumulation effect among $\mathrm{La}^{3+}$ ions of high field intensity and large radius, the glass-forming region of the $\mathrm{BO}_{3}-\mathrm{La}_{2} \mathrm{O}_{3}$ system is small, and phase separation occurs easily. Therefore, divalent heavy metal oxides are introduced to enlarge the glass-forming region. The resulting glass-forming region diagram and optical region figure that are presented in Fig. 30 enable comprehensive analysis and allow for the determination of the ideal basic compositions that can satisfy performance requirements 
and possess large glass-forming regions. Thus, such diagrams can be used as standard analysis methods in the search for practical glass composition.

Because the determination of the glass-forming region is achieved through actual melting experiments, it is inevitably constrained by the experimental conditions, such as the volume of the glass, the cooling method used, the atmosphere, and the cooling medium. That is to say, the glass-forming region can be affected by dynamic conditions. Therefore, it is necessary to indicate the glass-forming regions under different conditions in the glass-forming region diagram. Thus, we can gain an understanding of how the cooling rate affects the glass-forming region in a system and determine the effects of dynamic conditions on glass formation. However, in general, the information in these diagrams often refers to the traditional melting-quenching method. The dynamic conditions are often not specified under conventional experimental conditions.

In practical applications, although the number of components of most industrial glasses is greater than five or six, at least two or three of them must be major components. Therefore, the most common phase diagrams or glass-forming region diagrams are often binary or ternary. The effects of other components can be converted into those of the major components, depending on their properties and quantities. There are several types of glass-forming region diagrams. For example, in 1959, Imaoka [142] proposed three types: type A represents a ternary system with one network former $(G)$ and two network modifiers $\left(\mathrm{M}_{1}, \mathrm{M}_{2}\right)$; type $\mathrm{B}$ represents a ternary system with one network former $(\mathrm{G})$, one intermediate $(\mathrm{N})$ and one network modifier (M); type $\mathrm{C}$ represents a ternary system with three network-formers. Fig. 31 illustrates the glass-forming laws of type A and type B, as proposed by Imaoka, where the regions shaded with oblique lines represent composition regions in which glass can form. Imaoka believed that in general, glass cannot form in a type $\mathrm{C}$ system, although
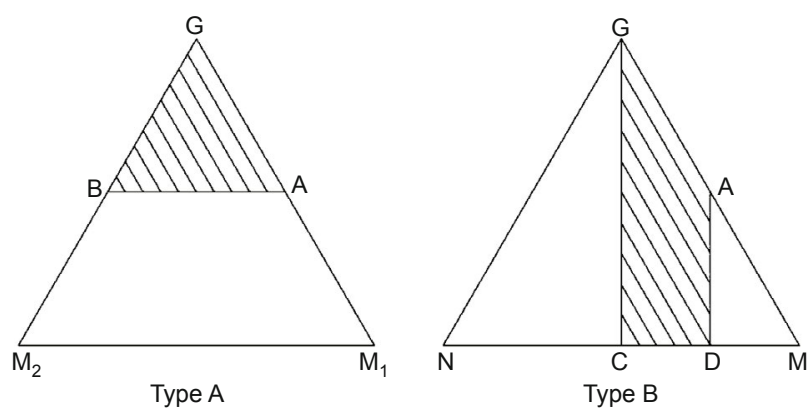

Figure 31 Glass-forming laws of type A and type B diagrams, as proposed by Imaoka. The regions shaded with oblique lines represent composition regions in which glass can form (Reproduced with permission from Ref. [102], Copyright 1964, The Ceramic Society of Japan). glass formation might be possible in a narrow region in the middle of the triangle in some cases. Therefore, type $\mathrm{C}$ is not depicted in the figure.

\section{Glass-forming ability in binary systems}

Glass is considered to be a vitreous, supercooled liquid that is in a thermodynamically metastable state between the molten liquid state and crystalline state. The stable glass regions discussed here are all the relative regions. When seeking glasses with certain desired properties, it is critical to forecast new glass-forming compositions. Therefore, it is of great practical significance to the study of novel types of glasses to learn how to determine the relatively stable glass region of glass in a system. There are various perspectives on the stability of glass formation in a binary system. We have found that the relatively stable region of glass formation in a binary system exists in a region with a tendency toward the formation of layer structures and is near the eutectic point with higher glass-former content [106,122,180-182]. Although compounds with layer structures have high viscosities, compounds with fixed components exist at the peak of the liquid line in the phase diagram, such as $\mathrm{Na}_{2} \mathrm{O} \cdot 2 \mathrm{SiO}_{2}$ and $\mathrm{BaO} \cdot \mathrm{P}_{2} \mathrm{O}_{5}$, and the viscosity in this region is lower than the viscosity near the eutectic point. The eutectic point is the freezing point shared by two structures, and the tendency toward crystallization is at a minimum at this point, as shown in Table 17.

It is difficult to form a stable glass region in a region with higher content of glass formers because both sides of the eutectic point near the layer-structure region are composed of different crystallization and liquid-phase regions. According to the phase diagram, most regions with higher glass-former contents contain immiscible regions. Phase separation occurs more easily when an additional ionic network with high valence and bond strength exists, such as the binary system of silicate or borate. In addition to alkali metal, devitrification in regions with higher glass-former content is typically caused by phase separation.

Based on the different behaviors of the various oxides during glass formation, they can be classified as glass formers (Nf), including $\mathrm{SiO}_{2}, \mathrm{~B}_{2} \mathrm{O}_{3}, \mathrm{P}_{2} \mathrm{O}_{5}, \mathrm{GeO}_{2}$, and $\mathrm{As}_{2} \mathrm{O}_{3}$; intermediate (NI), including $\mathrm{Al}_{2} \mathrm{O}_{3}, \mathrm{ZnO}$, and $\mathrm{TiO}_{2}$; network modifiers (NM). The last category can be further classified into alkali metal and alkaline earth metal ions, namely, $\mathrm{NM}_{1}$ and $\mathrm{NM}_{2}$, respectively. For glasses with $\mathrm{NM}_{1}$, there is no phase separation in high-glass-former regions; moreover, a glass with $\mathrm{NM}_{1}$ typically exhibits a large glass formation region (GFR). By contrast for glasses with $\mathrm{NM}_{2}$, phase separation will occur at high-glass-former contents. A metal oxide with inert electron pairs, such as $\mathrm{Pb}, \mathrm{Bi}$ or $\mathrm{Tl}$, generally exhibits a broad range of glass formation because of the effect of the polarization. Here, we refer to this type 
Table 17 Stable region of glass formation in a binary system and the layer structure composition

\begin{tabular}{|c|c|c|c|c|c|}
\hline \multirow{3}{*}{$\begin{array}{l}\text { Glass system } \\
\text { Silicates }\end{array}$} & \multicolumn{3}{|c|}{ Composition of the layer structure } & \multirow{2}{*}{\multicolumn{2}{|c|}{ Glass former at eutectic point (wt.\%) }} \\
\hline & \multirow{2}{*}{$\frac{\text { Composition }}{\mathrm{Li}_{2} \mathrm{O} \cdot 2 \mathrm{SiO}_{2}}$} & \multicolumn{2}{|c|}{ Glass former (wt.\%) } & & \\
\hline & & $\mathrm{SiO}_{2}$ & 80 & $\mathrm{SiO}_{2}$ & 82 \\
\hline & $\mathrm{Na}_{2} \mathrm{O} \cdot 2 \mathrm{SiO}_{2}$ & $\mathrm{SiO}_{2}$ & 67 & $\mathrm{SiO}_{2}$ & 75 \\
\hline & $\mathrm{K}_{2} \mathrm{O} \cdot 2 \mathrm{SiO}_{2}$ & $\mathrm{SiO}_{2}$ & 56 & $\mathrm{SiO}_{2}$ & 67.5 \\
\hline & $\mathrm{BaO} \cdot 2 \mathrm{SiO}_{2}$ & $\mathrm{SiO}_{2}$ & 44.5 & $\mathrm{SiO}_{2}$ & 53 \\
\hline \multirow[t]{5}{*}{ Borates } & $\mathrm{Li}_{2} \mathrm{O} \cdot 2 \mathrm{~B}_{2} \mathrm{O}_{3}$ & $\mathrm{~B}_{2} \mathrm{O}_{3}$ & 82 & \multicolumn{2}{|c|}{$\mathrm{B}_{2} \mathrm{O}_{3} 72.5$ (eutectic point beyond 8 ) } \\
\hline & $\mathrm{Na}_{2} \mathrm{O} \cdot 2 \mathrm{~B}_{2} \mathrm{O}_{3}$ & $\mathrm{~B}_{2} \mathrm{O}_{3}$ & 69.5 & $\mathrm{~B}_{2} \mathrm{O}_{3}$ & 72 \\
\hline & $\mathrm{K}_{2} \mathrm{O} \cdot 2 \mathrm{~B}_{2} \mathrm{O}_{3}$ & $\mathrm{~B}_{2} \mathrm{O}_{3}$ & 59.5 & $\mathrm{~B}_{2} \mathrm{O}_{3}$ & 62 \\
\hline & $\mathrm{CaO} \cdot 2 \mathrm{~B}_{2} \mathrm{O}_{3}$ & $\mathrm{~B}_{2} \mathrm{O}_{3}$ & 71 & $\mathrm{~B}_{2} \mathrm{O}_{3}$ & $71 \sim 77$ \\
\hline & $\mathrm{BaO} \cdot 2 \mathrm{~B}_{2} \mathrm{O}_{3}$ & $\mathrm{~B}_{2} \mathrm{O}_{3}$ & 50 & $\mathrm{~B}_{2} \mathrm{O}_{3}$ & 58.5 \\
\hline \multirow[t]{2}{*}{ Phosphates } & $\mathrm{CaO} \cdot \mathrm{P}_{2} \mathrm{O}_{5}$ & \multirow{2}{*}{\multicolumn{4}{|c|}{ The liquidus temperature becomes lower with higher content of $\mathrm{P}_{2} \mathrm{O}_{5}$. }} \\
\hline & $\mathrm{MgO} \cdot \mathrm{P}_{2} \mathrm{O}_{5}$ & & & & \\
\hline
\end{tabular}

of glass former as $\mathrm{NM}_{3}$. Glass formers such as $\mathrm{Zr}, \mathrm{Nb}$, $\mathrm{Ta}$, $\mathrm{La}$ and Th, will tend to behave as centers of crystallization because of the valency that accumulates with increasing bond strength, which hinders glass formation. Ions of this type are referred to $\mathrm{NM}_{4}$ in this paper.

A network modifier is also an external network body, as it is outside the network. Network modifiers can play quite different roles in the formation of glass depending on the properties of glass formation, For instance, easily polarized ions with inert electron pairs, such as $\mathrm{Pb}^{2+}$ and $\mathrm{Bi}^{3+}$, can be added in large quantities with the glass remaining transparent, but it becomes difficult to form glass in a region with a higher content of glass formers because of phase separation (such as $\mathrm{PbO}-\mathrm{B}_{2} \mathrm{O}_{3}$ ) or crystallization. By contrast, there are alkali metals without phase separation (stable phase above the liquid line) that exhibit a large broad range of glass formation. The properties of barium are similar to those of alkali metals. Other alkaline earth metals have a phase separation region in the region of high glass-former content. The range of glass formation tends to lie near the middle of a binary system. The range of glass formation shrinks as the alkaline earth ionic radius decreases. High-valence ions, also called accumulated bodies, have a phase separation region in the region of higher glass-former content. Using the melting-quenching method, we measured melts of $95 \mathrm{~B}_{2} \mathrm{O}_{3}-5 \mathrm{R}_{m} \mathrm{O}_{n}$ and $90 \mathrm{~B}_{2} \mathrm{O}_{3}-10 \mathrm{R}_{m} \mathrm{O}_{n}$, which form devitrified and obscure glass. X-ray and polarizing microscopy measurements indicated that these melts do not crystallize, thus indicating that a melt with high $\mathrm{B}_{2} \mathrm{O}_{3}$ content is present in the phase separation region $\left(\mathrm{R}_{m} \mathrm{O}_{n}\right.$ : $\mathrm{In}_{2} \mathrm{O}_{3}, \mathrm{La}_{2} \mathrm{O}_{3}, \mathrm{ThO}_{2}$, $\mathrm{Nb}_{2} \mathrm{O}_{5}, \mathrm{Ta}_{2} \mathrm{O}_{5}, \mathrm{TiO}_{2}, \mathrm{ZrO}_{2}$ ). The region of glass formation is confined to a small range near the eutectic point. Table 18 lists our experimental results for the range of glass formation in a binary system ( $5 \mathrm{~g}$ scale, the limiting range for the formation of transparent glass under typical conditions).

\section{Glass-forming ability in ternary glass systems}

Figs 32 and 33 show glass-forming regions in ternary borate and silicate glass systems. Based on a considerable body of work from our own laboratory and data from the

Table 18 Experiment results for glass-forming regions in the selected binary systems ( $5 \mathrm{~g}$ scale)

\begin{tabular}{|c|c|c|c|c|c|}
\hline Silicates & $\mathrm{SiO}_{2}(\mathrm{~mol} \%)$ & Borates & $\mathrm{B}_{2} \mathrm{O}_{3}(\mathrm{~mol} \%)$ & Phosphates & $\mathrm{P}_{2} \mathrm{O}_{5}(\mathrm{~mol} \%)$ \\
\hline $\mathrm{SiO}_{2}-\mathrm{Li}_{2} \mathrm{O}$ & $100 \sim 60$ & $\mathrm{~B}_{2} \mathrm{O}_{3}-\mathrm{Li}_{2} \mathrm{O}$ & $88 \sim 50$ & $\mathrm{P}_{2} \mathrm{O}_{5}-\mathrm{Li}_{2} \mathrm{O}$ & $100 \sim 62$ \\
\hline $\mathrm{SiO}_{2}-\mathrm{Na}_{2} \mathrm{O}$ & $100 \sim 52$ & $\mathrm{~B}_{2} \mathrm{O}_{3}-\mathrm{Na}_{2} \mathrm{O}$ & $100 \sim 48$ & $\mathrm{P}_{2} \mathrm{O}_{5}-\mathrm{Na}_{2} \mathrm{O}$ & $100 \sim 43$ \\
\hline $\mathrm{SiO}_{2}-\mathrm{K}_{2} \mathrm{O}$ & $100 \sim 48$ & $\mathrm{~B}_{2} \mathrm{O}_{3}-\mathrm{MgO}$ & & $\mathrm{P}_{2} \mathrm{O}_{5}-\mathrm{K}_{2} \mathrm{O}$ & $100 \sim 53.7$ \\
\hline $\mathrm{SiO}_{2}-\mathrm{BaO}$ & $78 \sim 50$ & $\mathrm{~B}_{2} \mathrm{O}_{3}-\mathrm{CaO}$ & $73 \sim 64$ & $\mathrm{P}_{2} \mathrm{O}_{5}-\mathrm{MgO}$ & $100 \sim 43$ \\
\hline $\mathrm{SiO}_{2}-\mathrm{CdO}$ & $63 \sim 50$ & $\mathrm{~B}_{2} \mathrm{O}_{3}-\mathrm{SrO}$ & $73 \sim 55$ & $\mathrm{P}_{2} \mathrm{O}_{5}-\mathrm{CaO}$ & $100 \sim 42.5$ \\
\hline $\mathrm{SiO}_{2}-\mathrm{PbO}$ & $80 \sim 30$ & $\mathrm{~B}_{2} \mathrm{O}_{3}-\mathrm{ZnO}$ & $42 \sim 40$ & $\mathrm{P}_{2} \mathrm{O}_{5}-\mathrm{SrO}$ & $100 \sim 40$ \\
\hline \multirow[t]{4}{*}{$\mathrm{SiO}_{2}-\mathrm{Bi}_{2} \mathrm{O}_{3}$} & $70 \sim 50$ & $\mathrm{~B}_{2} \mathrm{O}_{3}-\mathrm{CdO}$ & $65 \sim 45$ & $\mathrm{P}_{2} \mathrm{O}_{5}-\mathrm{BaO}$ & $100 \sim 43$ \\
\hline & & $\mathrm{B}_{2} \mathrm{O}_{3}-\mathrm{PbO}$ & $77 \sim 25$ & $\mathrm{P}_{2} \mathrm{O}_{5}-\mathrm{PbO}$ & $100 \sim 55$ \\
\hline & & $\mathrm{B}_{2} \mathrm{O}_{3}-\mathrm{Bi}_{2} \mathrm{O}_{3}$ & $67 \sim 50$ & $\mathrm{P}_{2} \mathrm{O}_{5}-\mathrm{Bi}_{2} \mathrm{O}_{3}$ & $100 \sim 70$ \\
\hline & & $\mathrm{B}_{2} \mathrm{O}_{3}-\mathrm{La}_{2} \mathrm{O}_{3}$ & $83 \sim 81$ & $\mathrm{P}_{2} \mathrm{O}_{5}-\mathrm{WO}_{3}$ & $100 \sim 78$ \\
\hline
\end{tabular}



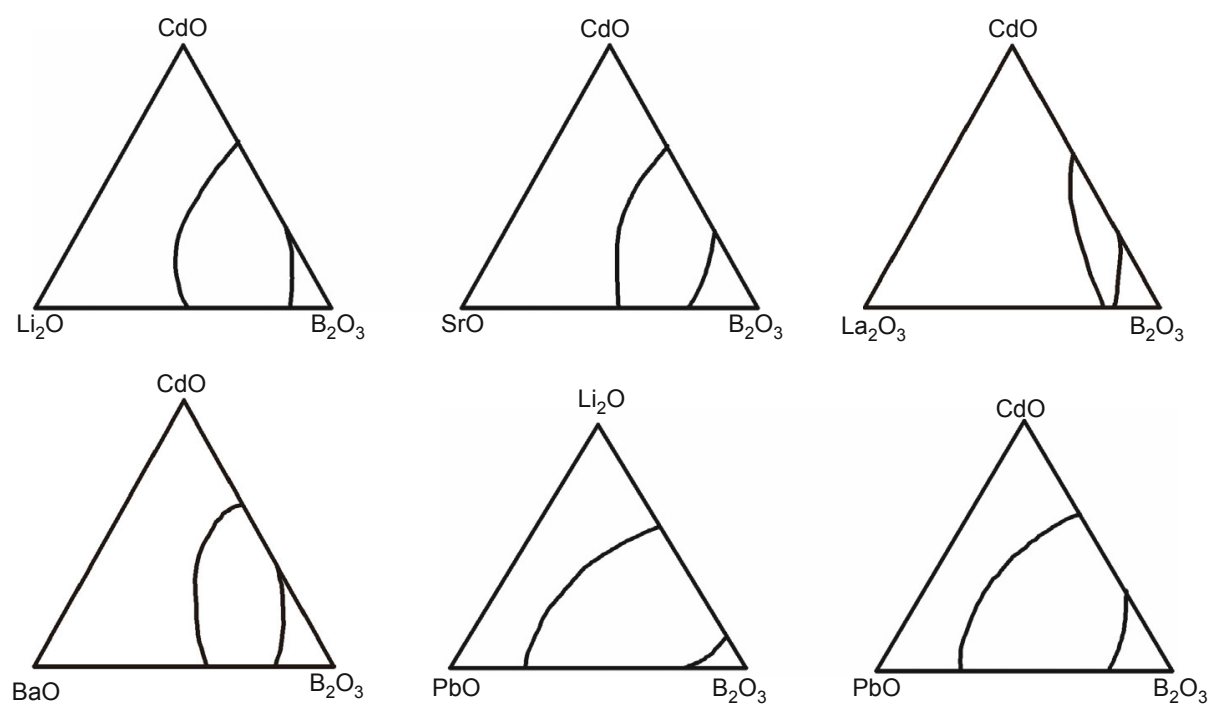

Figure 32 Glass-forming regions in ternary borate glass systems.
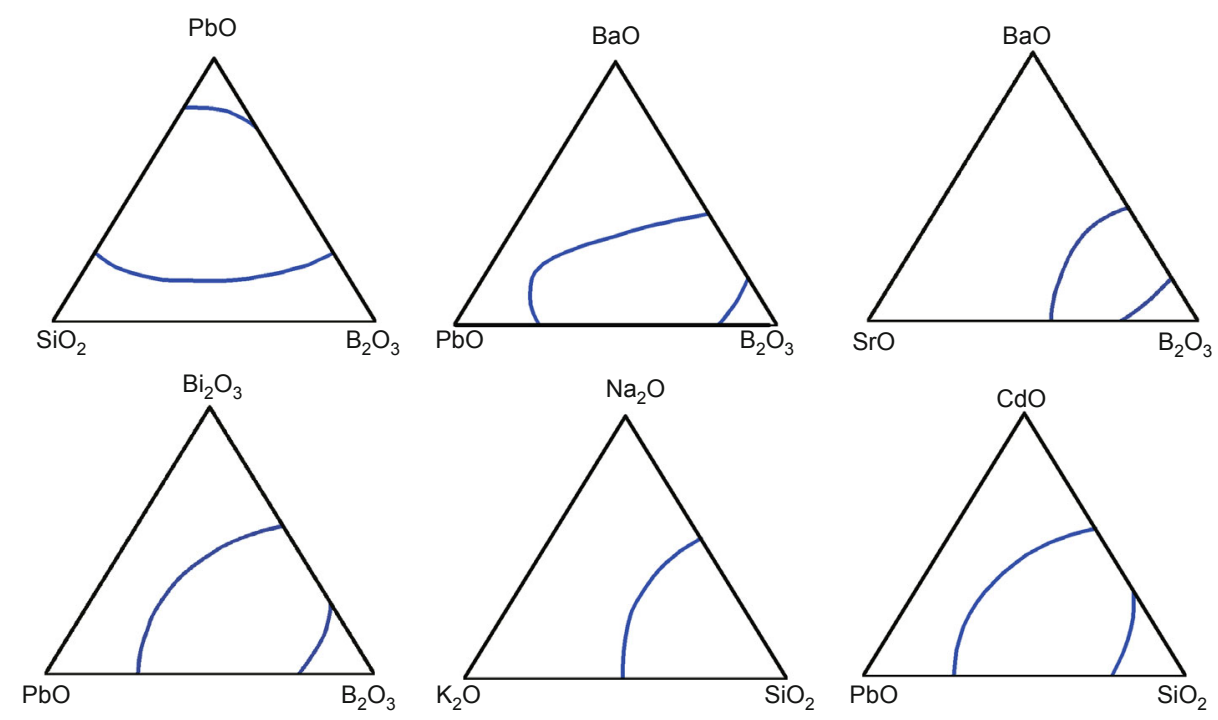

Figure 33 Glass-forming regions in ternary glass systems.

literatures, we have found that the glass-forming region in a ternary system can be treated as the sum of the regions in the corresponding binary systems. However, this sum is not merely a simple sum. The following qualifications must be added: (i) A projecting portion appear in the middle of the glass-forming region in a ternary system because of the formation of a new eutectic region. (ii) This projecting portion depends on the position of the eutectic point. The position of the eutectic point can be estimated from the melting temperature of the crystalline phase. The liquidus equations can be deduced from thermodynamics, Equations (5-8) and (11). The distance between the eutectic point and the side corresponding to the lowmelting-point component decreases as the difference between $T_{\mathrm{A}}$ and $T_{\mathrm{B}}$ increases, as shown in Table 19. Therefore, the glass-forming region on the borate side possesses the more projecting portion in the borosilicate ternary system. In the glass-forming region of a ternary system with only one glass former, the projecting portion is located on the side corresponding to the oxide with the lowest melting point. (iii) An intermediate can cause a crystallization region with a high content of network modifiers to become a glass-forming region instead, thereby expanding the range of glass formation. Generally, the projecting semicircular 
Table 19 Devitrification properties of binary glass

\begin{tabular}{|c|c|c|c|c|c|}
\hline Silicates & $T_{\mathrm{c}}\left({ }^{\circ} \mathrm{C}\right)$ & Phase separation & Borates & $T_{\mathrm{c}}\left({ }^{\circ} \mathrm{C}\right)$ & Phase separation \\
\hline $\mathrm{SiO}_{2}-\mathrm{Li}_{2} \mathrm{O}$ & 1000 & Metastable & $\mathrm{B}_{2} \mathrm{O}_{3}-\mathrm{Li}_{2} \mathrm{O}$ & 600 & Metastable \\
\hline $\mathrm{SiO}_{2}-\mathrm{Na}_{2} \mathrm{O}$ & 850 & Metastable & $\mathrm{B}_{2} \mathrm{O}_{3}-\mathrm{Na}_{2} \mathrm{O}$ & 590 & Metastable \\
\hline $\mathrm{SiO}_{2}-\mathrm{K}_{2} \mathrm{O}$ & 745 & Metastable & $\mathrm{B}_{2} \mathrm{O}_{3}-\mathrm{K}_{2} \mathrm{O}$ & 590 & Metastable \\
\hline $\mathrm{SiO}_{2}-\mathrm{MgO}$ & 2200 & Stable & $\mathrm{B}_{2} \mathrm{O}_{3}-\mathrm{Rb}_{2} \mathrm{O}$ & 590 & Metastable \\
\hline $\mathrm{SiO}_{2}-\mathrm{CaO}$ & 2100 & Stable & $\mathrm{B}_{2} \mathrm{O}_{3}-\mathrm{Cs}_{2} \mathrm{O}$ & 570 & Metastable \\
\hline $\mathrm{SiO}_{2}-\mathrm{SrO}$ & 1920 & Stable & $\mathrm{B}_{2} \mathrm{O}_{3}-\mathrm{MgO}$ & $>1500$ & Stable \\
\hline $\mathrm{SiO}_{2}-\mathrm{BaO}$ & 1460 & Metastable & $\mathrm{B}_{2} \mathrm{O}_{3}-\mathrm{CaO}$ & $>1500$ & Stable \\
\hline $\mathrm{SiO}_{2}-\mathrm{B}_{2} \mathrm{O}_{3}$ & 520 & Metastable & $\mathrm{B}_{2} \mathrm{O}_{3}-\mathrm{SrO}$ & 1100 & Stable \\
\hline $\mathrm{SiO}_{2}-\mathrm{PbO}$ & 775 & Stable & $\mathrm{B}_{2} \mathrm{O}_{3}-\mathrm{BaO}$ & 1150 & Stable \\
\hline $\mathrm{SiO}_{2}-\mathrm{Al}_{2} \mathrm{O}_{3}$ & 1650 & Metastable & $\mathrm{B}_{2} \mathrm{O}_{3}-\mathrm{PbO}$ & 775 & Stable \\
\hline $\mathrm{SiO}_{2}-\mathrm{La}_{2} \mathrm{O}_{3}$ & 2060 & Stable & $\mathrm{B}_{2} \mathrm{O}_{3}-\mathrm{CdO}$ & $1120 \pm 20$ & Stable \\
\hline $\mathrm{SiO}_{2}-\mathrm{Ti}_{2} \mathrm{O}_{2}$ & 2100 & Stable & & & \\
\hline $\mathrm{SiO}_{2}-\mathrm{ZrO}_{2}$ & 2450 & Stable & & & \\
\hline
\end{tabular}

shape appears on the side corresponding to high network modifier content when an intermediate is present in the glass-forming region in a ternary system. (iv) For Nf-NI and $\mathrm{Nf}-\mathrm{NM}_{4}$ systems that cannot form glass in the corresponding binary systems, a less stable, transparent glass region may be formed between them because of the formation of a eutectic region in the ternary system.

The range of glass formation in a phosphate glass is unique because no phase separation occurs in the region with high $\mathrm{P}_{2} \mathrm{O}_{5}$ content and because a flat region with only slight temperature variation appears in the region with high metaphosphate content in the phosphate binary system, meaning that the glass-forming region extends up to than $50 \mathrm{~mol} \% \mathrm{P}_{2} \mathrm{O}_{5}$ or slightly lower (5 g scale). Because $\mathrm{P}_{2} \mathrm{O}_{5}$ with double-bonded oxygen causes the intermediate to enter the network, the glass-forming region in the phosphate binary system changes only slightly, as shown in Table 19, and the region in the ternary system is similar to that of Nf-NM $-\mathrm{NM}_{1}{ }^{\prime}$.

Based on the above analysis, we identified 21 types of glass-forming regions in ternary glass systems under natural cooling, which can be summarized as follows: (i) 15 types of ternary systems with only one glass former, (ii) 5 types of ternary systems with two glass formers, and (iii) one type of ternary systems with three glass formers.

\section{Ternary systems with only one glass former}

(A1) Nf- $\mathrm{NM}_{1}-\mathrm{NM}_{1}{ }^{\prime}$ : The phase diagram illustrates that no phase separation occurs in the region of high glass-former content, regardless of whether $\mathrm{SiO}_{2}, \mathrm{~B}_{2} \mathrm{O}_{3}$ or $\mathrm{P}_{2} \mathrm{O}_{5}$ is used; this range is shown in the Fig. $34 \mathrm{a}$ and extends beyond $50 \%$ of the midline. A greater electric field strength of $\mathrm{NM}_{1}(Z$ is the valence and $a$ is the distance between the anion and cation) results in a narrower glass-forming range. The slight projecting portion in the middle of the figure is caused by the addition of $\mathrm{NM}_{1}{ }^{\prime}$ to $\mathrm{Nf}-\mathrm{NM}_{1}$, which lowers the melting point. The addition of $\mathrm{NM}_{1}$ to Nf- $\mathrm{NM}_{1}$ ' decreases the melting point and the eutectic point from near the middle of the figure and thus leads to certain of the projecting portion.

(A2) Nf- $\mathrm{NM}_{1}-\mathrm{NM}_{2}$ : Phase separation readily occurs in the region with high glass-former content in $\mathrm{Nf}-\mathrm{NM}_{2}$, and transparent glass cannot be obtained. Phase separation also occurs in Nf-NM $M_{1}$. Therefore, it is difficult to obtain transparent glass in the region with high $\mathrm{SiO}_{2}$ content in the ternary system. The projecting portion is located on the side of $\mathrm{NM}_{1}$ side, as shown in Fig. $34 \mathrm{~b}$.

(A3) Nf- $\mathrm{NM}_{2}-\mathrm{NM}_{2}^{\prime}$ : Phase separation or crystallization caused by phase separation, occurs in the region of high glass-former content. The glass-forming range changes with the variation in the electric field strengths of $\mathrm{NM}_{2}$ and $\mathrm{NM}_{2}{ }^{\prime}$ in the region with low glass-former content. The GFA in the case of $\mathrm{NM}_{2}$ such as $\mathrm{BaO}$, is quite different. $\mathrm{BaO}$ has low electric field strength, and its properties are similar to those of alkali metals. However, $\mathrm{MgO}$ has high electric field strength, and its properties are similar to those of accumulated bodies. Glass cannot form on the $\mathrm{MgO}$ side. Typical Nf- $\mathrm{NM}_{2}-\mathrm{NM}_{2}^{\prime}$ glass systems (see Fig. 34c) include $\mathrm{BaO}$ $\mathrm{CaO}-\mathrm{B}_{2} \mathrm{O}_{3}$ and $\mathrm{BaO}-\mathrm{SrO}-\mathrm{B}_{2} \mathrm{O}_{3}$.

(A4) $\mathrm{Nf}-\mathrm{NM}_{1}-\mathrm{NM}_{3}$ : Oxides with inert electron pairs lead to phase separation in the region with high glass-former contentand glass cannot be obtained. However, on the side corresponding to low glass-former content, the $\mathrm{NM}_{3}$ content at which glass can be obtained can far exceed 50\%, as shown in Fig. 34d. Typical glass systems containing these oxides include the $\mathrm{K}_{2} \mathrm{O}-\mathrm{PbO}-\mathrm{SiO}_{2}$ and $\mathrm{Na}_{2} \mathrm{O}-\mathrm{PbO}-\mathrm{B}_{2} \mathrm{O}_{3}$ systems.

(A5) $\mathrm{Nf}-\mathrm{NM}_{2}-\mathrm{NM}_{3}$ : Phase separation occurs in the region with high glass-former content. The glass-forming 

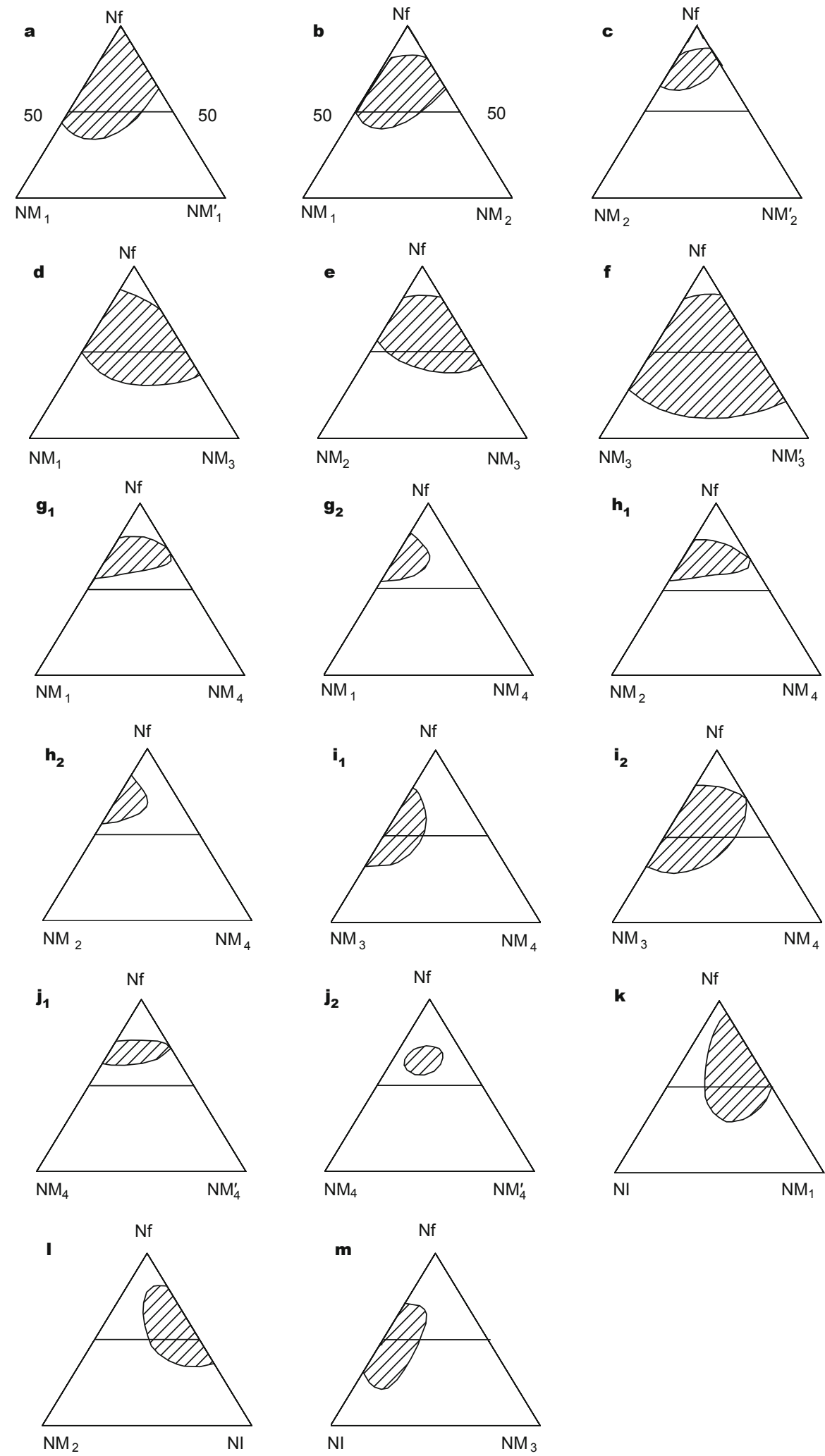

Figure 34 The glass-forming regions in ternary systems with one glass former. 
range is depicted in Fig. 34e. The $\mathrm{B}_{2} \mathrm{O}_{3}-\mathrm{BaO}-\mathrm{PbO}$ optical glass system belongs to this category.

(A6) $\mathrm{Nf}-\mathrm{NM}_{3}-\mathrm{NM}_{3}{ }^{\prime}$ : This system has the broadest range of glass formation. Glass can form when $\mathrm{NM}_{3}$ and $\mathrm{NM}_{3}{ }^{\prime}$ are added in quantities of up to $90 \mathrm{~mol} \%$, as shown in Fig. 34f. A typical example is the $\mathrm{PbO}-\mathrm{Bi}_{2} \mathrm{O}_{3}-\mathrm{B}_{2} \mathrm{O}_{3}$ system.

(A7) $\mathrm{Nf}-\mathrm{NM}_{1}-\mathrm{NM}_{4}$ : In a binary system with accumulated bodies, glass formation is often difficult or occurs only within a narrow range near the eutectic point. The glass-forming region in the ternary system is presented in Fig. 34g.

(A8) $\mathrm{Nf}-\mathrm{NM}_{2}-\mathrm{NM}_{4}$ : This type of glass system is widely studied among optical glass systems, such as the $\mathrm{La}_{2} \mathrm{O}_{3}$ $\mathrm{BaO}-\mathrm{B}_{2} \mathrm{O}_{3}$, ThO-BaO- $\mathrm{B}_{2} \mathrm{O}_{3}, \mathrm{La}_{2} \mathrm{O}_{3}-\mathrm{SrO}-\mathrm{B}_{2} \mathrm{O}_{3}$ and $\mathrm{BaO}-$ $\mathrm{Nb}_{2} \mathrm{O}_{5}-\mathrm{B}_{2} \mathrm{O}_{3}$ systems. Because of the low melting point of divalent metal borates, a more clearly projecting region appears on the side corresponding to $\mathrm{Nf}_{-} \mathrm{NM}_{2}$, as shown in Fig. 34h.

(A9) $\mathrm{Nf}-\mathrm{NM}_{3}-\mathrm{NM}_{4}$ : Glasses of this type include the $\mathrm{LaF}$ and TaF models of optical glass systems, such as $\mathrm{La}_{2} \mathrm{O}_{3}$ $\mathrm{PbO}-\mathrm{B}_{2} \mathrm{O}_{3}$ and $\mathrm{Ta}_{2} \mathrm{O}_{5}-\mathrm{PbO}-\mathrm{B}_{2} \mathrm{O}_{3}$, as shown in Fig. $34 \mathrm{i}$.

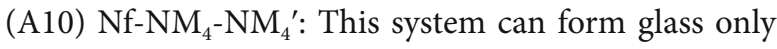
within a narrow region. Even if two $\mathrm{Nf}-\mathrm{NM}_{4}$ compounds cannot form glass in the original binary system, glass may yet be formed in the intermediate region because of the formation of a new eutectic point, as shown in Fig. 34j.

(A11) Nf-NM $-\mathrm{NI}$ : The intermediates and glass formers are melted under typical conditions, and glass cannot be obtained (they can form glass under an oxyhydrogen flame, as in the case of $\mathrm{TiO}_{2}-\mathrm{SiO}_{2}$ and $\mathrm{Al}_{2} \mathrm{O}_{3}-\mathrm{SiO}_{2}$ ). Therefore, no glass-forming region exists in the Nf-NI region.
On the side corresponding to a high content of alkali metal ions in the Nf- $\mathrm{NM}_{1}$ region, the addition of the intermediate can reconnect the broken network, thereby forming a glass-forming region that projects dropwise, as shown in Fig. 34k.

(A12) $\mathrm{Nf}-\mathrm{NM}_{2}-\mathrm{NI}$ : The property of $\mathrm{NM}_{2}$ will cause the number of intermediates entering the network to decrease with increasing electric field strength. The glass-forming range shifts from a range similar to that of $\mathrm{Nf}-\mathrm{NM}_{1}-\mathrm{NI}$ (where $\mathrm{NM}_{2}$ is $\mathrm{BaO}$ ) to a range similar to that of $\mathrm{Nf}_{-} \mathrm{NM}_{4}^{-}$ $\mathrm{NI}$ (where $\mathrm{NM}_{2}$ is $\mathrm{MgO}$ ). The eutectic region typically appears in the middle of the NI-NM $\mathrm{N}_{2}$ region and may form a narrow glass-forming region, as shown in Fig. 341.

(A13) $\mathrm{Nf}-\mathrm{NM}_{3}-\mathrm{NI}$ : The intermediate NI in this system can still enter the network and cause the glass-forming region to expand, as shown in Fig. 34m.

(A14) Nf-NM $\mathrm{N}_{4}$-NI: As discussed above, because the bond strength of $\mathrm{NM}_{4}$ is high, and NI ions cannot capture oxygen to reduce the coordination number, the role of $\mathrm{NI}$ is similar to that of $\mathrm{NM}_{4}$ and the glass-forming region is also similar to that of Nf- $\mathrm{NM}_{4}-\mathrm{NM}_{4}{ }^{\prime}$, as shown in Fig. 34j.

(A15) Nf -NI-NI': NI and Nf melt under typical conditions, and glass cannot be obtained. The role of NI is similar to that of $\mathrm{NM}_{4}$, and the glass-forming region is also the same as that of $\mathrm{Nf}-\mathrm{NM}_{4}-\mathrm{NM}_{4}{ }^{\prime}$, as shown in Fig. 34j.

\section{Ternary systems with two glass formers}

(B1) Nf-Nf'-NM $\mathrm{N}_{1}$ : There are two cases in the Nf-Nf' region. In the first case, the two types of glass are immiscible. In the second case, they are miscible to form a homogeneous body (visible to the naked eye). However, two types of
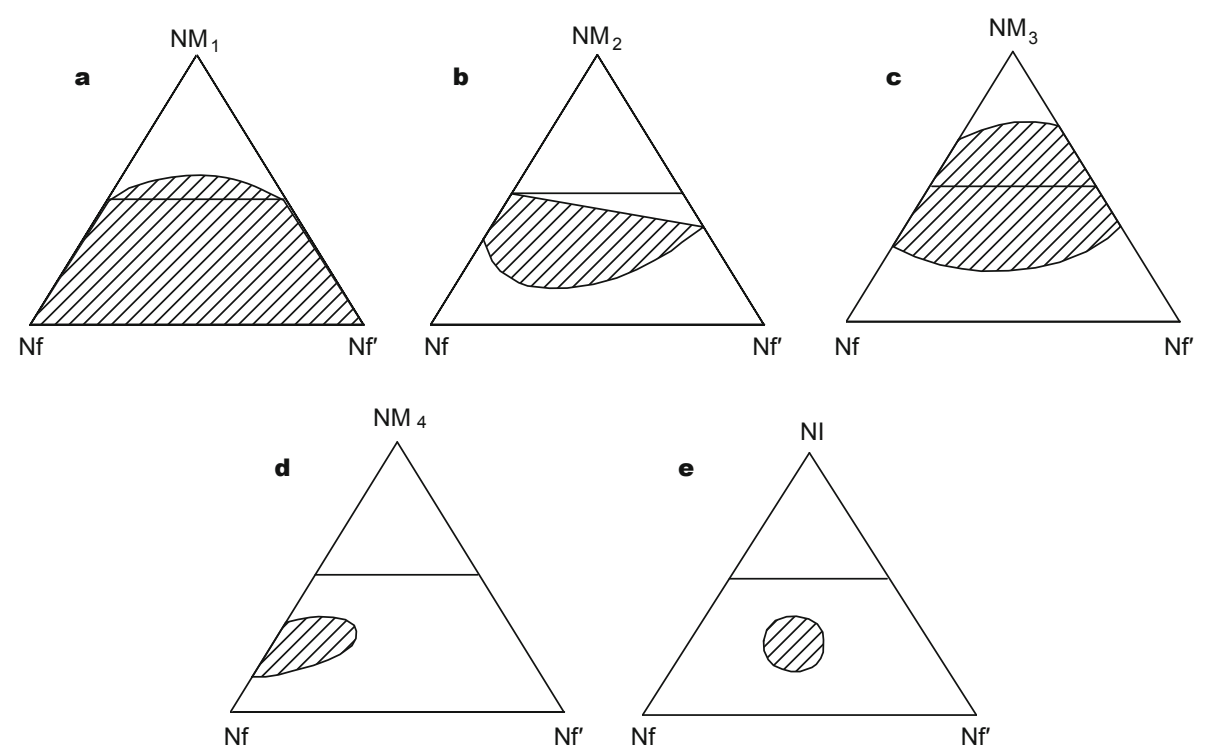

Figure 35 The glass-forming regions in ternary systems with two glass formers. 
glass formers initially have a strong tendency toward phase separation, as in the $\mathrm{B}_{2} \mathrm{O}_{3}-\mathrm{SiO}_{2}$ and $\mathrm{P}_{2} \mathrm{O}_{5}-\mathrm{SiO}_{2}$ systems. Although the phase separation region is still regarded as the glassy state in theory, we consider only the transparent glass region in our definition of the glass-forming region, as shown in Fig. 35a.

(B2) Nf-Nf'- $\mathrm{NM}_{2}$ : There are two liquids in the region of high glass-former content. A transparent glass can be formed onlyin the middle region. After careful analysis, the glass-forming region is found to occupy a large area toward the side corresponding to low-melting-point glass, and it is depicted in Fig. 35b.

(B3) Nf-Nf'-NM $\mathrm{N}_{3}$ : Phase separation occurs in the region of high glass-former content. Glass can still form when $\mathrm{NM}_{3}$ content is greater than 80 mol.\%, as shown in Fig. 35c.

(B4) Nf-Nf'- $\mathrm{NM}_{4}$ : The glass-forming region is typically relatively narrow when there is a high level of accumulated bodies. Glass cannot be formed on the silicate side, as shown in Fig. 35d.

(B5) Nf-Nf'-NI: The intermediates lack oxygen and have low coordination numbers. Their role is similar to that of $\mathrm{NM}_{4}$. However, the bond strength of $\mathrm{ZnO}$ is relatively low, and its role is similar to that of $\mathrm{NM}_{2}$. If glass cannot form in the NI-Nf and NI-Nf' regions, a narrow glass-forming region may still appear in the lower part of the diagram as shown in Fig. 35e.

\section{Ternary systems with three glass formers}

There is little research regarding the Nf-Nf'-Nf" glass system. The only phase diagram that is available for comparison is the $\mathrm{B}_{2} \mathrm{O}_{3}-\mathrm{SiO}_{2}-\mathrm{P}_{2} \mathrm{O}_{5}$ system of Englert and Hummel $[183,184]$. These authors suggested that non-crystallization regions lie in the region of $\mathrm{P}_{2} \mathrm{O}_{5}-\mathrm{SiO}_{2}$ and in the region of high $\mathrm{SiO}_{2}$ content, as shown in Fig. 36. No phase separation region is indicated in their simple ternary system. These non-crystallization regions exist but may not be entirely transparent glass regions, which have not yet been further

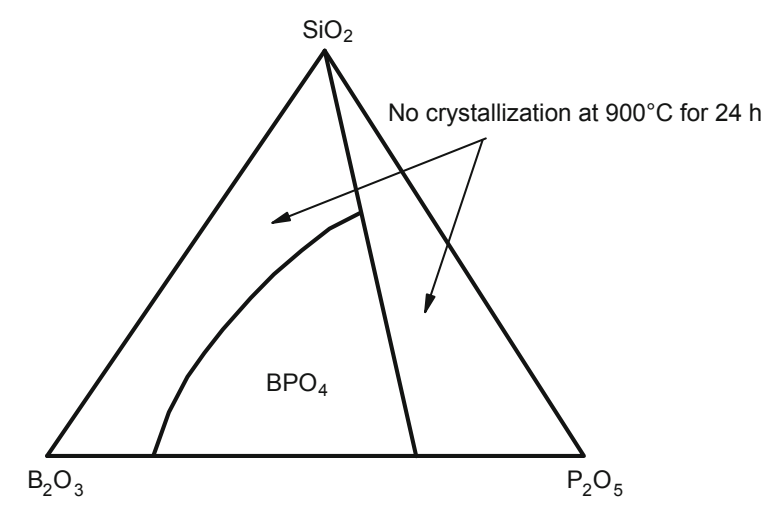

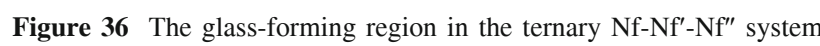
with three glass formers. described.

\section{CONCLUDING REMARKS AND PERSPECTIVES}

In summary, this paper presents a comprehensive review of glass formation and the glass-forming region that emphasizes the key role of the melt viscosity and cooling rate in understanding the structural characteristics and physical properties of glass, glass formation and glass transitions. Based on the kinetic formula, we conclude that the GFA is proportional to both the viscosity and cooling rate. The factors that predominantly determine the viscosity include the chemical bonds, structure, and eutectic point of the glass. The findings of this study can be summarized as follows: (1) Glass is a vitreous, supercooled liquid that exists in a thermodynamically metastable state between a molten liquid state and crystalline state. From the perspective of thermodynamic phase equilibrium, no substance can persist in a glassy state because glass is a metastable state. However, from a dynamics standpoint, any material can exist in a glassy state as long as the cooling rate and melt viscosity are sufficiently high to prevent crystallization. (2) We propose a viscosity/cooling-rate approach to the prediction of glass formation. The ability to form glass, which is deduced using this viscosity/cooling-rate approach, is proportional to both the cooling rate and viscosity. The cooling rate is predominantly determined by the fabrication techniques that are used, whereas the viscosity depends on the nature of the materials, which is in turn determined by the following factors: (i) chemical bonds. Metallic and ionic bonds exhibit large liquidities and small viscosities. Ionic and covalent bonds may form network structures and thus have large viscosities. The viscosities of alloys composed of metals and metalloids with covalent bonds are much greater than those based on metallic bonds. (ii) The linkage of the structure. The viscosities of materials decrease with their structural dimensionality in the following order: 3-dimensional structures, 2-dimensional structures, 1-dimensional structures, and isolated points. (iii) The eutectic point. The viscosity of a substance with several intertwined structures at the eutectic point is greater than that of each separate structure. (3) The eutectic point plays an important role in the formation of glasses. The glass-forming regions of a system are most likely to be situated in the eutectic region, where the glass-former content is high. Almost all glass systems follow this rule, from silicate to borate, boron silicate, metaphosphate, germinates and tellurites as well as non-oxide glasses such as fluorides, halogenides, chalcogenides, and even metallic glasses. The reason for this phenomenon is that the viscosity of the melt increases rapidly with decreasing temperature at the eutectic point, where it is difficult to achieve the nucleation and growth of particles in the melt; this situation is conducive to the ready formation of glass. 
We find that (i) the eutectic temperature and composition for the formation of glasses can be quantitatively predicted and calculated based on the Gibbs free energy and thermodynamics methods; (ii) a eutectic point can be treated as a "quasi-compound", and its thermodynamic parameters, such as heat of fusion and melting temperature, can be used to calculate a new eutectic point, allowing the glass-forming region to be predicted using a multiple-addition method; (iii) a tangential condition calculated based on analytical geometry can simplify the calculations required to deduce the phase diagram; (iv) the effect on the immiscibility range of adding a third component to a binary immiscible system can be calculated quantitatively, in agreement with the experimental results represented in the phase diagram; (v) in halide systems, all eutectic points are located at the positions where the ratios of the network former to the network modifier are 3:1, 2:1 and 1:1. For binary fluoride glass systems with $\mathrm{A}_{1} \mathrm{~F}_{3}$ or $\mathrm{ZrF}_{4}$, the eutectic point can be treated as a "quasi-compound", and the glass-forming region can be predicted using the multiple-addition method. Phase separation has a strong influence on glass properties, especially the GFA. The phase-separating region of a glass is located in a high-glass-former region and thus directly determines the range of glass formation. (4) An important method of presenting the GFA and glass-forming region is to draw the corresponding phase diagram. The calculated results for a series of physical and chemical parameters of various glass systems are provided to directly show the glass-forming regions and reveal the internal consistency of the laws governing glass formation, thus demonstrating that these laws can play a guiding role in theoretical research and practical application.

\section{Received 17 March 2015; accepted 27 April 2015;} published online 22 May 2015

1 Rao KJ. Structural Chemistry of Glasses. New York: Elsevier, 2002

2 Sakka S. Foundation and Application of Glass Science. Tokyo: Uchida Rokakuho Publishing Co.,1997

3 Shackelford JF, Doremus RH. Ceramic and Glass Materials: Structure, Properties and Processing. New York: Springer, 2008

4 Yamane M, Asahara Y, Asahara Y. Glasses for Photonics. London: Cambridge University Press, 2000

5 Jha A, Richards B, Jose G, et al. Rare-earth ion doped $\mathrm{TeO}_{2}$ and $\mathrm{GeO}_{2}$ glasses as laser materials. Prog Mater Sci, 2012, 57: 1426-1491

6 Wang WH, Dong C, Shek CH. Bulk metallic glasses. Mater Sci Eng R, 2004, 44: 45-89

7 Jiang ZH, Hu LL. Phase diagram structure model of glass. Sci China E, 1997, 40: 1-11

8 Zhang QY, Li T, Jiang ZH, Ji XH. 980-nm laser-diode-excited intense blue-upconversion in $\mathrm{Tm}^{3+} / \mathrm{Yb}^{3+}$-codoped gallate-bismuthlead glasses. Appl Phys Lett, 2005, 87: 171911

9 Tanabe S, Fujiwara T, Yano T, et al. Glass and ceramic materials for photonics: preface. J Ceram Soc Jpn, 2008, 116: i

10 Zhang QY, Yang ZM, Yang GF, Jiang ZH. Enhanced blue-green-red up-conversion and 1.3- $\mu \mathrm{m}$ emission of $\mathrm{Pr}^{3+} / \mathrm{Yb}^{3+}$-codoped oxyha- lide tellurite glasses with $\mathrm{PbCl}_{2}$ doping. J Phys Chem Solids, 2005, 66: 1281-1286

11 Zhang QY, Li T, Shi DM, Jiang ZH. Effects of $\mathrm{PbF}_{2}$ doping on structure and spectroscopic properties of $\mathrm{Ga}_{2} \mathrm{O}_{3}-\mathrm{GeO}_{2}-\mathrm{Bi}_{2} \mathrm{O}_{3}-\mathrm{PbO}$ glasses doped with rare-earths. J Appl Phys, 2006, 99: 033510

12 Stanworth JE. Physical Properties of Glass. Oxford: Clarendon Press, 1950

13 Muller G. Amorphisation processes in silicon, Curr Opin Solid State Mater Sci, 1998, 3: 364-370

14 Wakaki M. Optical Materials and Applications. Boca Raton: CRC press, 2013

15 Gan FX. Optical Glass. Beijing: Science Press, 1982 (In Chinese)

16 Digonnet MJF. Rare-earth-doped Fiber Lasers and Amplifiers. New York: Marcel Dekker, 2001

17 Sakka S, MacKenzie JD. Relation between apparent glass transition temperature and liquids temperature for inorganic glasses. J NonCryst Solids, 1971, 6: 145-162

18 Jiang ZH, Liu YH, Dai SX. New Functional Glasses. Beijing: Chemical Industry Press, 2008 (In Chinese)

19 Ye H, Hou CL. Optical Materials and Optical Components Fabrication Process. Hangzhou: Zhejiang University Press, 2014 (In Chinese)

20 Jiang ZH, Zhang QY. The structure of glass: a phase equilibrium diagram approach. Prog Mater Sci, 2014, 61: 144-215

21 Deng ZB. Introduction to Non-Crystalline Materials. Beijing: Science Press, 1987 (In Chinese)

22 Adam JL. Lanthanides in non-oxide glasses. Chem Rev, 2002, 102: 2461-2476

23 Karpukhina N, Hill RG, Law RV. Crystallisation in oxide glasses. Chem Soc Rev, 2014, 43: 2174-2186

24 Inayat A, Reinhardt B, Uhlig H, Einicke WD, Enke D. Silica monoliths with hierarchical porosity obtained from porous glasses. Chem Soc Rev, 2013, 42: 3753-3764

25 Qiu JR, Jiang XW, Zhu CS, et al. Manipulation of gold nanoparticles inside transparent materials. Angew Chem Int Ed, 2004, 43: 2230-2234

26 Zheng FQ. Dynamic and steady-state viscosity of the metallic glass $\mathrm{Ni}_{30} \mathrm{Zr}_{70}$. Acta Phys Sinica, 1991, 40: 262-268

27 Wang WK, Xu YF, Huang XM. Glass formation of $\mathrm{Pd}_{40} \mathrm{Ni}_{40} \mathrm{P}_{20}$ metallic glass. Sci China A, 1992, 12: 1305-1310 (in Chinese)

28 Tomozawa M, Doremus RH. Glass. New York: Academic Press, 1977

29 Sestak J, Mares JJ, Hubik P. Glassy, Amorphous and Nano-Crystalline Materials: Thermal Physics, Analysis, Structure and Properties. New York: Springer, 2011

30 Goldschmidt VM. Geochemische Verteilungsgesetze der Elemente, Part V, Isomorphie und Polymorphie der Sesquioxyde. Oslo: Die Lanthaniden-Kontraktion und ihre Konsequenzen, 1925

31 Fen D, Shi CX, Liu ZG. Introduction to Materials Science: an Integrated Approach. Beijing: Chemical Industry Press, 2002 (In Chinese)

32 Vogel W. Glass Chemistry. Berlin: Springer-Verlag, 1992

33 Greaves GN. X-ray Absorption Spectroscopy. In: Uhlmann DH, Kreidl NJ (eds.). Glass Science and Technology. New York: Academic Press, 1990, 1-76

34 Smekal AG. The structure of glass. J Soc Glass Technol, 1951, 35: $411-420$

35 Zachariasen WH. The atomic arrangement in glass. J Am ChemSoc, 1932, 54: 3841-3851

36 Zarzycki J. Glasses and Amorphous Materials. In: Cahn RW, Haasen P, Kramer EJ (eds.). Materials Science and Technology: a Comprehensive Treatment. Weinheim: VCH, 1991

37 Winter A. The glass formers and the periodic system of elements. Verres Refract, 1955, 9: 147-156

38 Stanworth JE. The structure of glass. J Soc Glass Technol, 1946, 30: 
$54-64$

39 Stanworth JE. On the structure of glass. J Soc Glass Technol, 1948, 32: 154-172

40 Stanworth JE. The ionic structure of glass. J Soc Glass Technol, 1948, 32: 366-372

41 Stanworth JE. Tellurite glasses. J Soc Glass Technol, 1952, 36: 217241

42 Stanworth JE. Glass formation from melts of nonmetallic compounds of the type $\mathrm{A}_{x} \mathrm{~B}_{y}$. Phys Chem Glasses, 1979, 20: 116-118

43 Myuller RL. Structure of solid glasses on electro-conductivity data. Proc AS USSR Ser Phys, 1940, 4: 607-615

44 Myuller RL. Chemical peculiarities of polymeric glass forming substances and nature of glass formation. In: Vitreous State. Moscow: AS USSR Publishers, 1960

45 Myuller RL, Baydakov LA, Borisova ZU. Electro-conductivity of As-Se-Ge system in vitreous state. Bull Leningrad State Univ, 1962, 17: $94-102$

46 Myuller RL. Chemistry of Solid State and Vitreous State. Leningrad: Leningrad State University Publishers, 1965

47 Borisova ZU. Chemistry of Glassy Semiconductors. Leningrad: LGU Publishers, 1972

48 Sun KH. Fundamental condition of glass-formation. J Am Ceram Soc, 1947, 30: 277-281

49 Rawson H. Inorganic Glass-forming Systems. London: Academic Press, 1967

50 Rawson H. Properties and Applications of Glass. New York: Elsevier, 1980, 318

51 Rawson, H. The relationship between liquidus temperature, bond strength, and glass formation. Paris: 4 th International Congress on Glass, 1956, 62-69

52 Turnbull D, Cohen MH. Modern Aspects of the Vitreous State, Vol. I. Mackenzie JD, Ed. London: Butterworths, 1988

53 Johnson WL. Thermodynamic and kinetic aspects of the crystal to glass transformation in metallic materials. Prog Mater Sci, 1986, 30: 81-134

54 Uhlmann DR. Glass-formation. J Non-Cryst Solids, 1977, 25: 43-85

55 Uhlmann DR. A kinetic treatment of glass formation. J Non-Cryst Solids, 1972, 7: 337-348.

56 Onorato PIK, Uhlmann DR. Nucleating heterogeneities and glass formation. J Non-Cryst Solids, 1976, 22: 367-378

57 Uhlmann DR, Kreidl NJ (eds.). Glass: Science and Technology, Vol. 1: Glass-Forming Systems. New York: Academic Press, 1983

58 Lu ZP, Liu CT. Glass formation criterion for various glass-forming systems. Phys Rev Lett, 2003, 91: 115505

59 Chen HS. Glassy metal. Rep Prog Phys, 1980, 43: 353-432

60 Sakka S. Handbook of Glass. Jiang GD, Ed. Beijing: China Architecture \& Building Press, 1985 (in Chinese)

61 Jiang YS, Hou LS. Handbook of New Glass. Shanghai: Glass and Enamel Press. 2004 (in Chinese)

62 Doremus RH. Glass Science (2nd ed.). New York: Wiley-Interscience, 1994

63 Zallen R. The Physics of Amorphous Solids. Weinheim: WileyVCH, 2007

64 Hewak DW, Brady D, Curry RJ, et al. Chalcogenide Glasses for Photonics Device Applications. In: MurgganGS (ed.). Photonic Glasses and Glass-Ceramics. Kerala: Research Signpost, 2010, 29-102

65 Hilton AR, Hayes DJ, Rechtin MD. Infrared absorption of some high purity chaicogenide glasses. J Non-Cryst Solids, 1975, 14: 319-338

66 Suryanarayana C, Inoue A. Bulk Metallic Glasses. London: CRC Press, 2011

67 Piarristeguy AA, Barthelemy E, Krbal M, et al. Glass formation in the $\mathrm{Ge}_{x} \mathrm{Te}_{100-x}$ binary system: synthesis by twin roller quenching and co-thermal evaporation techniques. J Non-Cryst Solids, 2009, 355: 2088-2091
68 Zarzycki J, Naudin F. A study of kinetics of the metastable phase separation in the $\mathrm{PbO}-\mathrm{B}_{2} \mathrm{O}_{3}$ system by small-angle scattering of X-rays. Phys Chem Glasses, 1967, 8: 11-18

69 Guggenheim EA. Modern Thermodynamics by the Methods of Willard Gibbs. London: Methuen, 1993

70 Gotze W. Recent tests of the mode-coupling theory for glassy dynamics. J Phys Condens Matter, 1999, 11: A1

71 Vedeshcheva NM, Shakhmatkin BA, Wright AC. The structure of sodium borosilicate glasses: thermodynamic modelling $v s$. experiment. J Non-Cryst Solids, 2004, 345-346: 39-44

72 Martinez LM, Angell CA. A thermodynamic connection to the fragility of glass-forming liquids. Nature, 2001, 410: 663-667

73 Hoffmann HJ. Thermodynamic aspects of melting and glass formation. Phys Chem Glasses, 2007, 48: 23-32

74 Greavesa GN, Sen S. Inorganic glasses, glass-forming liquids and amorphizing solids. Adv Phys, 2007, 56: 1-166

75 Dubey KS, Ramachandrarao P, Lele S. Thermodynamic and viscous behavior of undercooled liquids. Thermochimica Acta, 1996, 280 281: $25-62$

76 Stillinger FH, Debenedetti PG. Glass transition thermodynamics and kinetics. Annu Rev Condens Matter Phys, 2013, 4: 263-285

77 Wunderlich B. Glass transition as a key to identifying solid phases. J Appl Polym Sci, 2007,105: 49-59

78 Leuzzi L, Nieuwenhuizen TM. Thermodynamics of the Glassy State. London: CRC Press, 1986

79 Debenedetti PG, Stillinger FH. Supercooled liquids and the glass transition. Nature, 2001, 410: 259-267

80 Ediger MD, Angell CA, Nagel SR. Supercooled liquids and glasses. J Phys Chem, 1996, 100: 13200-13212

81 Brawer SA. Relaxation in Viscous Liquids and Glasses. Columbus: American Ceramic Society, 1985

82 Scherer W. Relaxation in Glass and Composites. New York: Wiley-Interscience, 1986

83 Smedskjaer MM, Jensen M, Yue YZ. Effect of thermal history and chemical composition on hardness of silicate glasses. J Non-Cryst Solids, 2010, 356: 893-897

84 Wang LM, Li ZJ, Chen ZM, et al. Glass transition in binary eutectic systems: best glass-forming composition. J Phys Chem B, 2010, 114: 12080-12084

85 Hruby A. Evaluation of glassforming tendency by means of DTA. Czech J Phys B, 1972, 22: 1187-1193

86 Uhlmann DR. Small angle X-ray scattering from glassy $\mathrm{SiO}_{2}$. J NonCryst Solids, 1974, 16: 325-327

87 Uhlmann DR. Glass formation, a contemporary view. J Am Ceram Soc, 1983, 66: 95-100.

88 Uhlmann DR. Polymer glasses and oxide glasses. J Non-Cryst Solids, 1980, 42: 119-142

89 Uhlmann DR. Crystallization and glass formation. J Non-Cryst Solids, 1985, 73: 585-592

90 Uhlmann DR. Nucleation, crystallization and glass formation. J Non-Cryst Solids, 1980, 38-39: 693-698

91 Uhlmann DR. On the internal nucleation of melting. J Non-Cryst Solids, 1980, 41: 347-357

92 Uhlmann DR. Kinetics of glass formation and devitrification behavior. J Phys Colloque, 1982, 43: 175-190

93 Yinnon $\mathrm{H}$, Uhlmann DR. A kinetic treatment of glass formation. VII. Transient nucleation in non-isothermal crystallization during cooling. J Non-Cryst Solids, 1982, 50: 189-202

94 Dietzel A. The cation field strengths and their relation to devitrifying process to compound formation and to the melting points of silicates. Z Elektrochem, 1942, 48: 9-23

95 Dietzel A. On the so-called mixed alkali effect. Phys Chem Glasses, 1983, 24: 172-180

96 Dietzel A, Poegel H. Über die Glasbildung im System KaliumnitratCalciumnitrat.Venice: 3rd International Congress on Glass. 1954 
219-243

97 Sun KH. Aluminate glasses. Glass Ind. 1949, 30: 199-200

98 Winter A. The glassformers and the periodic system of elements. Verres Refract, 1955, 9: 147-156

99 Stanworth JE. Tellurite glasses. J Soc Glass Technol, 1954, 38: 425435

100 Balta P. Introduction to the Physical Chemistry of the Vitreous State. Oxford: Taylor \&Francis, 1976

101 Sokolov OK. Calculation of Viscosity in Molten Salts (Oxides). Washington DC: National Aeronautics and Space Administration, 1966

102 Qiu GM, Huang LZ. Glass Formation. Beijing: The Publishing House of Ordnance Industry, 1987 (In Chinese)

103 Fairman R, Ushkov B. Semiconducting Chalcogenide Glass I: Glass Formation, Structure, and Simulated Transformations in Chalcogenide Glasses. Amsterdam: Elsevier, 2004

104 Doremus RH. Structure of inorganic glasses. Ann Rev Mater Sci, 1972, 2: 93-120

105 Jiang ZH, Hu XY, Zhao XS. Determation of eutectic and phase separation regions in glass formation by thermodynamics method. J Chin Ceram Soc, 1982, 10: 309-318 (In Chinese)

106 Jiang ZH, Hu XY, Zhao XS. Prediction of eutectics and phase separation in the glass formation range using a thermodynamic. J NonCryst Solids, 1982, 52: 235-247

107 Charles RJ, Wagstaff FE. Metastable immiscibility in the $\mathrm{B}_{2} \mathrm{O}_{3}-\mathrm{SiO}_{2}$ system. J Am Ceram Soc, 1968, 51: 16-20

108 Slater JC. Introduction of Chemical Physics. New York: McGraw-Hill Book Company, 1939

109 Cottrell AH. Theoretical Structural Metallurgy. New York: St. Martin's Press, 1955

110 Barin I, Knacke O, Kubaschewski O. Thermochemical Properties of Inorganic Substances. Berlin: Springer-Verlag, 1977

111 Morey GW, Merwin HE. Phase equilibrium relationships in the binary system, sodium oxide-boric oxide, with some measurements of the optical properties of the glasses. J Am Chem Soc, 1936, 58: 2248-2254

112 Kracek FC. The system sodium oxide-silica. J Phys Chem, 1930, 34 1583-1598

113 Ghanbari-Ahari K, Cameron AM. Phase diagram of $\mathrm{Na}_{2} \mathrm{O}-\mathrm{B}_{2} \mathrm{O}_{3}$ $\mathrm{SiO}_{2}$ system. J Am Ceram Soc, 1993, 76: 2017-2022

114 Poulain M. Advanced glasses. Ann Chim Sci Mat, 2003, 28: 87-94

115 Lezal D, Pedlikova J, Zavadil J, Kostka P, Poulain M. Preparation and characterization of sulfide, selenide and telluride glasses. J Non-Cryst Solids, 2003, 326: 47-52

116 Arias AC, MacKenzie JD, McCulloch I, Rivnay J, Salleo A. Materials and applications for large area electronics: solution-based approaches. Chem Rev, 2010, 110: 3-24

117 France PW. Fluoride Glass Optical Fibres. Glasgow: Blackie, 1990

118 France PW. Optical Fibre Lasers and Amplifiers. Glasgow: Blackie, 2000

119 Casella JF, Flanagan MD, Lin S. Cytochalasin D inhibits actin polymerization and induces depolymerization of actin filaments formed during platelet shape change. Nature, 1981, 293: 302-305

120 Poulin M, Poulin M. ThF ${ }_{4}$ and LiF based glasses. J Non-Cryst Solids, 1983, 56: 57-61

121 Lucas J. Fluoride glasses. J Mater Sci, 1989, 24: 1-13

122 Jiang ZH, Hu XY, Song XY, Zhao XS. Research on some IR transimission halide glass systems. J Non-Cryst Solids, 1983, 56: 69-74

123 Fedorov VA, Babitsyna AA, Emel'yanova TA. Glass formation in the $\mathrm{ZrF}_{4}-\mathrm{LaF}_{3}-\mathrm{BaF}_{2}-\mathrm{NaF}$ system. Glass Phys Chem, 2001, 27: 512-519

124 Merkulov EB, Logoveev NA, Goncharuk VK, Yaroshenko RM. Glass formation in the $\mathrm{ZrF}_{4}-\mathrm{BiF}_{3}-\mathrm{MeF}(\mathrm{Me}=\mathrm{Li}, \mathrm{Na}, \mathrm{K})$ fluoride systems. Glass Phys Chem, 2007, 33: 106-108

125 Babitsyna AA, Emel'yanova TA, Fedorov VA. Glass formation in quaternary systems of group I-IV fluorides. Inorg Mater, 2008, 44:
1378-1385

126 Higginbottom R, Shelby JE. Formation and properties of lead fluorogallate glasses. Phys Chem Glasses, 1998, 39: 281-285

127 Fedorov PP. Glass formation criteria for fluoride systems. Inorg Mater, 1997, 33: 1197-1205

128 Carrier GB. Characterization of glasses and ceramics with the analytical electron microscope. J Non-Cryst Solids, 1980, 38-39: 15-20

129 Zhao XJ, Li XJ, Chen JX. X-ray diffraction and molecular dynamics study of $\mathrm{ThF}_{4}-\mathrm{BaF}_{2}-\mathrm{LiF}$ glass. J Non-Cryst Solids, 1995, 184: 172-176

130 Kiihne K. Werkstoff Glass. Berlin: Akacleunie, 1976

131 Takayama S. Review: amorphous structures and their formation and stability. J Mat Sci, 1976, 11: 164-185

132 Dean JA, Lange NA. Lange's Handbook of Chemistry (15th Ed.). New York: Mc-Graw-Hill Inc., 1999

133 Ugai YA, Shatillo VA. The polytherm of the ternary system zinc chloride-lead chloride-potassium chloride. J Phys Chem USSR. 1949, 23: 744-754

134 Iqbal T, Shahriari MR, Weitz G, Sigel Jr GH. New highly stabilized $\mathrm{AlF}_{3}$-Based glasses. J Non-Cryst Solids, 1995, 184: 190-193

135 Zakalyukin RM, Fedorov PP. Classification of fluoroaluminate glasses. Inorg Mater, 2003, 39: 640-644. Translated from Neorganicheskie Materialy. 2003, 39: 756-760

136 Yasui I, Hagihara $\mathrm{H}$, Arai Y. Glass formation in the system of $\mathrm{AlF}_{3}$ $\mathrm{BaF}_{2}-\mathrm{CaF}_{2}$ and properties of these glasses. Mater Sci Forum, 1988, 32-33: $173-178$

137 Graig DF, Brown JJ. Phase equilibria in the system $\mathrm{CaF}_{2}-\mathrm{AlF}_{3}$. J Am Ceram Soc, 1977, 60: 396-400

138 de Kozak A, Samouel M, Ranaudin J, Ferey G. The binary system $\mathrm{BaF}_{2} / \mathrm{AlF}_{3}, \mathrm{Z}$ Anorg Allg Chem, 1992, 613: 98-104

139 Imaoka M, Yamazaki T. Glass-formation ranges of ternary systems. IV. Tellurites of a-group elements. Rep Instit Industrial Sci Univ Tokyo, 1975, 24: 27-80

140 Imaoka M, Yamazaki T. Studies of the glass-formation range of silicate systems. Investigations on the glass-formation range. J Ceram Soc Jpn, 1963, 71: 215-223

141 Imaoka M, Yamazaki T. Glass-formation ranges of ternary systems. Part 1-Silicates of a-group elements (Graphical and tabulated data on glass formation ranges of ternary silicate systems). J Ceram SocJpn, 1968, 76: 160-172

142 Imaoka M, Yamazaki T. The glass-forming region in the binary and ternary germanate systems. J Ceram Soc Jpn, 1964, 72, 182-191

143 Angell CA, Sare EI. Glass-forming composition regions and glass transition temperatures for aqueous electrolyte solutions. J Chem Phys, 1970, 52: 1058-1068

144 Angell CA. Liquid fragility and the glass transition in water and aqueous solutions. Chem Rev, 2002, 102: 2627-2649

145 Kirilenko IA. Glass formation in the $\mathrm{ZnCl}_{2}-\mathrm{H}_{2} \mathrm{O}$ system. Russian J Inorg Chem, 2013, 58: 1183-1186

146 Kirilenko IA. Glass formation in the $\mathrm{Al}_{2}\left(\mathrm{SO}_{4}\right)_{3}-\mathrm{Al}\left(\mathrm{NO}_{3}\right)_{3}-\mathrm{H}_{2} \mathrm{O}$ system. Russian J Inorg Chem, 2010, 55: 602-606

147 Yang QH, Jiang ZH. Prediction of glass forming region by means of compositions with equal crystallization tendency. J Inorg Mater, 1994, 9: 399-403 (In Chinese)

148 Thilo E, Wiecker W, Stade H. Chemische Untersuchungen von Silicaten, XXXI. Über Beziehungen zwischen dem Polymerisationsgrad silicatischer Anionen und ihrem Reaktionsvermögen mit Molybdänsäure. Zeitschrift für anorganische Chemie, 1965, 340: 261-276

149 Doremus RH. Glass Science. New York: Wiley-Interscience, 1973

150 Kaufmann L. Proceeding the 4th calphad. Maryland: Gaithersburg, 1975, 1-69

151 Weast RW, Lide D. CRC Handbook of Chemistry and Physics (70th Ed.). Boca Raton: CRC Press, 1990

152 Jänecke E. Das quaternäre System der Nitrate von $\mathrm{Na}-\mathrm{K}-\mathrm{Ca}-\mathrm{Mg}$ 
und seine Teilsysteme. Z Elektrochem, 1942, 48: 453-512

153 Popescu MA. Non-Crystalline Chalcogenides. New York: Kluwer Academic Publishers, 2002

154 Vassilev V, Radonova M, Boycheva S. Glass-formation in the $\mathrm{GeSe}_{2}$ $\mathrm{Sb}_{2} \mathrm{Te}_{3}$-CdSe system. J Non-Cryst Solids, 2010, 356: 2728-2733

155 Ichikawa M, Wakasugi T, Kadono K. Glass formation, physico-chemical properties, and structure of glasses based on $\mathrm{Ga}_{2} \mathrm{~S}_{3}$ $\mathrm{GeS}_{2}-\mathrm{Sb}_{2} \mathrm{~S}_{3}$ system. J Non-Cryst Solids, 2010, 356: 2235-2240

156 Aliev II, Aliev IG. Interactions and glass formation in the TlAs $\mathrm{Se}_{4}$ $\mathrm{Tl}_{3} \mathrm{As}_{2} \mathrm{Se}_{3} \mathrm{Te}_{3}$ system. Russian J Inorg Chem, 2010, 55: 1142-1145

157 Lukic SR, Petrovic DM, Skuban SJ, Radonjic L, Cvejic Z. Formation of complex structural units and structure of As-S-Se-Te-I of glasses. J Optoelectron Adv Mater, 2003, 5: 1223-1229

158 Hristova-Vasileva T, Vassilev V, Aljihmani L, Boycheva S. Glass formation in the $\mathrm{As}_{2} \mathrm{Se}_{3}-\mathrm{As}_{2} \mathrm{Te}_{3}-\mathrm{Sb}_{2} \mathrm{Te}_{3}$ system. J Phys Chem Solids, 2008, 69: 2540-2543

159 Amova A, Hristova-Vasileva T, Aljihmani L. Region of glass formation and main physicochemical properties of glasses from the $\mathrm{As}_{2} \mathrm{Se}_{3}-\mathrm{Ag}_{4} \mathrm{SSe}-\mathrm{PbTe}$ system. J Alloy Compd, 2013, 573: 32-36

160 Adam AB, Sakrani S, Wahab Y. Glass-formation region of ternary Sn-Sb-Se-based chalcogenide glasses. J Mater Sci, 2005, 40: 15711576

161 Minaev VS, Timoshenkov SP. Glass-formation in chalcogenide systems and periodic system. In: Fairman R, Ushkov B (eds.). Semiconducting Chalcogenide Glass I, Volume 78: Glass Formation, Structure, and Simulated Transformations in Chalcogenide Glasses. Amsterdam: Elsevier, 2004

162 Goryunova NA, Kolomiets BT. Glassy semiconductors. IV. On the problem of regularities of glass-formation. J Tech Phys, 1958, 28: 1922-1932

163 Goryunova NA, Kolomiets BT. Glassy semiconductors. IX. Glass-formation in compound chalcogenides based on arsenic sulfide and selenide. Solid State Phys, 1960, 2: 280-283

164 Borisova ZU. Glass-formation in chalcogenide systems and Periodic Table of elements. Proc AS USSR Non-Org Mater, 1971, 7: $1720-1724$

165 Borisova ZU. Glass-formation in Chalcogenide Systems and the Periodic Table. Structure and Properties of Non-crystalline Semiconductors. Leningrad: Nauka Publishers, 1976

166 Hilton AR, Jones CE, Brau M. Non-oxide IVA-VA-VIA chalcogenide glasses. Phys Chem Glasses, 1966, 7: 105-126

167 Baker H. Okamoto H. ASM Handbook, Vol. 3-Alloy Phase Diagrams. Ohio: ASM International, 1992

168 Minaev VS. Glass-Forming Semiconductor Alloys. Moscow: Metallurgy Publishers, 1991

169 Minaev VS. New glasses and some peculiarities of glass-formation in ternary telluride systems. Phys Chem Glass, 1983, 9: 432-436

170 Vinogradova GZ. Glass formation and Phase Equilibriums in Chalcogenide Systems. Binary and Ternary Systems. Moscow: Nauka Publishers, 1984

171 He CX, Li GF. Precious Metal Alloy Phase-Diagrams. Beijing: Metallurgical Industry Press, 1986 (In Chinese)

172 Yu JQ. Binary Alloy Phase-Diagrams. Shanghai: Shanghai scientific \& Technical Publishers, 1987 (In Chinese)

173 Ye DL. Handbook of Practical Inorganic Thermodynamic Data. Beijing: Metallurgical Industry Press, 1981 (In Chinese)

174 Yang QH, Jiang ZH. Using thermodynamics of phase diagram to predict the metallic glass-forming region. J Inorg Mater, 1994, 9: 89-93 (In Chinese)

175 Yang QH, Jiang $\mathrm{ZH}$. The prediction of metallic glass forming region by the compositions of having equal crystallization tendency. J Shanghai Institute Build Mater, 1992, 5: 272-279 (In Chinese)

176 Boettinger WJ. In Rapidly Solidified Amporphous and Crystalline Alloys, Kear BH. Ed. New York: Elsevier, 1982

177 Lu ZP, Shen J, Xing DW, Sun JF, Liu CT. Binary eutectic clusters and glass formation in ideal glass-forming liquids. Appl Phys Lett, 2006, 89: 071910

178 Haasen P. Metallic glasses. J Non-Cryst Solids, 1983, 56: 191-199

179 Davies HA. Amorphous Metallic Alloys. Ke C (Chinese Transl.). Beijing: Metallurgical Industry Press, 1989 (In Chinese)

180 Ding Y, Jiang $\mathrm{ZH}$. The modern continuous phase transition theory of phase separation in binarysystems. J Inorg Mater, 1989, 4: 211-216 (In Chinese)

181 Jiang ZH. Some aspects on regions of glass formation and devitrification of glasses. J Chin Ceram Soc, 1981, 9: 323-339

182 Jiang ZH. Some aspects of phase separation in glasses. J Non-Cryst Solids, 1989, 112: 48-57

183 Englert WJ, Hummel FA. Notes on the system $\mathrm{B}_{2} \mathrm{O}_{3}-\mathrm{SiO}_{2}-\mathrm{P}_{2} \mathrm{O}_{5}$ : II ternary system. J Soc Glass Technol, 1955, 39: 121-127

184 Salmang H. Die Physikalischen und Chemischen Grundlagen der Glasfabrikation. Berlin: Springer, 1957

Acknowledgements This research was supported by the National Natural Science Foundation of China (51125005 and 51472088). Techniques supports and helpful discussions with Drs. Hu LL, Ding Y, Yang QH, and Ye $\mathrm{H}$ are gratefully acknowledged.

Author contributions Zhang QY wrote the paper; Jiang ZH and Zhang QY provided the overall concept and revised the manuscript. Both of the authors participated in the discussion.

Conflict of interest The authors declare that they have no conflict of interest. 


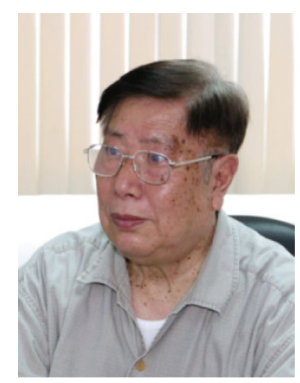

Zhonghong Jiang is a professor of Shanghai Institute of Optics and Fine Mechanics, Chinese Academy of Sciences (CAS), and Academician of the CAS. He received his BSc degree in materials science from South China University of Technology in 1953. He has received several awards, including the 1st class National Scientific Technology Progress Award (1990) and the 2nd class National Scientific Technology Progress Awards (1985, 1989). His research interests include glass formation, laser glass, and optical glass and glass-fiber.

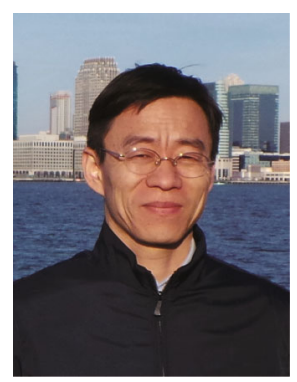

Qinyuan Zhang received his PhD degree in materials science from Shanghai Institute of Optics and Fine Mechanics, CAS in 1998. He is a Cheung Kong Scholar Professor at the School of Materials Science and Engineering, South China University of Technology. He has authored and co-authored more than 200 peer-reviewed international journal articles, including Progress in Materials Science, Materials Science and Engineering R: Reports, Journal of the American Ceramic Society, Journal of Non-Crystalline Solids, and more than 20 patents. His research activity focuses on glass science and technology, and luminescent materials.

中文摘要 自古以来玻璃被广泛使用, 目前仍然是人类生活中无处不在的最有价值材料. 然而, 对众多材料而言, 较低的玻璃形成能力 和玻璃形成区是困扰玻璃广泛而更好应用的难题. 深入研究和阐明玻璃形成能力的本质是发展应用新玻璃的关键所在. 新材料发展很 快且组成愈加复杂, 然而在新玻璃研究中缺乏相关相图资料. 目前玻璃科学研究往往通过大量实验才获得一些数据, 需要的人、财、 物力巨大且效率低下. 本文从玻璃科学基础问题出发综述了玻璃形成和玻璃形成区的最新进展, 通过探讨玻璃结构与性能、玻璃形成 与玻璃形成区计算和预测, 建立了一些简便、快速、具有预测性的研究方法, 并对玻璃形成和玻璃形成区从定性的理解到定量的预测 研究和未来的发展趋势与努力的方向作了进一步的远景展望. 